2. To: (Receiving Organization)

Distribution

5. Proj./Prog./Dept./Div.:

W-314/TWRS

8. Originator Remarks:

This EDT release the approved ATP's for the 241-AN-A and B packages part of Project $W-314$.

11. Receiver Remarks:

11A. Design Basel ine Document?

[] Yes

[X] No USA not reguired per ANF-IP-O84 2 , vou 58 section 5 , 4 , rev lla. The be per formedas a part ofa JCS work package that will be Usa reviewed prior to performance of the whrk. These A7pyarenota designor facility modificationand are not expected to resuitinan. exposure Ji erson AEM (whole body)

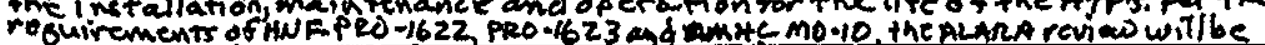
accomplishedas partosthenormalkadiol gical work planning process.

\begin{tabular}{|c|c|c|c|c|c|c|c|c|c|c|}
\hline 15. & \multicolumn{6}{|c|}{ DATA TRANSMITTED } & (F) & (G) & (H) & (I) \\
\hline $\begin{array}{l}\text { (A) } \\
\text { Item } \\
\text { No. }\end{array}$ & \multicolumn{2}{|c|}{ (B) Document/Drawing No. } & $\begin{array}{l}\text { (C) } \\
\text { Sheet } \\
\text { No. }\end{array}$ & $\begin{array}{l}\text { (D) } \\
\text { Rev. } \\
\text { No. }\end{array}$ & \multicolumn{2}{|c|}{$\begin{array}{l}\text { (E) Title or Description of Data } \\
\text { Transmitted }\end{array}$} & $\begin{array}{l}\text { Approval } \\
\text { Desig- } \\
\text { nator }\end{array}$ & $\begin{array}{l}\text { Reason } \\
\text { for } \\
\text { Trans- } \\
\text { mittal }\end{array}$ & $\begin{array}{l}\text { Origi- } \\
\text { nator } \\
\text { Dispo- } \\
\text { sition }\end{array}$ & $\begin{array}{c}\text { Receiv- } \\
\text { er } \\
\text { Dispo- } \\
\text { sition }\end{array}$ \\
\hline 1 & \multicolumn{2}{|l|}{$\begin{array}{l}\text { ATP-W314-001 } \\
\text { HNE - 4642 }\end{array}$} & & 0 & \multicolumn{2}{|c|}{$\begin{array}{l}\text { 241-AN-A Valve Pit Manifold } \\
\text { Valves \& Position Indication } \\
\text { ATP }\end{array}$} & $\begin{array}{l}\text { ES Q } \\
\text { Deses }\end{array}$ & 1 & 1 & 1 \\
\hline 1 & \multicolumn{2}{|c|}{$\begin{array}{l}A T P-W 314-002 \\
H N F-4644\end{array}$} & & 0 & \multicolumn{2}{|c|}{$\begin{array}{l}\text { 241-AN-B Valve Pit Manifold } \\
\text { Valves \& Position Indication } \\
\text { ATP }\end{array}$} & $\begin{array}{l}\text { ES Q } \\
D, 5 / 27 / 49\end{array}$ & 1 & 1 & 1 \\
\hline 1 & \multicolumn{2}{|c|}{$\begin{array}{l}\text { ATP-W314-003 } \\
H N E-4646\end{array}$} & & 0 & \multicolumn{2}{|c|}{$\begin{array}{l}241-A N-B \text { Pit Leak Detection } \\
\text { ANB-WT-LDSTA-231 ATP }\end{array}$} & ES $Q$ & 1 & 1 & 1 \\
\hline 1 & \multicolumn{2}{|c|}{$\begin{array}{l}\text { ATP-W314-004 } \\
A N F-4648\end{array}$} & & 0 & \multicolumn{2}{|c|}{$\begin{array}{l}\text { 241-AN-A Pit Leak Detection } \\
\text { ANA-WT-LDSTA-331 ATP }\end{array}$} & $\left\{\begin{array}{l}E S Q \\
x=5 / 20149\end{array}\right.$ & 1 & 1 & 1 \\
\hline 1 & \multicolumn{2}{|c|}{$\begin{array}{l}\text { ATP-W314-005 } \\
\text { HNF- }-4650\end{array}$} & & 0 & \multicolumn{2}{|c|}{$\begin{array}{l}\text { SN-268 Encasement Leak } \\
\text { Detection ANR-WT-LDSTA-335 } \\
\text { ATP A DU } 6.9-94\end{array}$} & $\begin{array}{l}\text { ES Q } \\
\text { Des } r / 27 / 4\end{array}$ & 1 & 1 & 1 \\
\hline \multicolumn{11}{|l|}{16.} \\
\hline \multicolumn{2}{|c|}{ Approval Designator $(F)$} & \multicolumn{4}{|c|}{ Reason for Transmittal (G) } & \multicolumn{5}{|c|}{ Disposition $(\mathrm{H})$ \& (I) } \\
\hline \multicolumn{2}{|c|}{$\begin{array}{l}E, S, Q, D \text { or N/A } \\
\text { (see WHC-CM-3-5, } \\
\text { Sec.12.7) }\end{array}$} & $\begin{array}{l}\text { 1. Approval } \\
\text { 2. Release } \\
\text { 3. Information }\end{array}$ & \multicolumn{2}{|c|}{$\begin{array}{l}\text { 4. Review } \\
\text { 5. Post-Review } \\
\text { 6. Dist. (Receipt }\end{array}$} & ow. Required) & \multicolumn{2}{|c|}{$\begin{array}{l}\text { 1. Approved } \\
\text { 2. Approved w/comment } \\
\text { 3. Disapproved w/comment }\end{array}$} & \multicolumn{3}{|c|}{$\begin{array}{l}\text { 4. Reviewed no/comment } \\
\text { 5. Reviewed w/comment } \\
\text { 6. Receipt acknowledged }\end{array}$} \\
\hline
\end{tabular}

17. SIGNATURE/DISTRIBUTION

(See Approval Designator for required signatures)

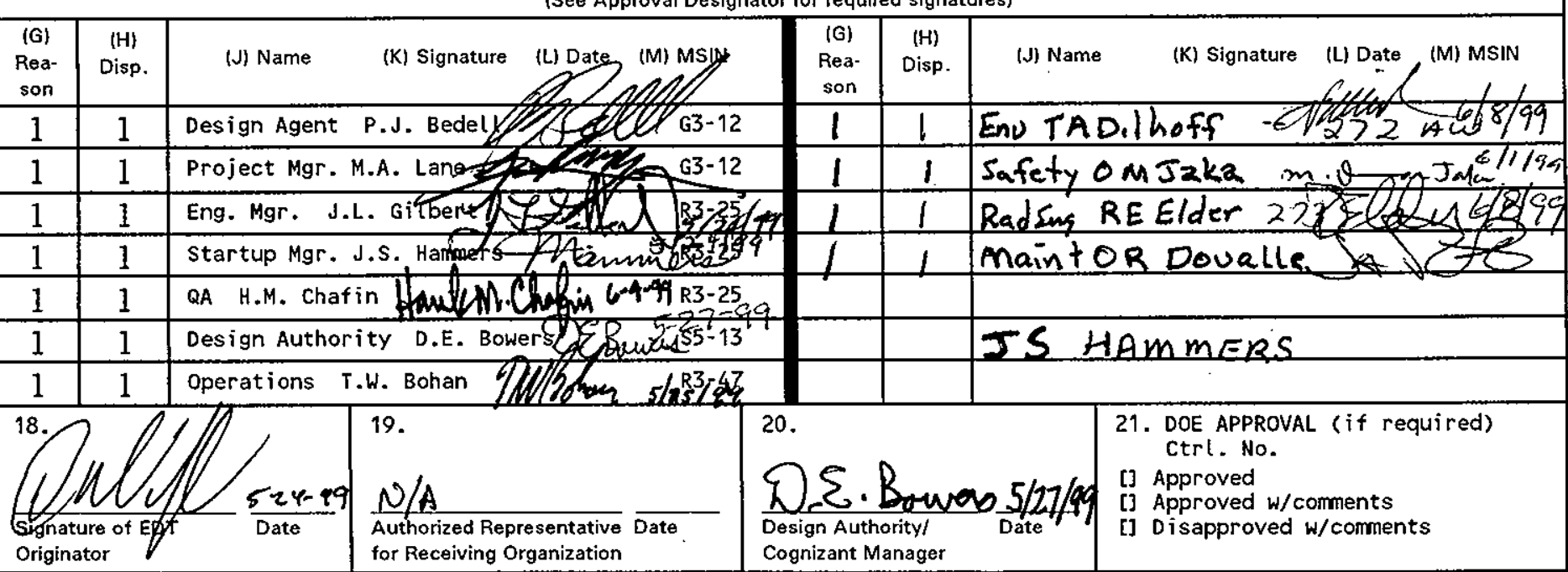




\section{1-AN-A Valve Pit Manifold Valves And Position Indication Acceptance Test Procedure}

David w. VanDyke

Maintenance Concepts

Richland, WA 99352

U.S. Department of Energy Contract DE-AC06-96RL13200

$\begin{array}{lll}\text { EDT/ECN: } & 626838 & \text { UC: } 2030 \\ \text { Org Code: } & \text { LJH20000 } & \text { Charge Code: } 106065 \\ \text { B\&R Code: } & \text { EW3130010 } & \text { Total Pages: } 122 \\ & & \end{array}$

Key Words: Acceptance Test Procedure

Abstract: This document describes the method used to test design criteria for gear actuated ball valves installed in 241-AN-A valve Pit located at $200 \mathrm{E}$ Tank Farms.

TRADEMARK DISCLAIMER. Reference herein to any specific commercial product, process, or service by trade name, trademark, manufacturer, or otherwise, does not necessarily constitute or imply its endorsement, recommendation, or favoring by the United States Government or any agency thereof or its contractors or subcontractors.

Printed in the United States of America. To obtain copies of this document, contact: Document Control Services, P.O. Box 950, Mailstop 46-08, Richland WA 99352, Phone (509) 372-2420; Fax (509) 376-4989.
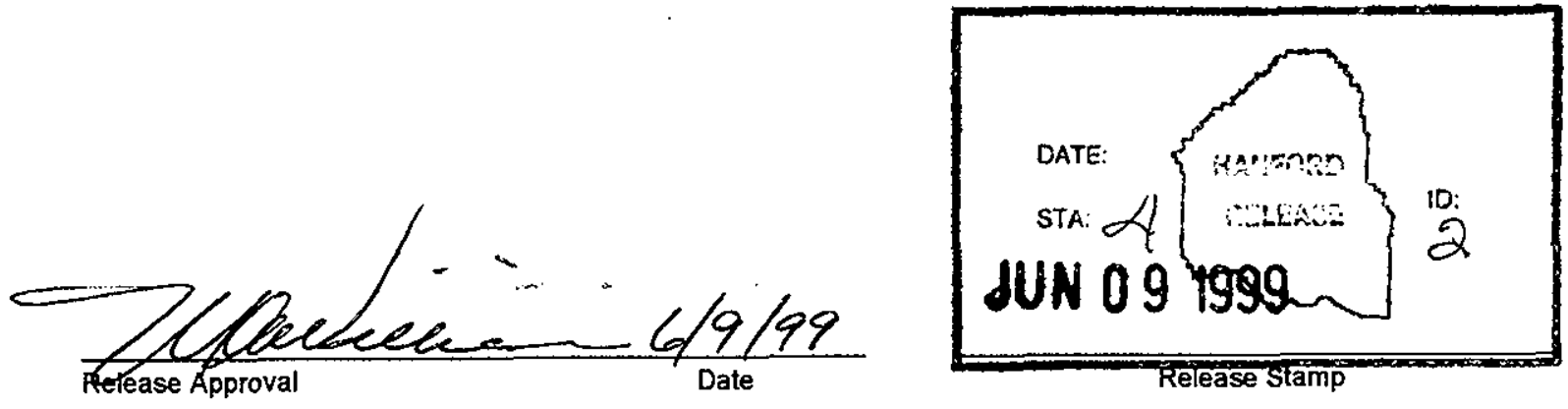

\section{Approved For Public Release}




\section{1-AN-A VALVE PIT MANIFOLD VALVES AND POSITION INDICATION ACCEPTANCE TEST PROCEDURE}

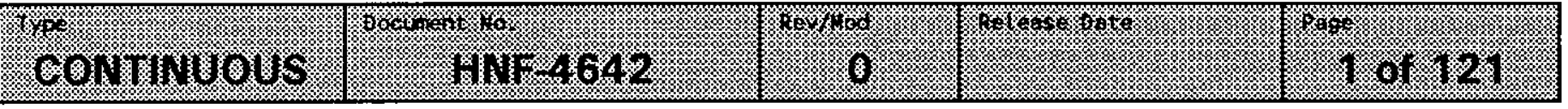




\section{TABLE OF CONTENTS}

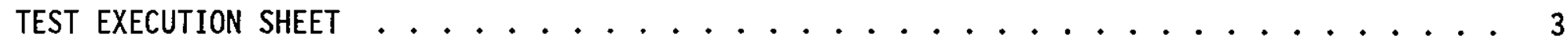

1.0 PURPOSE AND SCOPE ...................... 4

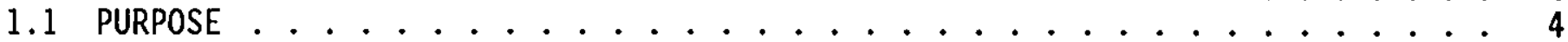

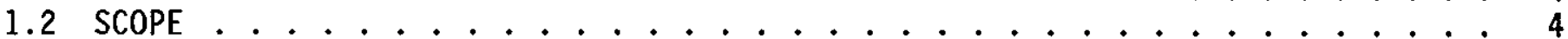

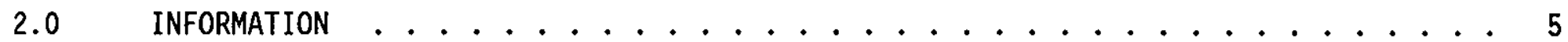

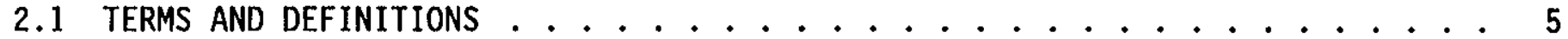

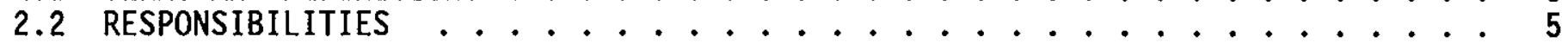

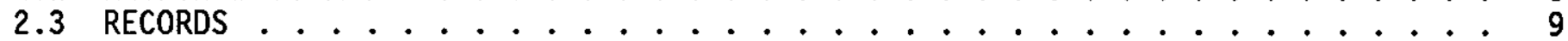

2.4 REFERENCES . . . . . . . . . . . . . . . . . . . . . . 9

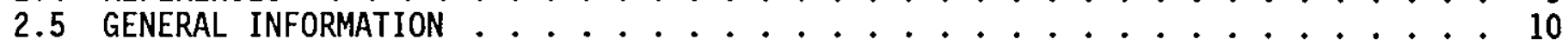

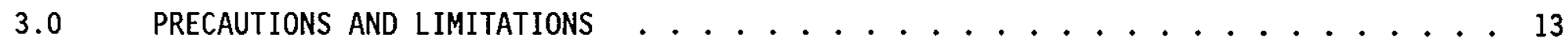

3.1 PERSONNEL SAFETY . . . . . . . . . . . . . . . . . . . . . . . 13

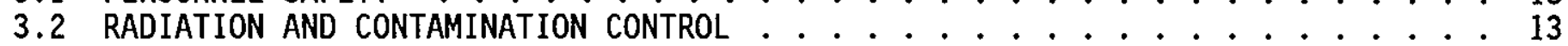

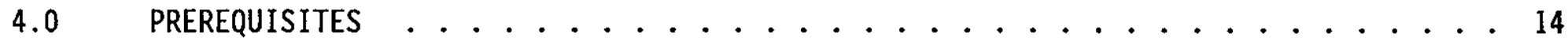

4.1 SPECIAL TOOLS, EQUIPMENT, AND SUPPLIES ............... 14

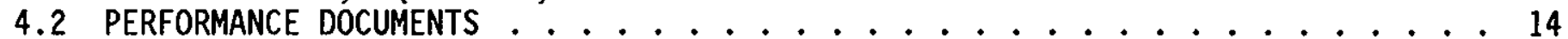

4.3 CONSTRUCTION STATUS . . . . . . . . . . . . . . . . . . 14

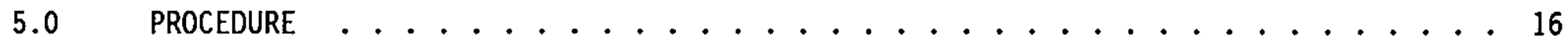

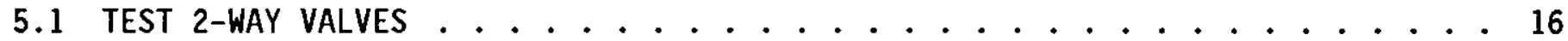

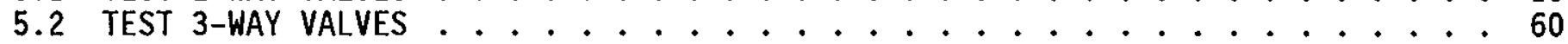

5.3 VALVE TORQUING $\ldots \ldots \ldots . \ldots \ldots$

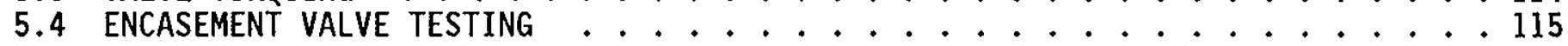

ATP PERFORMANCE LOG . . . . . . . . . . . . . . . . . . . . . 117

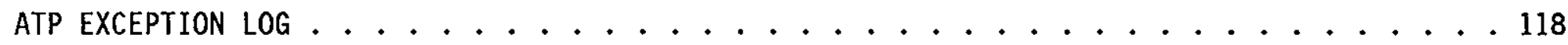

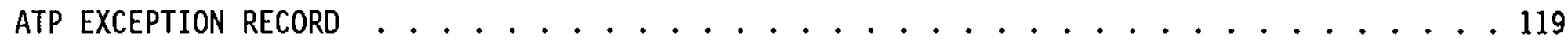

PROCEDURE SIGNATURE SHEET . . . . . . . . . . . . . . . . . 120

PROCEDURE HISTORY SIGNATURE SHEET . . . . . . . . . . . . . . . 121

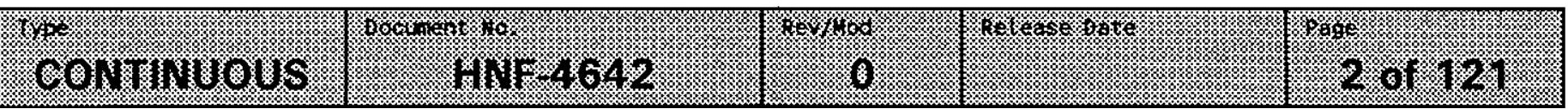




\section{TEST EXECUTION SHEET}

\begin{tabular}{|c|c|}
\hline DATE: & 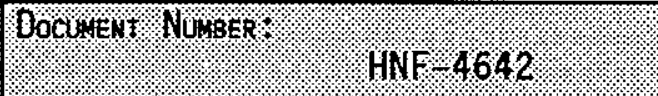 \\
\hline \multirow{2}{*}{\multicolumn{2}{|c|}{ W. }} \\
\hline & \\
\hline TEST DiRECTOR: & RECORDER: \\
\hline OPERATIONS EngineER: & AUTHORIZED INSPECTOR: \\
\hline \multicolumn{2}{|c|}{ TESTEXEQUTION } \\
\hline Test Director Signature/Date: & $\begin{array}{l}\text { Fluor Daniel Northiest } \\
\text { Construction Engineer Sighature/Date: }\end{array}$ \\
\hline Operations Engineer Signature/Date: & Recorder Signature/Date: \\
\hline \multicolumn{2}{|c|}{ APPROYAI AND ACCEPTANCE OF TEST RESUITS } \\
\hline $\begin{array}{c}\text { WITHOUT EXCEPTION } \\
(\mathcal{N})\end{array}$ & $\begin{array}{l}\text { Resolved With Exceptions Remaining } \\
(\checkmark)\end{array}$ \\
\hline Test Director Signature/Date: & W-314 Project Manager Signature/Date: \\
\hline $\begin{array}{l}\text { Fluor Daniel Northlest Project Manager } \\
\text { Signature/Date: }\end{array}$ & FDNW Quality Assurance Signature/Date: \\
\hline LMHC Quality Assurance Signature/Date: & Operations Engineer Sigmature/Date: \\
\hline Authorized Inspector Signature/Date: & Design Authority Signature/Date: \\
\hline
\end{tabular}


$t 0 t-\Lambda-1 M-g N \forall$

$\rightarrow 0 \downarrow-\Lambda-\perp M-\forall N \forall$ $\varepsilon 0 t-\Lambda-\perp M-\forall N \forall$ I $2 \varepsilon-\Lambda-1 M-\forall N \forall$ 6 I $\varepsilon-\Lambda-\perp M-\forall N \forall$ $8 \mathrm{I} \varepsilon-\Lambda-\perp M-\forall N \forall$

$\varepsilon Z \varepsilon-\Lambda-\perp M-\forall N \forall$ $2 Z \varepsilon-\Lambda-\perp M-\forall N \forall$ $0 Z \varepsilon-\Lambda-\perp M-\forall N \forall$ $\angle I \varepsilon-\Lambda-\perp M-\forall N \forall$ GIE-A-IM- $\forall N \forall$
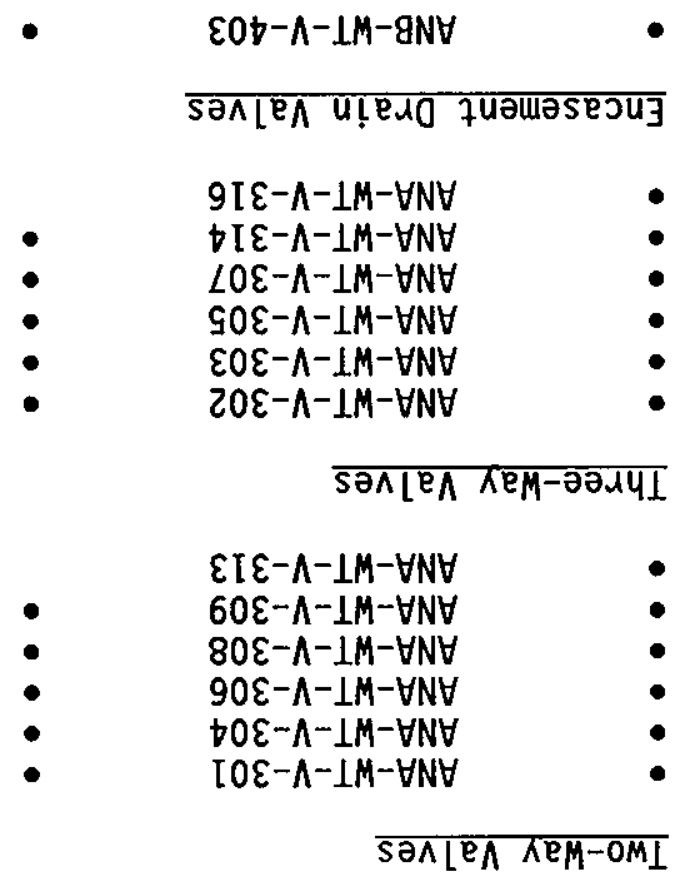

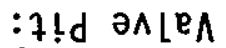

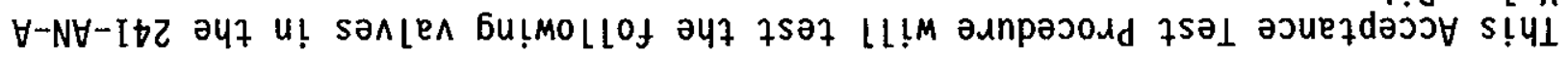
ヨdOOS Z"L

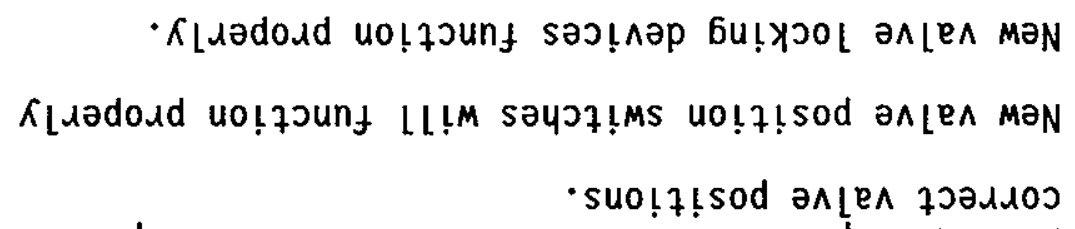

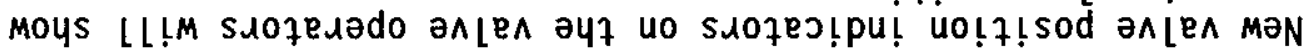

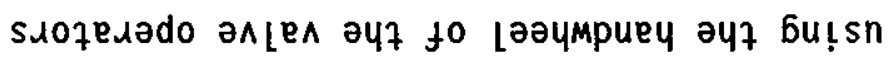

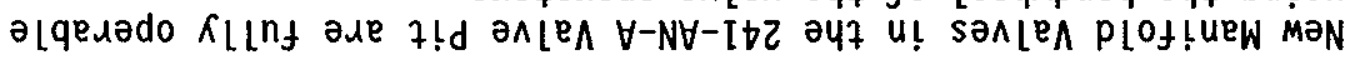
s6utme up

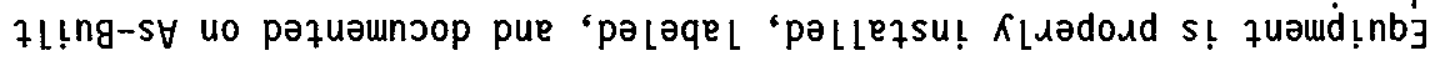

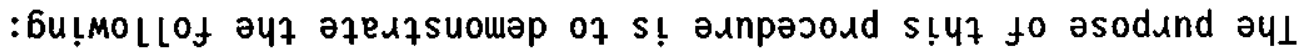




\subsection{INFORMATION}

\subsection{TERMS AND DEFINITIONS}
2.1 .1
ATR -
Acceptance Test Report
2.1.2 ATP - Acceptance Test Procedure

\subsection{RESPONSIBILITIES}

2.2.1 Each company or organization participating in the conduct of this procedure will designate personnel to assume the responsibilities and duties as defined herein for their respective roles. The names of these designees shall be provided to the Recorder for listing on the Working Copy of the Test Execution Sheet prior to the performance of any part of this procedure.

2.2.2 The Fluor Daniel Northwest Project Manager is responsible for the following:

- Designation of a test director

- Signing the Test Execution Sheet when the Acceptance Test Procedure is approved and accepted as complete

2.2.3 The Operations Engineer is responsible for the following:

- Setting the safe boundaries for performing this procedure

- Ensuring plant configuration is in proper status for performing this procedure

- Signing for operations where applicable in this procedure.

- Performing a Post-Test Review of Acceptance Test documentation

- Obtaining concurrence from Tank Farm Shift Manager prior to commencing the test, or upon restart of testing after a temporary suspension of testing

2.2.4 The Operations Representative is responsible for the following:

- Ensuring that safe work boundaries for testing are complied with

- Coordinating all support craft and personnel in field with the Test Director and the Construction Engineer.

- Obtaining release of this ATP for field testing from shift office. 


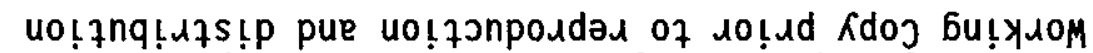

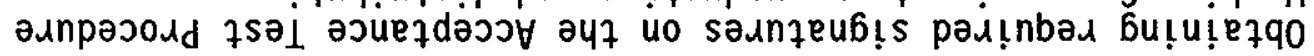

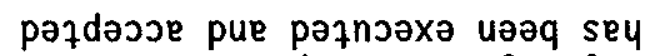

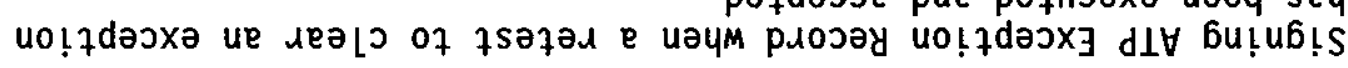
pəwıоляәd uәәq sey

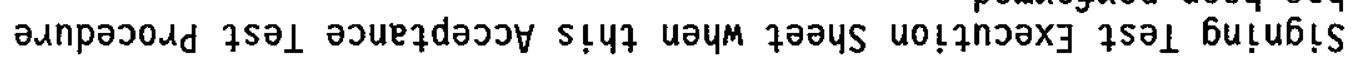

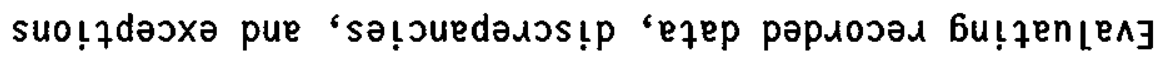
əגnpəכoגd 7sə1

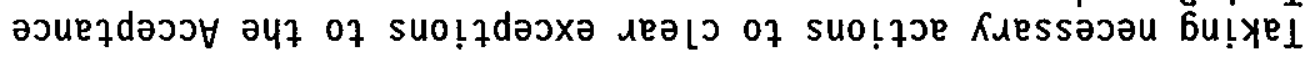

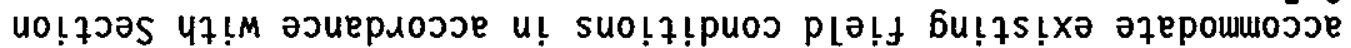

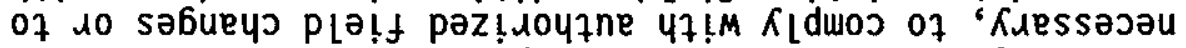

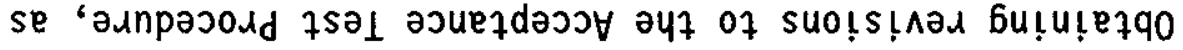

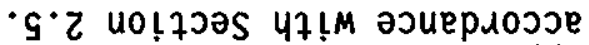

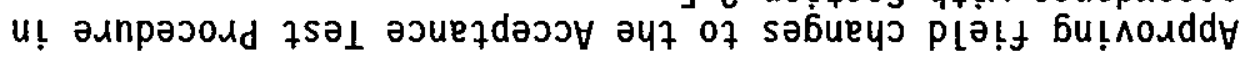

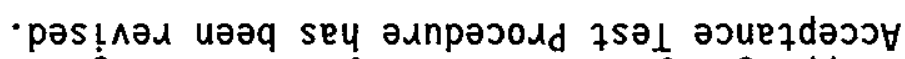

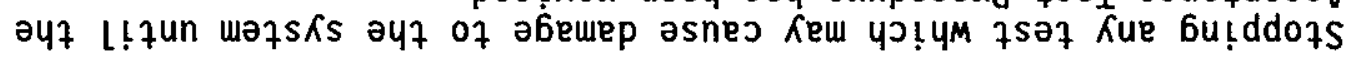

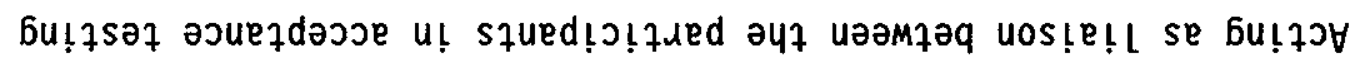

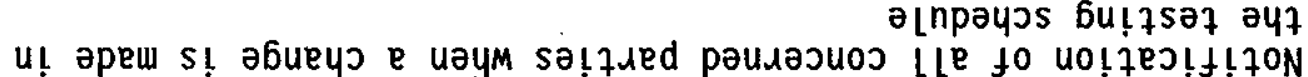
6u!fsaz to z1e7s ayz of $10 ! 4 d$

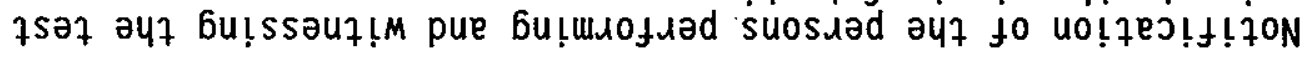

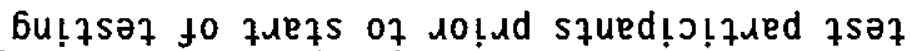

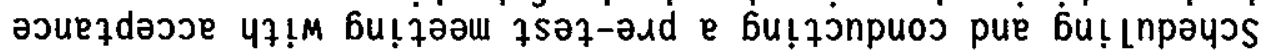

-

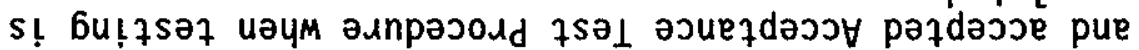

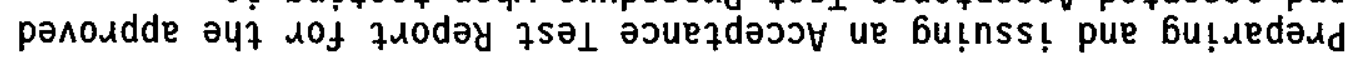
panlosad

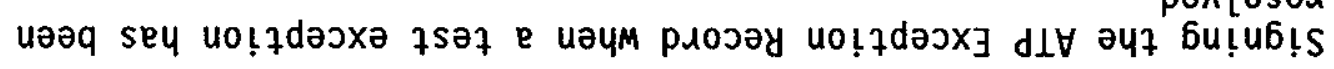

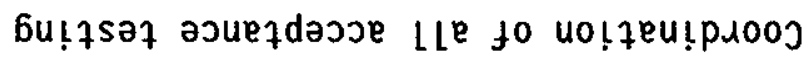

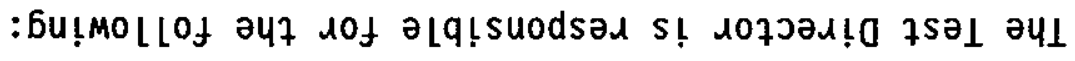
$9 \cdot 2 \cdot 2$

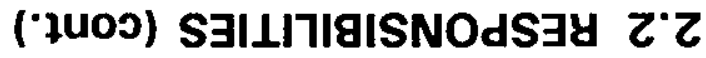




\subsection{RESPONSIBILITIES (cont.)}

2.2.6 The Recorder is responsible for the following:

- Performing all recording duties using black ink

- Recording the names of all designated personnel on the Working Copy of this procedure prior to start of testing

- Observing tests, recording test data, and maintaining the ATP Performance Log

- $\quad$ Signing the Test Execution Sheet as the Recorder

- Initialing every test verification step requiring initials on the Working Copy of this Acceptance Test Procedure as that step is successfully performed, to indicate that Acceptance Criterion has been met

- Recording authorized field changes to this Acceptance Test Procedure

- Recording Test Exceptions and individual Test Procedure steps that are not performed satisfactorily on the ATP Exception Record and ensuring that the information is transferred (in ink or typed) to the master Working Copy of ATP Exception Record(s). Additional ATP Exception Records are to be added as needed

- Notifying the Test Director at the time any objection is made during performance of the Acceptance Test Procedure

- Submitting the completed master Working Copy of this Acceptance Test Procedure to the Test Director for approval signatures and distribution.

2.2.7 The Construction Engineer is responsible for the following:

- Ensuring all equipment required for performing this Acceptance Test Procedure listed in Section 4.1 will be available at the start of testing

- Obtaining from the NHC and LMHC Project Engineer any information or changes necessary to clear or resolve objections

- Coordinating field personnel and activities with the Test Director and Operations Representative

- Ensuring that field testing and inspection of the system or portion of the system to be tested has been completed prior to start of this ATP

- Providing technical input to test personnel as needed relating to the configuration of equipment and systems to be tested and utilized in this procedure.

- Post Review of Acceptance Test Documentation. 


\subsection{RESPONSIBILITIES (cont.)}

2.2.8 Fluor Daniel Northwest Quality Assurance is responsible for the following:

- Review and approval of test exception resolutions

- Performing a Post-Test Review of Acceptance Test documentation

- Assisting Construction Engineer in Pre-Test verification of construction documentation (i.e. CWPs, submittals, receiving reports etc.

2.2.9 Lockheed Martin Quality Assurance is responsible for the following:

- Review and approval of test results

- Performing a Post-Test Review of Acceptance Test documentation

2.2.10 Fluor Daniel Hanford Authorized Inspector is responsible for the following:

- Witnessing test execution

- Approval and signature of acceptance upon completion of this procedure.

2.2.11 Industrial Health And Safety Tech, is responsible for the following:

- Monitor for toxic and combustible gases or vapors and report out of compliance levels to TWRS Industrial Hygiene technician

- Evaluate exposure potential using field data and according to HNF-SD-WM-HSP-002 or other industrial hygiene exposure prevention criteria and recording monitored levels in applicable steps in work package.

2.2.12 Quality Control is responsible for the following:

- Witness and signing, lift 1 and records, torquing and the installation and removal of all temporary wiring and devices as applicable in this procedure. 


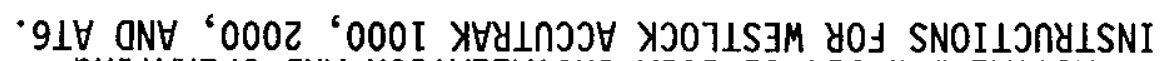

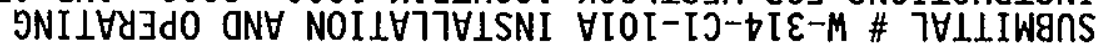

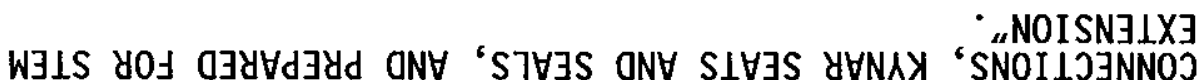

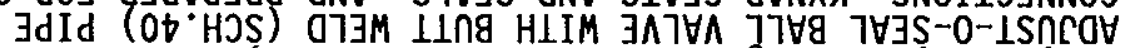

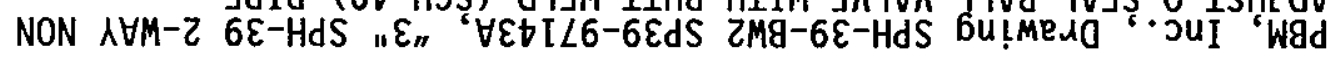

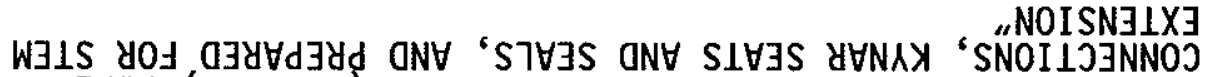

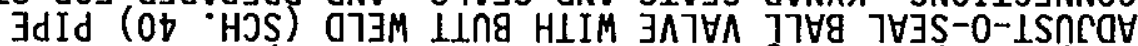
NON $A \forall M-Z \angle E-H d S$ "Z" " $\forall Z \forall I \angle 6-\angle E d S$ ZMg- $\angle E-H d S$ bu!meid " ouI "Wgd

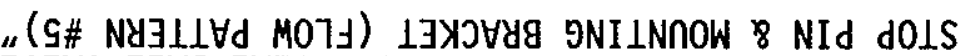

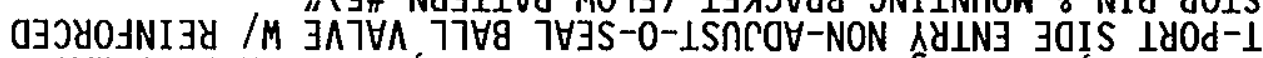
$\Lambda \forall M-\varepsilon 6 L-H d W " \varepsilon "$ " $\forall S t[\angle 6-6 \angle d W 2 M g-6 L-H d W$ bu!Meda " ouI Wgd

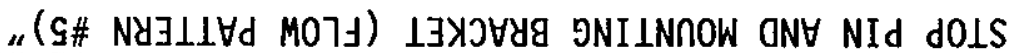

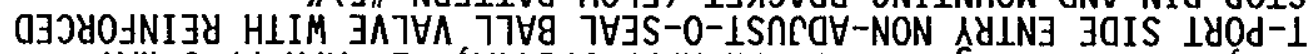

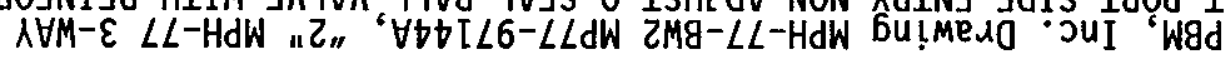

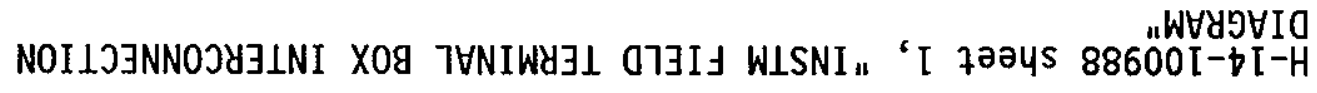

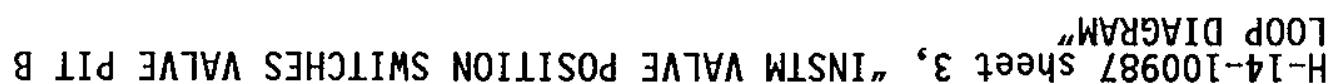
V LId JATVA S3HOLIMS NOILISOd

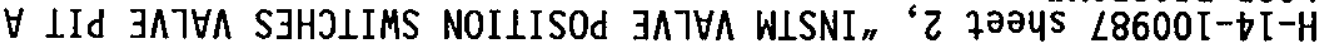

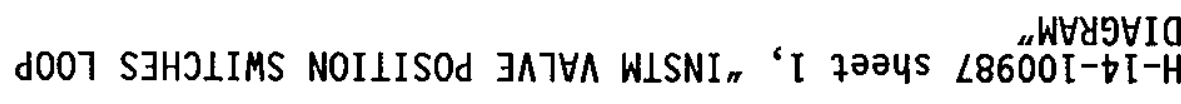

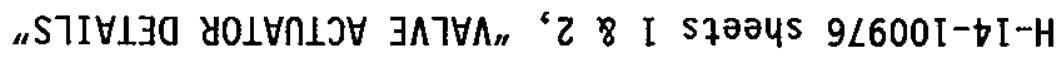

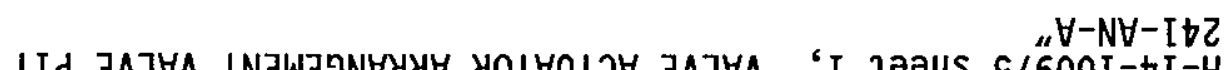

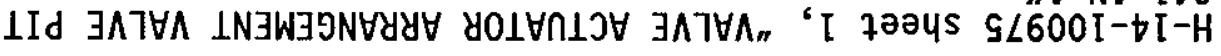

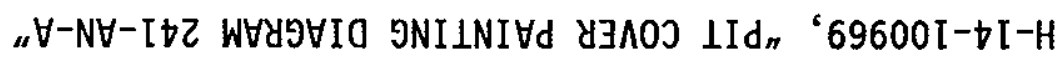

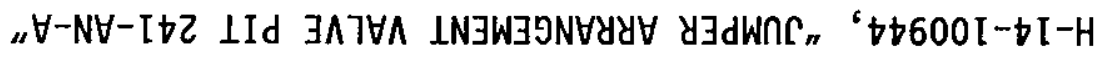
« $\forall-N \forall-I b Z$ LId $\exists \Lambda 7 \forall \Lambda$ aI $8 d_{n}$ "Ib600I: :unpasoud

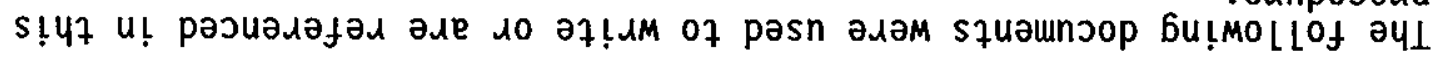
$[\cdot 6 \cdot 2$

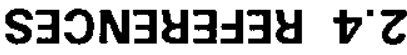

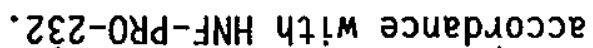

u! spıоэәл quәuem

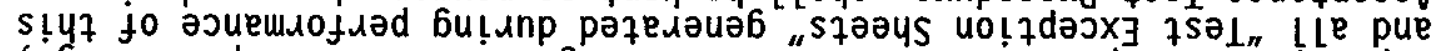

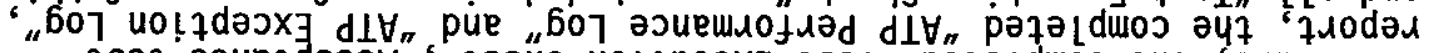

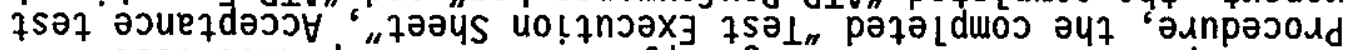

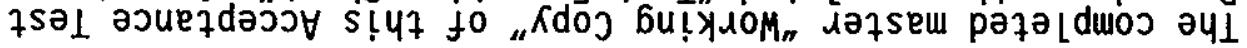




\subsection{GENERAL INFORMATION}

2.5.1 All steps in this Acceptance Test Procedure are performed at the 241-AN-A Valve Pit and at Terminal Box AN241-WT-TBX-101, unless otherwise noted.

2.5.2 The OPEN or CLOSED position of a 2-way valve is indicated by the position of flow ports on decal, on the round indicating disc, attached to the valve extension handle. (Ref. H-14-100976).

2.5.3 The three positions ( $A, B$, and $C$ ) of a 3-way valve in the valve pit are indicated at the valve operator by the position of flow ports on decal on the round Indicating Disc attached to the valve extension handle (see H-14-100976).

2.5.4 Valves are aligned such that the stripes on decal align with stripes on housing when valve is in the fully CLOCKWISE position: (Closed for Two-Way OR "C", or $180^{\circ}$ for Three-Way).

2.5.5 ACCEPTANCE CRITERIA: All Test Procedure steps using the word VERIFY are considered Acceptance Criteria steps, and each must have successful execution indicated by having initials and the date entered in the provided space to be considered complete.

2.5.6 All entries recorded in this procedure shall be made in black ink, except for those noted using the redline method.

2.5.7 Editorial changes to this procedure may be made by the Test Director and Cognizant Engineer per HNF-IP-0842 Vol I sect. 2.11 "Technical Procedure Requirements", as long as the changes do not impact operational facility safety function or performance, and will not compromise or influence the test data. Any technical change must be made by ECN.

2.5.8 Acceptance Test steps detailed in individual Test Sections shall be performed sequentially, unless otherwise noted or as directed by the Test Director.

- Individual Test Sections may be performed out of sequence at the direction of the Test Director, if the intent of the test is not compromised.

- As required by subsection 2.2.6, as each step is completed, the Recorder will check off, enter appropriate mark or initial each Test step as required in the spaces provided on the Working Copy of this Acceptance Test Procedure.

- Any step that requires verification of data must also be recorded on the Working Copy. 


\subsection{GENERAL INFORMATION (Cont).}

2.5.9 Any non-conformance of the instrumentation, unexpected results or exceptions during testing shall be sequentially numbered and recorded in the ATP Exception Log and on individual ATP Exception Records. Thus, case-by-case resolution, recording, approval, and distribution of each exception will be achieved.

2.5.10 When an exception is identified during testing, initiate an ATP Exception Record in the following manner (an example of a test exception would be when the system, fabricated per the design media, does not perform as expected):

- Number each exception sequentially as it occurs and record it on the ATP Exception Log

- Enter the sequential exception number, Date, and a description of the exception on an ATP Exception Record; identify additional detail as required

- Enter the name of the initiator of the objecting party for each exception in the "Initiator of Exception" section of the ATP Exception Record

- Enter a description of actions planned to resolve each exception on the ATP Exception Record when such a determination is made.

2.5.11 Resolve test exceptions in the following manner:

- Record the action taken to resolve each exception in the "Resolution of Exception" section of the ATP Exception Record (the action taken does not have to be the same as the recorded planned action)

- When the action taken results in an acceptable retest, initial and date the Correction Approval section of the Exception Sheet

- When the action taken does not result in an acceptable retest, provide a detailed explanation of why the retest action was not acceptable, and what additional plans are required. The explanation may include why the system should be Accepted-As-Is. The Project Engineer then signs and dates the Resolution of Exception section of the ATP Exception Record, and obtains any other approvals required

- Distribute requisite copies of the completed ATP Exception Records to the client at the completion of the Acceptance Test Procedure.

2.5.12 Upon completion of the Acceptance Test Procedure, obtain approval of the test performance. The Acceptance Test will be complete when all the test sections have been performed, all test exceptions resolved, and the Acceptance Test Report is prepared. The test will be approved by checking the proper response, with or without exceptions, on the Test Execution Sheet under the "Approval and Acceptance of Test Results" Section of the Test Execution Sheet. 


\subsection{GENERAL INFORMATION (Cont).}

NOTE - The following three sections detail the possible conditions that may exist at the completion of the Acceptance Test Procedure, and the steps necessary to complete Procedure acceptance in those conditions.

2.5.13 The completed test may be approved without test exceptions:

- Check applicable space on Test Execution Sheet to show that the Acceptance Test Procedure has been performed and no exceptions have been recorded

- Appropriate individual Test Performers will sign and date the Test Execution Sheet in the spaces provided

- Distribute requisite copies as directed by the client

- Send the Master Copy of the completed Acceptance Test Procedure to the client.

2.5.14 The completed test may be approved with exceptions resolved:

- Check applicable space on Test Execution Sheet to show that this procedure has been performed with exceptions recorded and resolved

- Appropriate individual Test Performers will sign and date the Test Execution Sheet in the spaces provided

- Distribute requisite copies as directed by the client

- Send the Master Copy of the completed Acceptance Test Procedure to the client.

2.5.15 The completed test may be approved with test exceptions outstanding:

- Check applicable space on Test Execution Sheet to show that this procedure has been performed with exceptions recorded, part or al1 of which are presently outstanding, unresolved

- Appropriate individual Test Performers will sign and date the Test Execution Sheet in the spaces provided

- Distribute requisite copies as directed by the client

- Send the Master Copy of the completed Acceptance Test Procedure to the client.

- All outstanding exceptions shall be added to project punchlist.

2.5.16 It is the intent to perform this Acceptance Test Procedure uninterrupted from beginning to end. If testing is terminated due to time constraints at the end of an individual Test Section, the system will be placed in a safe configuration by the Test Director, with concurrence of the Operations Engineer, and the terminated test configuration noted in the ATP Performance Log. The test will restart at the next scheduled shift by establishing the noted test configuration, and documenting this in ATP Performance Log. 


\subsection{PRECAUTIONS AND LIMITATIONS}

\subsection{PERSONNEL SAFETY}

3.1.1 Individuals shall carry out their assigned work in a safe manner to protect themselves, others, and the equipment from undue hazards and to prevent damage to property and environment.

3.1.2 Operations Representative shall assure the safety of all activities within their areas to prevent injury, property damage, or interruption of operation.

3.1.3 Any hazard identified during the performance of the procedure shall be reported to the appropriate waste tank farm facility line manager.

3.1.4 Performance of test activities shall always include safety and health aspects as delineated in the Operations Manuals and as directed by the Test Director.

3.1.5 The primary safety concerns for the performance of this Acceptance Test Procedure are related to the force required to operate valve operator handwheel. Maintain proper body alignment at all times while operating valve handwheel.

\subsection{RADIATION AND CONTAMINATION CONTROL}

Work in Radiological Areas will be performed using an approved Radiation Work Permit, following review by Radiological Control per the ALARA Program (HNF-IP-0842, Volume VII, Section 1.1). 


\subsection{PREREQUISITES}

\subsection{SPECIAL TOOLS, EQUIPMENT, AND SUPPLIES}

The following supplies shall be available at the test site:

- Electrician protective gloves

- Electrician protective eyewear (goggles or face shield)

- Calibrated Volt Ohm Meter (Fluke)

- Long-shank lockout padlock

- Ruler, with minimum scale markings of $1 / 16$ inch

- Fuse Puller

- Torquing Screwdriver (17-20 inch 1bs)

- $\quad 24$ volt de Power Supply.

NOTE - Calibrated electrical test equipment data shall be recorded at the beginning of each individual test section.

\subsection{PERFORMANCE DOCUMENTS}

The following documents are required to be at the test site, before and during the performance of this procedure:

- HNF-4642 "241-AN-A VALVE PIT MANIFOLD VALVES AND POSITION INDICATION ACCEPTANCE TEST PROCEDURE".

\subsection{CONSTRUCTION STATUS}

4.3.1 Al1 documentation and construction work is complete to the point of support for this ATP.

Construction Engineer Signature

Date 


\subsection{CONDITIONS AND ACTIONS}

The following conditions must be met before this Acceptance Test Procedure (ATP) may commence.

NOTE- The following shall be documented on ATP Performance Log DAILY if test is stopped and continued OR if personnel changes during performance of this ATP.

4.4.1 A pre-job briefing has been held. and all participants have been thoroughly briefed on job safety, hazards, and their responsibilities before performing this ATP.

Test Director Signature $\quad$ Date

4.4.2 Test Director VERIFY 241-AN-A Valve Pit is isolated from all other Transfer Routes by SIGNING below.
Test Director Signature
Date

4.4.3 Test Director VERIFY Section 4.0 has been COMPLETED by SIGNING below.

Test Director Signature

Date 
5.0 PROCEDURE

\subsection{TEST 2-WAY VALVES}

5.1.1 TEST 2-inch valve ANA-WT-V-301:

5.1.1.1 RECORD calibrated electrical test equipment data below. ELECTRICAL TEST EQUIPMENT DATA TABLE

\begin{tabular}{||l|l|l|l||}
\hline TOOL NAME & ID. NUMBER & CAL DUE DATE & INITIAL/DATE \\
\hline & & & \\
\hline & & & \\
\hline & & & \\
\hline
\end{tabular}

5.1.1.2 ENSURE that ANA-WT-V-301 is CLOSED by rotating the valve handwheel CLOCKWISE until the handwheel turns no farther.

5.1.1.3 VERIFY the indicator line is oriented to BLOCK flow from $\mathrm{L} 3$ to ANA-WT-V-302.
Test Director Initial
Date

5.1.1.4 VERIFY the indicator line is 1 ined up with the correct reference pins for the CLOSED position, AND black stripe within the RED area on the decal is aligned as to be touching the applicable line on valve housing.

\section{Test Director Initia1}

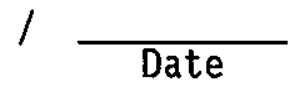

5.1.1.5 PLACE the long-shank padlock through the locking device in the ANA-WT-V-301 handwheel.

5.1.1.6 VERIFY that limited movement of the handwheel does NOT cause valve movement in either direction.

Test Director Initial
Date

5.1.1.7 REMOVE the long-shank padlock that was placed on the handwheel.

5.1.1.8 RENOVE the cover from ANA-WT-V-301 valve position sensor assembly.

5.1.1.9 ADJUST the top cam so the pointer on the CAM is centered on the non-contact switch wired for valve position $A$.

5.1.1.10 POSITION ANA-WT-V-301 OPEN by rotating the valve handwheel COUNTER CLOCKWISE until the handwheel turns no farther. 


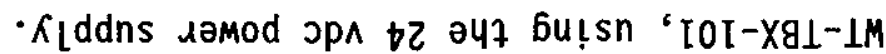

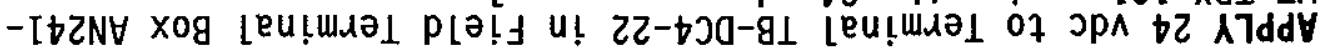
$6 I \cdot I \cdot I \cdot s$

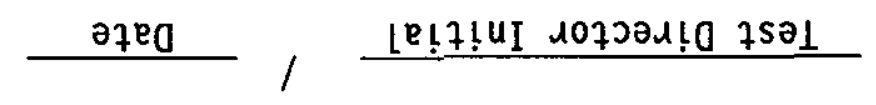

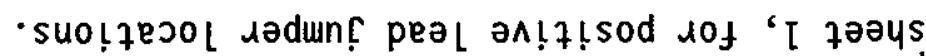

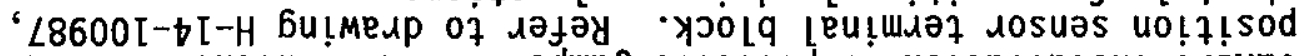

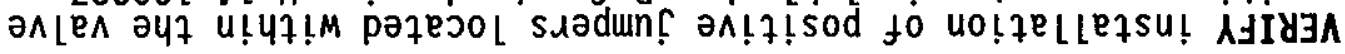

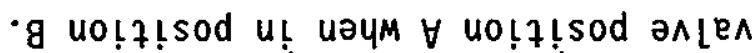

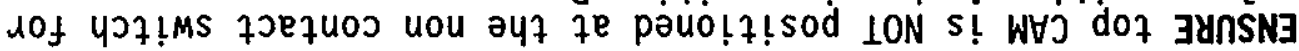

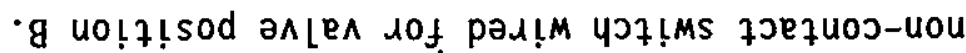

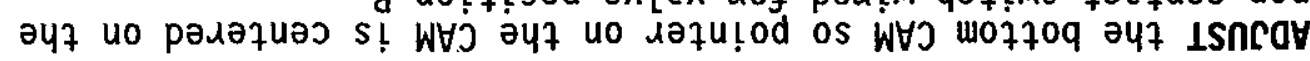

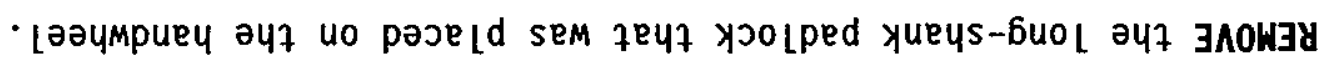
$8 I \cdot I \cdot T \cdot G$ $\angle I^{*} I^{*} I \cdot S$ $9 I \cdot I \cdot I \cdot g$ $\mathrm{GI} \cdot[\cdot \mathrm{I} \cdot \mathrm{G}$

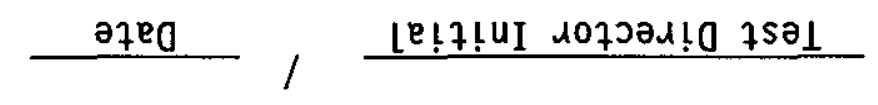

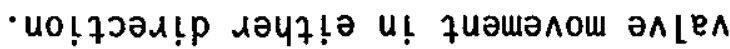

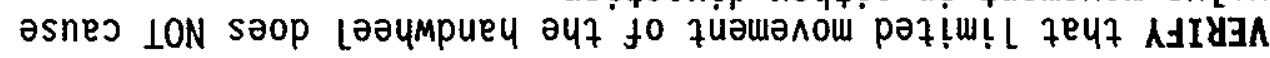
- Lәуцмриеу IOE- $-\perp M-\forall N \forall$

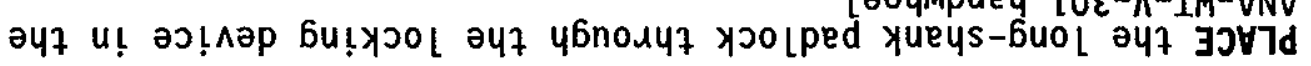

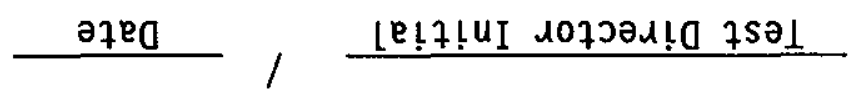
- ¿еәәр әч7

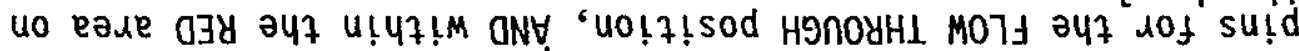

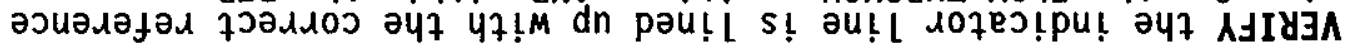

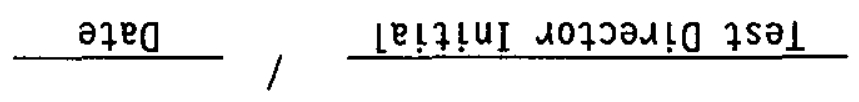
$20 \varepsilon-\Lambda-1 M-\forall N \forall$

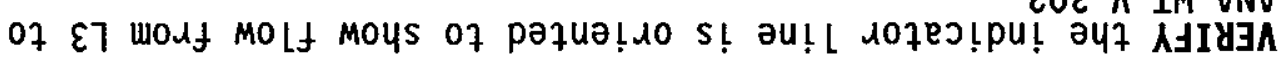

$\forall[\cdot[\cdot I \cdot G$

$\varepsilon[\cdot[\cdot[\cdot \mathrm{g}$

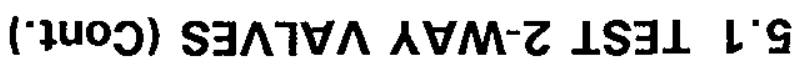




\subsection{TEST 2-WAY VALVES (Cont.)}

5.1.1.20 MEASURE AND RECORD the voltage BETWEEN Terminal TB-DC1-2 AND the NEGATIVE Terminal on the 24 volt dc power supply.

VOLTAGE

5.1.1.21 VERIFY the voltage recorded in Step 5.1.1.20 is at a nominal voltage of " 24 " Volts dc.

Test Director Initial Date

5.1.1.22 MEASURE AND RECORD the voltage BETWEEN Terminal TB-DC1-1 AND the NEGATIVE Terminal on the 24 volt dc power supply.

VOLTAGE

5.1.1.23 VERIFY the voltage recorded in Step 5.1.1.22 is at a nominal voltage of " 0 " Volts dc.

Test Director Initial

5.1.1.24 POSITION ANA-WT-V-301 CLOSED by rotating the valve handwheel CLOCKWISE until the handwheel turns no farther.

5.1.1.25 VERIFY that ANA-WT-V-301 valve operator position indicator is oriented to BLOCK flow from "L3" to ANA-WT-V-302.

Test Director Initial $\quad /$ Date

5.1.1.26 MEASURE AND RECORD the voltage BETWEEN Terminal TB-DC1-2 AND the NEGATIVE Terminal on the 24 volt dc power supply.

VOLTAGE

5.1.1.27 VERIFY the voltage recorded in Step 5.1.1.26 is at a nominal voltage of " 0 " Volts dc.

Test Director Initial

Date 
әұеg

ә7е0 aגnzeu6!s suo!̣edodo

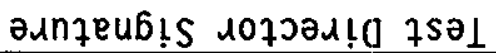

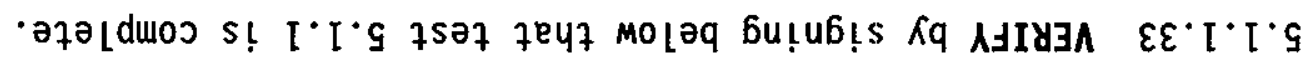

\begin{tabular}{|l|l||}
\hline & \\
\hline & 035079
\end{tabular}

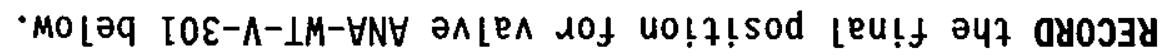

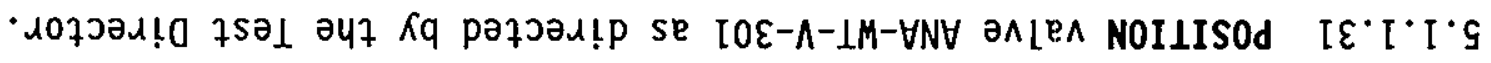
- anbu07

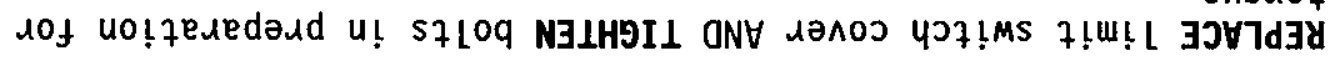
$0 \varepsilon \cdot I \cdot I \cdot g$ - $\mathrm{sql}$

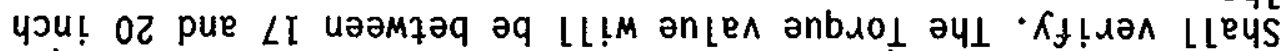

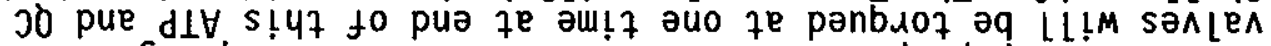

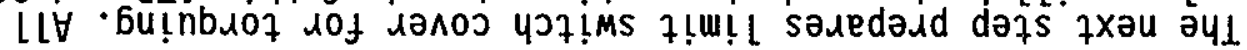
$-310 N$ ә7е0 $/$ Le!7!UI 10702ג!07501

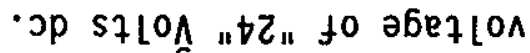

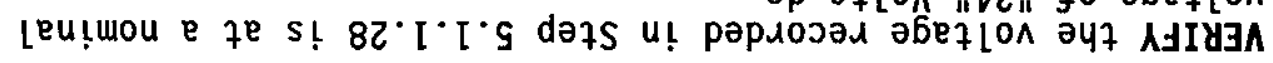
$62 \cdot[\cdot[\cdot G$ $39 \forall 170 \wedge$

- $\kappa$ Lddns lamod op $710 \Lambda$ t乙 әч7 uo Leutusol $\exists \Lambda I L \forall 9 \exists N$

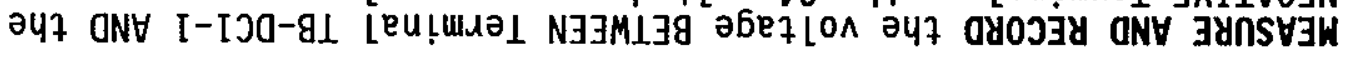

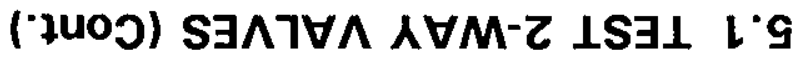




\subsection{TEST 2-WAY VALVES (Cont.)}

5.1.2 TEST 2-inch valve ANA-WT-V-309:

5.1.2.1 RECORD calibrated electrical test equipment data below. ELECTRICAL TEST EQUIPMENT DATA TABLE

\begin{tabular}{||l|l|l|l|}
\hline TOOL NAME & ID. NUMBER & CAL DUE DATE & INITIAL/DATE \\
\hline & & & \\
\hline & & & \\
\hline & & & \\
\hline
\end{tabular}

5.1.2.2 ENSURE that ANA-WT-V-309 is CLOSED by rotating the valve handwheel CLOCKWISE until the handwheel turns no farther.

5.1.2.3 VERIFY the indicator line is oriented to BLOCK flow from Blank Connection "C" to ANA-WT-V-307.

Test Director Initial

Date

5.1.2.4 VERIFY the indicator line is lined up with the correct reference pins for the CLOSED position, AND black stripe within the RED area on the decal is aligned as to be touching the applicable line on valve housing.

Test Director Initial Date

5.1.2.5 PLACE the long-shank padlock through the locking device in the ANA-WT-V-309 handwheel.

5.1.2.6 VERIFY limited movement of the handwheel does NOT cause valve movement in either direction.

Test Director Initial Date

5.1.2.7 REMOVE the long-shank padlock that was placed on the handwheel.

5.1.2.8 REMOVE the cover from ANA-WT-V-309 valve position sensor assembly.

5.1.2.9 ADJUST the top cam so pointer on the CAM is centered on the noncontact switch wired for valve position $A$.

5.1.2.10 POSITION ANA-WT-V-309 OPEN by rotating the valve handwhee COUNTER CLOCKWISE until the handwheel turns no farther. 


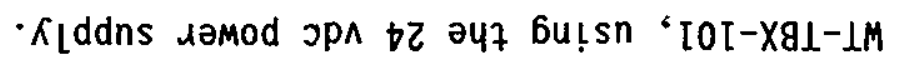

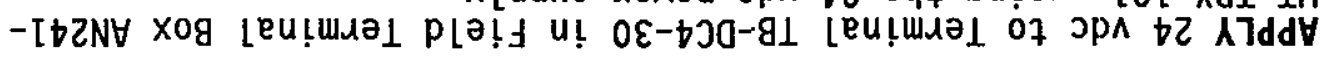

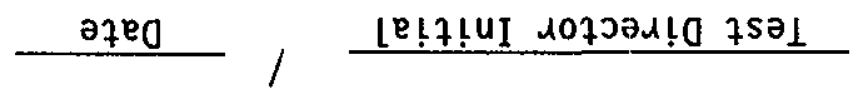

- suo!fejol dədunC peal $ә \wedge ! 7 !$ sod lof 'I fәәчs

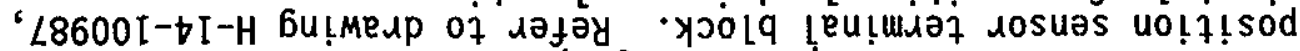

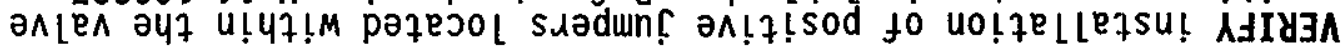

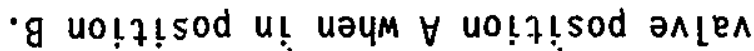

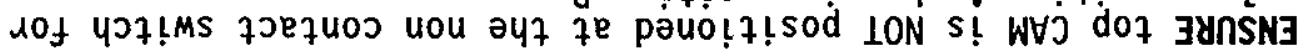

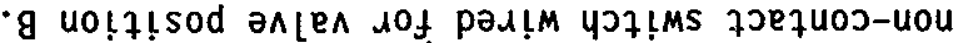

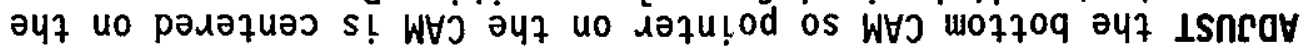

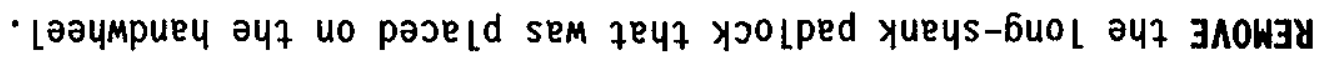
$9 I \cdot Z \cdot I \cdot s$

SI $\cdot Z \cdot I \cdot S$

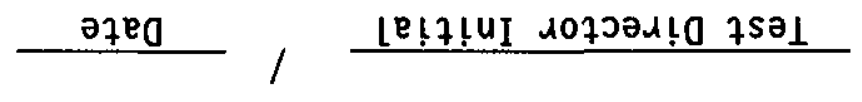

-

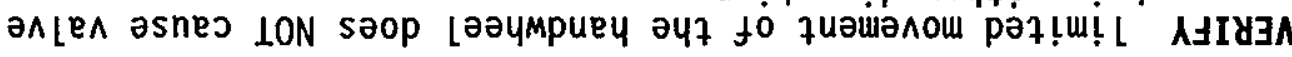
- Lәәчмриеу $60 \varepsilon-\Lambda-1 M-\forall N \forall$

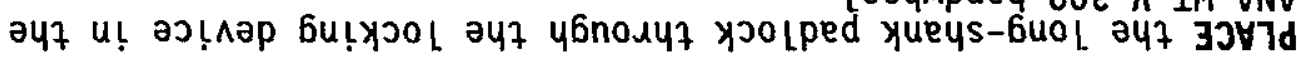

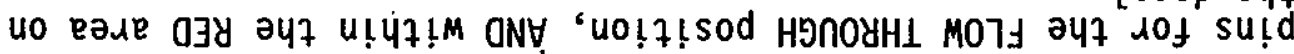

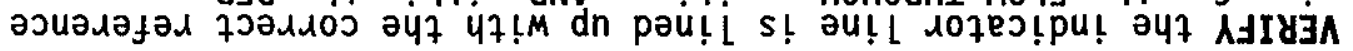

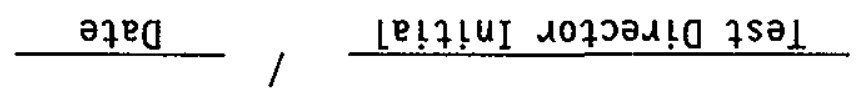

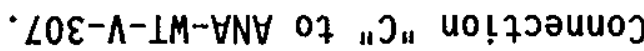

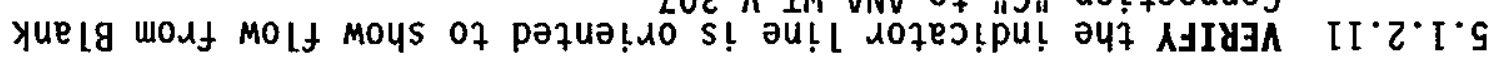

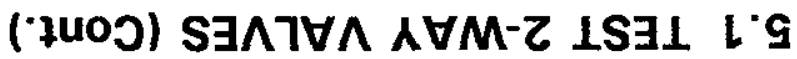




\subsection{TEST 2-WAY VALVES (Cont.)}

5.1.2.20 MEASURE AND RECORD the voltage BETWEEN Terminal TB-DC1-22 AND the NEGATIVE Terminal on the 24 volt dc power supply.

VOLTAGE

5.1.2.21 VERIFY the voltage recorded in Step 5.1.2.20 is at a nominal voltage of "24" Volts dc.
Test Director Initial

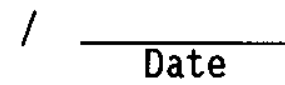

5.1.2.22 MEASURE AND RECORD the voltage BETWEEN Terminat TB-DC1-21 AND the NEGATIVE Terminal on the 24 volt dc power supply.

VOLTAGE

5.1.2.23 VERIFY the voltage recorded in Step 5.1.2.22 is at a nominal voltage of " 0 " Volts dc.
Test Director Initial
Date

5.1.2.24 POSITION ANA-WT-V-309 CLOSED by rotating the valve handwheel CLOCKWISE until the handwheel turns no farther.

5.1.2.25 VERIFY that ANA-WT-V-309 valve operator position indicator is oriented to BLOCK flow from "Blank Connection "C" " to ANA-WT-V307.
Test Director Initial
/

5.1.2.26 MEASURE AND RECORD the voltage BETWEEN Terminal TB-DCI-22 AND the NEGATIVE Terminal on the 24 volt dc power supply.

VOLTAGE

5.1.2.27 VERIFY the voltage recorded in Step 5.1.2.26 is at a nominal voltage of "O" Volts dc.
Test Director Initial
Date

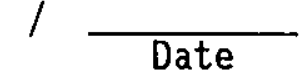




\subsection{TEST 2-WAY VALVES (Cont.)}

5.1.2.28 MEASURE AND RECORD the voltage BETWEEN Terminal TB-DC1-21 AND the NEGATIVE Terminal on the 24 volt dc power supply.

VOLTAGE

5.1.2.29 VERIFY the voltage recorded in Step 5.1.2.28 is at a nominal voltage of "24" Volts dc.

Test Director Initia] $/$ Date

NOTE - The next step prepares limit switch cover for torquing. A11 valves will be torqued at one time at end of this ATP and QC Shall verify. The Torque value will be between 17 and 20 inch lbs.

5.1.2.30 REPLACE limit switch cover AND TIGHTEN bolts in preparation for torque.

5.1.2.31 POSITION valve ANA-WT-V-309 as directed by the Test Director. 5.1.2.32 RECORD the final position for valve ANA-WT-V-309 below.

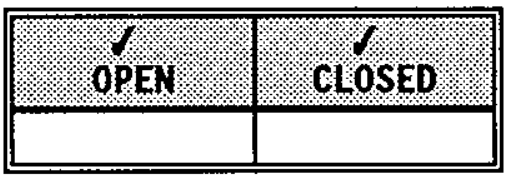

5.1.2.33 VERIFY by signing below that test 5.1.2 is complete.

\begin{tabular}{l} 
Test Director Signature \\
\hline Operations Signature
\end{tabular}

$\overline{\text { Date }}$




\subsection{TEST 2-WAY VALVES (Cont.)}

5.1.3 TEST 3-inch valve ANA-WT-V-322:

5.1.3.1 RECORD calibrated electrical test equipment data below. ELECTRICAL TEST EQUIPMENT DATA TABLE

\begin{tabular}{|l|l|l|l||}
\hline TOOL NAME & ID. NUMBER & CAL DUE DATE & INITIAL/DATE \\
\hline & & & \\
\hline & & & \\
\hline & & & \\
\hline
\end{tabular}

5.1.3.2 ENSURE that ANA-WT-V-322 is CLOSED by rotating the valve handwheel CLOCKWISE until the handwheel turns no farther.

5.1.3.3 VERIFY the indicator line is oriented to BLOCK flow from Blank Connection "G" to ANA-WT-V-321.

Test Director Initial

Date

5.1.3.4 VERIFY the indicator line is lined up with the correct reference pins for the CLOSED position, AND black stripe within the RED area on the decal is aligned as to be touching the applicable line on valve housing.

Test Director Initial Date

5.1.3.5 PLACE the long-shank padlock through the locking device in the ANA-WT-V-322 handwheel.

5.1.3.6 VERIFY limited movement of the handwhee 1 does NOT cause valve movement in either direction.

Test Director Initial Date

5.1.3.7 REMOVE the long-shank padlock that was $\mathrm{placed}$ on the handwheel.

5.1.3.8 REMOVE the cover from ANA-WT-V-322 valve position sensor assembly.

5.1.3.9 ADJUST the top cam so pointer on the CAM is centered on the noncontact switch wired for valve position $A$.

5.1.3.10 POSITION ANA-WT-V-322 OPEN by rotating the valve handwhee COUNTER CLOCKWISE until the handwheel turns no farther. 


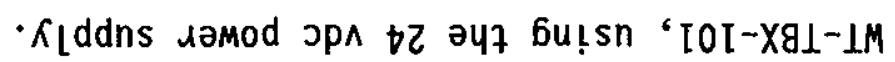

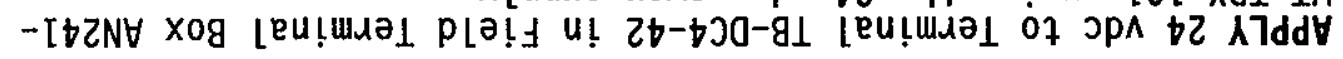

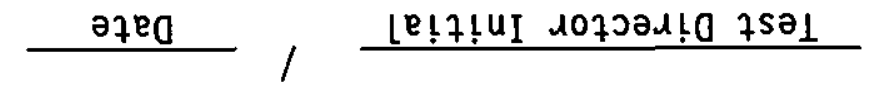

- suo!7ezol dədun

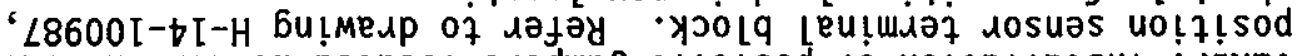

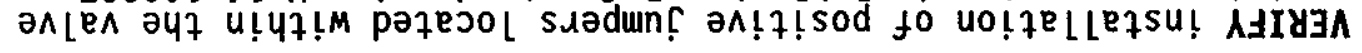

- $g$ Uo!f!sod U! UәYM $\forall$ Uo!f!sod $ә \Lambda$ LA

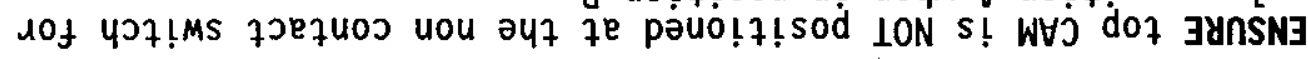

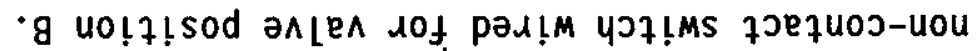

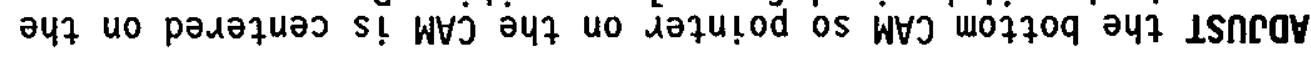

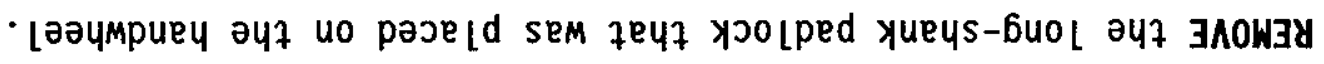

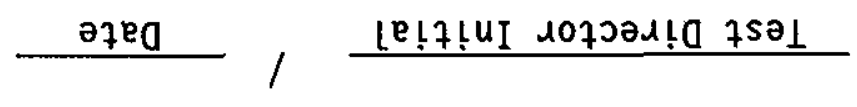

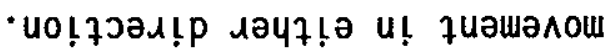

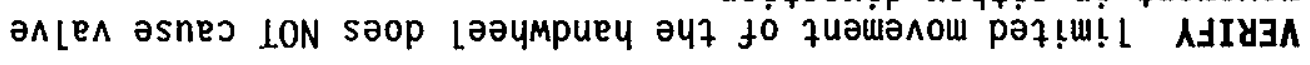

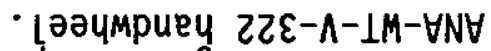

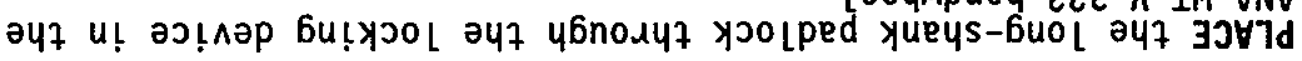

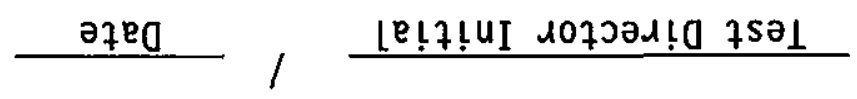
- lejap әу7

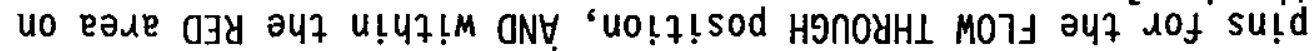

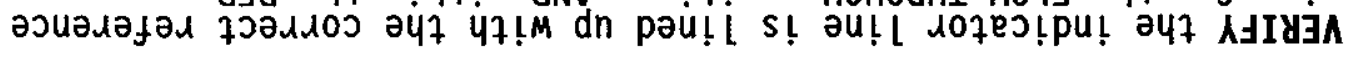
$Z I^{\cdot} \varepsilon^{\cdot} I^{\prime} \mathrm{G}$

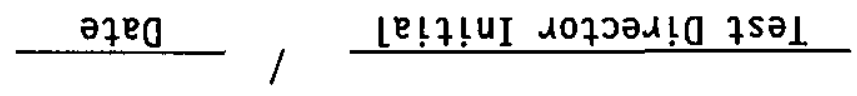

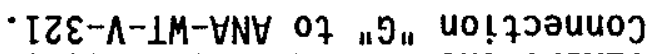

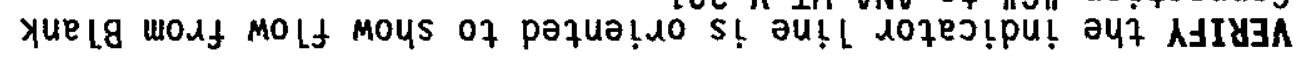

$8 I^{\circ} \varepsilon \cdot I^{\prime} \cdot \mathrm{s}$

$\angle I \cdot \varepsilon^{*}[\cdot \mathrm{g}$

$2[\cdot \varepsilon \cdot i \cdot g$

$\mathrm{s}\left[\cdot \varepsilon^{\circ}[\cdot \mathrm{s}\right.$

$t[\cdot \varepsilon \cdot[\cdot s$

$\varepsilon[\cdot \varepsilon \cdot[\cdot q$

('quoJ) S 


\subsection{TEST 2-WAY VALVES (Cont.)}

5.1.3.20 MEASURE AND RECORD the voltage BETWEEN Termina1 TB-DC1-52 AND the NEGATIVE Terminal on the 24 volt dc power supply.

VOLTAGE

5.1.3.21 VERIFY the voltage recorded in Step 5.1.3.20 is at a nominal voltage of "24" Volts dc.
Test Director Initial
Date

5.1.3.22 MEASURE AND RECORD the voltage BETWEEN Terminal TB-DC1-51 AND the NEGATIVE Terminal on the 24 volt dc power supply.

VOLTAGE

5.1.3.23 VERIFY the voltage recorded in Step 5.1.3.22 is at a nominal voltage of " 0 " Volts dc.
Test Director Initial
Date

5.1.3.24 POSITION ANA-WT-V-322 CLOSED by rotating the valve handwheel CLOCKWISE until the handwheel turns no farther.

5.1.3.25 VERIFY that ANA-WT-V-322 valve operator position indicator is oriented to BLOCK flow from "Blank Connection "G" " to ANA-WT-V321 .

Test Director Initial

Date

5.1.3.26 MEASURE AND RECORD the voltage BETWEEN Terminal TB-DC1-52 AND the NEGATIVE Terminal on the 24 volt dc power supply.

VOLTAGE

5.1.3.27 VERIFY the voltage recorded in Step 5.1.3.26 is at a nominal voltage of " 0 " Volts dc.

Test Director Initial

Date 


\subsection{TEST 2-WAY VALVES (Cont.)}

5.1.3.28 MEASURE AND RECORD the voltage BETWEEN Terminal TB-DC1-51 AND the NEGATIVE Terminal on the 24 volt dc power supply.

VOLTAGE

5.1.3.29 VERIFY the voltage recorded in Step 5.1.3.28 is at a nominal voltage of "24" Volts dc.

Test Director Initial

NOTE - The next step prepares limit switch cover for torquing. A11 valves will be torqued at one time at end of this ATP and QC Shall verify. The Torque value will be between 17 and 20 inch 1bs.

5.1.3.30 REPLACE limit switch cover AND TIGHTEN bolts in preparation for torque.

5.1.3.31 POSITION valve ANA-WT-V-322 as directed by the Test Director. 5.1.3.32 RECORD the final position for valve ANA-WT-V-322 below.

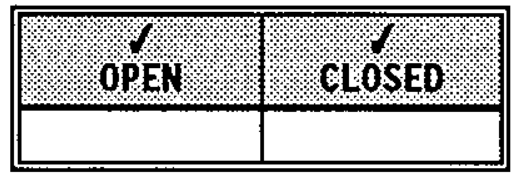

5.1.3.33 VERIFY by signing below that test 5.1 .3 is complete.

\begin{tabular}{ccc}
\hline Test Director Signature & Date \\
\hline Operations Signature & & Date
\end{tabular}




\subsection{TEST 2-WAY VALVES (Cont.)}

5.1.4 TEST 3 -inch vaTve ANA-WT-V-323:

5.1.4.1 RECORD calibrated electrical test equipment data below. ELECTRICAL TEST EQUIPMENT DATA TABLE

\begin{tabular}{|l|l|l|l||}
\hline TOOL NAME & ID. NUMBER & CAL DUE DATE & INITIAL/DATE \\
\hline & & & \\
\hline & & & \\
\hline & & & \\
\hline
\end{tabular}

5.1.4.2 ENSURE that ANA-WT-V-323 is CLOSED by rotating the valve handwhee] CLOCKWISE until the handwheel turns no farther.

5.1.4.3 VERIFY the indicator line is oriented to BLOCK flow from Connector "L1" to ANA-WT-V-321.

Test Director Initial

Date

5.1.4.4 VERIFY the indicator line is lined up with the correct reference pins for the CLOSED position, AND black stripe within the RED area on the decal is aligned as to be touching the applicable line on valve housing.

Test Director Initial

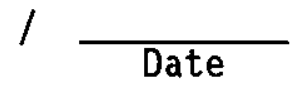

5.1.4.5 PLACE the long-shank padlock through the locking device in the ANA-WT-V-323 handwheel.

5.1.4.6 VERIFY limited movement of the handwheel does NOT cause valve movement in either direction.

Test Director Initial

Date

5.1.4.7 REMOVE the long-shank padlock that was placed on the handwheel.

5.1.4.8 REMOVE the cover from ANA-WT-V-323 vaTve position sensor assembiy.

5.1.4.9 ADJUST the top cam so pointer on the CAM is centered on the noncontact switch wired for valve position $A$.

5.1.4.10 POSITION ANA-WT-V-323 OPEN by rotating the valve handwhee COUNTER CLOCKWISE until the handwheel turns no farther. 


\subsection{TEST 2-WAY VALVES (Cont.)}

5.1.4.11 VERIFY the indicator line is oriented to show flow from Connector "LI" to ANA-WT-V-321.

Test Director Initial Date

5.1.4.12 VERIFY the indicator line is lined up with the correct reference pins for the FLOW THROUGH position, AND within the RED area on the decal.

Test Director InitiaT $/ \frac{}{\text { Date }}$

5.1.4.13 PLACE the long-shank padlock through the locking device in the ANA-WT-V-323 handwhee?.

5.1.4.14 VERIFY limited movement of the handwheel does NOT cause valve movement in either direction.

Test Director Initial

5.1.4.15 REMOVE the long-shank padlock that was placed on the handwheel.

5.1.4.16 ADJUST the bottom CAM so pointer on the CAM is centered on the non-contact switch wired for valve position $B$.

5.1.4.17 ENSURE top CAM is NOT positioned at the non contact switch for valve position $A$ when in position $B$.

5.1.4.18 VERIFY installation of positive jumpers located within the valve position sensor terminal block. Refer to drawing H-14-100987, sheet 1, for positive lead jumper locations.

Test Director Initial $/$ Date

5.1.4.19 APPLY 24 vdc to Terminal TB-DC4-43 in Field Terminal Box AN241WT-TBX-101, using the 24 vdc power supply. 


\subsection{TEST 2-WAY VALVES (Cont.)}

5.1.4.20 MEASURE AND RECORD the voltage BETWEEN Terminal TB-DC1-54 AND the NEGATIVE Terminal on the 24 volt dc power supply.

VOLTAGE

5.1.4.21 VERIFY the voltage recorded in Step 5.1.4.20 is at a nominal voltage of "24" Volts dc.

Test Director Initial

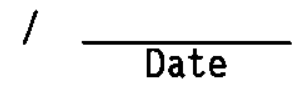

5.1.4.22 MEASURE AND RECORD the voltage BETWEEN Terminal TB-DC1-53 AND the NEGATIVE Terminal on the 24 volt dc power supply.

VOLTAGE

5.1.4.23 VERIFY the voltage recorded in Step 5.1.4.22 is at a nominal voltage of " 0 " Volts dc.

Test Director Initial

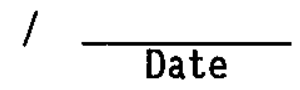

5.1.4.24 POSITION ANA-WT-V-323 CLOSED by rotating the valve handwheel CLOCKWISE until the handwheel turns no farther.

5.1.4.25 VERIFY that ANA-WT-V-323 vaTve operator position indicator is oriented to BLOCK flow from Connector "L1" to ANA-WT-V-321.

Test Director Initial

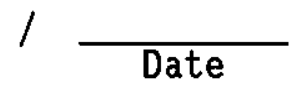

5.1.4.26 MEASURE AND RECORD the voltage BETWEEN Terminat TB-DC1-54 AND the NEGATIVE Terminal on the 24 volt dc power supply.

VOLTAGE

5.1.4.27 VERIFY the voltage recorded in Step 5.1.4.26 is at a nominal voltage of " 0 " Volts dc.

Test Director Initial
Date 


\subsection{TEST 2-WAY VALVES (Cont.)}

5.1.4.28 MEASURE AND RECORD the voltage BETWEEN Terminal TB-DC1-53 AND the NEGATIVE Terminal on the 24 volt dc power supply.

VOLTAGE

5.1.4.29 VERIFY the voltage recorded in Step 5.1.4.28 is at a nominal voltage of 24 Volts dc.

Test Director Initial

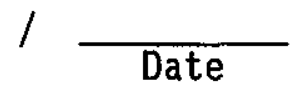

NOTE -

The next step prepares limit switch cover for torquing. All valves will be torqued at one time at end of this ATP and QC Shall verify. The Torque value will be between 17 and 20 inch 1bs.

5.1.4.30 REPLACE 1imit switch cover AND TIGHTEN bolts in preparation for torque.

5.1.4.31 POSITION valve ANA-WT-V-323 as directed by the Test Director.

5.1.4.32 RECORD the final position for valve ANA-WT-V-323 below.

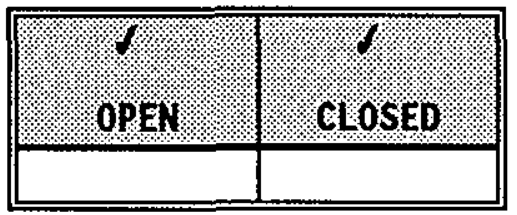

5.1.4.33 VERIFY by signing below that test 5.1 .4 is complete.

Test Director Signature

Operations Signature
Date

Date 


\subsection{TEST 2-WAY VALVES (Cont.)}

5.1.5 TEST 2-inch valve ANA-WT-V-304:

5.1.5.1 RECORD calibrated electrical test equipment data below. ELECTRICAL TEST EQUIPMENT DATA TABLE

\begin{tabular}{|l|l|l|l||}
\hline \hline TOOL NAME & ID. NUMBER & CAL DUE DATE & INITIAL/DATE \\
\hline & & & \\
\hline & & & \\
\hline & & & \\
\hline
\end{tabular}

5.1.5.2 ENSURE that ANA-WT-V-304 is CLOSED by rotating the valve handwheel CLOCKWISE until the handwheel turns no farther.

5.1.5.3 VERIFY the indicator line is oriented to BLOCK flow from Connector "L5" to ANA-WT-V-303.

Test Director Initial $/$ Date

5.1.5.4 VERIFY the indicator line is lined up with the correct reference pins for the CLOSED position, AND black stripe within the RED area on the decal is aligned as to be touching the applicable line on valve housing.

Test Director Initial

Date

5.1.5.5 PLACE the long-shank padlock through the locking device in the ANA-WT-V-304 handwhee?.

5.1.5.6 VERIFY limited movement of the handwheel does NOT cause valve movement in either direction.

Test Director Initial

Date

5.1.5.7 REMOVE the long-shank padlock that was placed on the handwheel.

5.1.5.8 REMOVE the cover from ANA-WT-V-304 valve position sensor assembly.

5.1.5.9 ADJUST the top cam so pointer on the CAM is centered on the noncontact switch wired for valve position $A$.

5.1.5.10 POSITION ANA-WT-V-304 OPEN by rotating the valve handwhee COUNTER CLOCKWISE until the handwheel turns no farther. 


\subsection{TEST 2-WAY VALVES (Cont.)}

5.1.5.11 VERIFY the indicator line is oriented to show flow from Connector "L5" to ANA-WT-V-303.

Test Director Initial

5.1.5.12 VERIFY the indicator line is lined up with the correct reference pins for the FLOW THROUGH position, AND within the RED area on the decal.

Test Director Initial

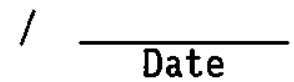

5.1.5.13 PLACE the long-shank padlock through the locking device in the ANA-WT-V-304 handwhee I.

5.1.5.14 VERIFY limited movement of the handwheel does NOT cause valve movement in either direction.

Test Director Initial $/$ Date

5.1.5.15 REMOVE the long-shank padlock that was placed on the handwheel.

5.1.5.16 ADJUST the bottom CAM so pointer on the CAM is centered on the non-contact switch wired for valve position $B$.

5.1.5.17 ENSURE top CAM is NOT positioned at the non contact switch for valve position $A$ when in position $B$.

5.1.5.18 VERIFY installation of positive jumpers located within the valve position sensor terminal block. Refer to drawing H-14-100987, sheet 1 , for positive lead jumper locations.

Test Director Initial

Date

5.1.5.19 APPLY 24 vdc to Terminal TB-DC4-25 in Field Terminal Box AN241WT-TBX-101, using the 24 vdc power supply. 


\subsection{TEST 2-WAY VALVES (Cont.)}

5.1.5.20 MEASURE AND RECORD the voltage BETWEEN Terminal TB-DC1-10 AND the NEGATIVE Terminal on the 24 volt dc power supply.

VOLTAGE

5.1.5.21 VERIFY the voltage recorded in Step 5.1.5.20 at a nomina] voltage of 24 Volts dc.
Test Director Initial

Date

5.1.5.22 MEASURE AND RECORD the voltage BETWEEN Terminal TB-DC1-9 AND the NEGATIVE Terminal on the 24 volt dc power supply.

VOLTAGE

5.1.5.23 VERIFY the voltage recorded in Step 5.5.5.22 is at a nominal voltage of "O" Volts $d c$.

Test Director Initial

5.1.5.24 POSITION ANA-WT-V-304 CLOSED by rotating the valve handwheel CLOCKWISE until the handwheel turns no farther.

5.1.5.25 VERIFY that ANA-WT-V-304 valve operator position indicator is oriented to BLOCK flow from Connector "L5" to ANA-WT-V-303.
Test Director Initial

/ Date

5.1.5.26 MEASURE AND RECORD the voltage BETWEEN Terminal TB-DC1-10 AND the NEGATIVE Terminal on the 24 volt dc power supply.

VOLTAGE

5.1.5.27 VERIFY the voltage recorded in Step 5.1.5.26 is at a nominal voltage of " 0 " Volts dc.
Test Director Initial
Date 


\subsection{TEST 2-WAY VALVES (Cont.)}

5.1.5.28 MEASURE AND RECORD the voltage BETWEEN Terminal TB-DC1-9 AND the NEGATIVE Terminal on the 24 volt dc power supply.

VOLTAGE

5.1.5.29 VERIFY the voltage recorded in Step 5.1.5.28 at a nominal voltage of 24 Volts dc.

Test Director Initial

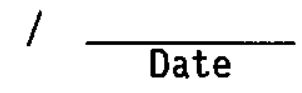

NOTE - The next step prepares limit switch cover for torquing. All valves will be torqued at one time at end of this ATP and QC Shall verify. The Torque value will be between 17 and 20 inch lbs.

5.1.5.30 REPLACE limit switch cover AND TIGHTEN bolts in preparation for torque.

5.1.5.31 POSITION valve ANA-WT-V-304 as directed by the Test Director.

5.1.5.32 RECORD the final position for valve ANA-WT-V-304 below.

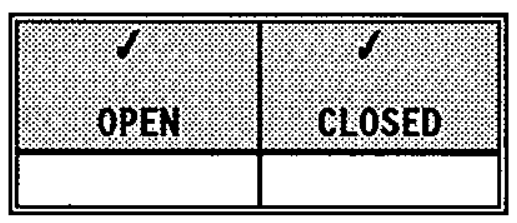

5.1.5.33 VERIFY by signing below that test 5.1.5 is complete.

\begin{tabular}{ccc}
\hline Test Director Signature & & Date \\
\hline 0perations Signature & & Date
\end{tabular}




\subsection{TEST 2-WAY VALVES (Cont.)}

5.1.6 TEST 2-inch valve ANA-WT-V-306:

5.1.6.1 RECORD calibrated electrical test equipment data below. ELECTRICAL TEST EQUIPMENT DATA TABLE

\begin{tabular}{|l|l|l|l|}
\hline TOOL NAME & ID. NUMBER & CAL DUE DATE & INITIAL/DATE \\
\hline & & & \\
\hline & & & \\
\hline & & & \\
\hline
\end{tabular}

5.1.6.2 ENSURE that ANA-WT-V-306 is CLOSED by rotating the valve handwheel CLOCKWISE until the handwheel turns no farther.

5.1.6.3 VERIFY the indicator line is oriented to BLOCK flow from Connector "L7" to ANA-WT-V-305.

Test Director Initial

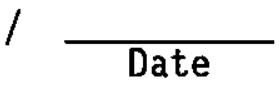

5.1.6.4 VERIFY the indicator line is lined up with the correct reference pins for the CLOSED position, AND black stripe within the RED area on the decal is aligned as to be touching the applicable line on valve housing.

\section{Test Director Initial}

5.1.6.5 PLACE the long-shank padlock through the locking device in the ANA-WT-V-306 handwhee?.

5.1.6.6 VERIFY limited movement of the handwheel does NOT cause valve movement in either direction.

Test Director Initial

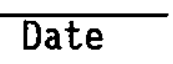

5.1.6.7 REMOVE the long-shank padlock that was placed on the handwheel.

5.1.6.8 REMOVE the cover from ANA-WT-V-306 valve position sensor assembly.

5.1.6.9 ADJUST the top cam so pointer on the CAM is centered on the noncontact switch wired for valve position $A$.

5.1.6.10 POSITION ANA-WT-V-306 OPEN by rotating the valve handwheel COUNTER CLOCKWISE until the handwhee 7 turns no farther. 


\subsection{TEST 2-WAY VALVES (Cont.)}

5.1.6.11 VERIFY the indicator line is oriented to show flow from Connector "L7" to ANA-WT-V-305.
Test Director Initial

/ Date

5.1.6.12 VERIFY the indicator line is lined up with the correct reference pins for the FLOW THROUGH position, AND within the RED area on the decal.
Test Director Initial

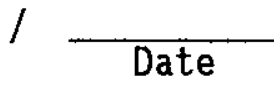

5.1.6.13 PLACE the long-shank padlock through the locking device in the ANA-WT-V-306 handwhee1.

5.1.6.14 VERIFY limited movement of the handwheel does NOT cause valve movement in either direction.

\section{Test Director Initial}

5.1.6.15 REMOVE the long-shank padlock that was placed on the handwheel.

5.1.6.16 ADJUST the bottom CAM so pointer on the CAM is centered on the non-contact switch wired for valve position $B$.

5.1.6.17 ENSURE top CAM is NOT positioned at the non contact switch for valve position $A$ when in position $B$.

5.1.6.18 VERIFY installation of positive jumpers located within the valve position sensor terminal block. Refer to drawing H-14-100987, sheet 1 , for positive lead jumper locations.

Test Director Initial $/$ Date

5.1.6.19 APPLY 24 vdc to Terminal TB-DC4-27 in Field Terminal Box AN241WT-TBX-101, using the 24 vdc power supply. 


\subsection{TEST 2-WAY VALVES (Cont.)}

5.1.6.20 MEASURE AND RECORD the voltage BETWEEN Terminal TB-DC1-15 AND the NEGATIVE Terminal on the 24 volt dc power supply.

VOLTAGE

5.1.6.21 VERIFY the voltage recorded in Step 5.1.6.20 at a nominal voltage of 24 Volts dc.
Test Director Initial
Date

5.1.6.22 MEASURE AND RECORD the voltage BETWEEN Terminal TB-DC1-14 AND the NEGATIVE Terminal on the 24 volt dc power supply.

VOLTAGE

5.1.6.23 VERIFY the voltage recorded in Step 5.1.6.22 is at a nominal voltage of " 0 " Volts dc.

\section{Test Director Initial Date}

5.1.6.24 POSITION ANA-WT-V-306 CLOSED by rotating the valve handwhee CLOCKWISE until the handwheel turns no farther.

5.1.6.25 VERIFY that ANA-WT-V-306 valve operator position indicator is oriented to BLOCK flow from Connector "L7" to ANA-WT-V-305.
Test Director Initial
Date

5.1.6.26 MEASURE AND RECORD the voltage BETWEEN Terminal TB-DCI-15 AND the NEGATIVE Terminal on the 24 volt dc power supply.

VOLTAGE

5.1.6.27 VERIFY the voltage recorded in Step 5.1.6.26 is at a nominal voltage of " 0 " Volts $\mathrm{dc}$.
Test Director Initial
Date 


\subsection{TEST 2-WAY VALVES (Cont.)}

5.1.6.28 MEASURE AND RECORD the voltage BETWEEN Terminal TB-DC1-14 AND the NEGATIVE Terminal on the 24 volt dc power supply.

VOLTAGE

5.1.6.29 VERIFY the voltage recorded in Step 5.1.6.28 at a nominal voltage of 24 Volts dc.

Test Director Initial $/ \frac{}{\text { Date }}$

NOTE - The next step prepares limit switch cover for torquing. All valves will be torqued at one time at end of this ATP and QC Shall verify. The Torque value will be between 17 and 20 inch lbs.

5.1.6.30 REPLACE 1imit switch cover AND TIGHTEN bolts in preparation for torque.

5.1.6.31 POSITION valve ANA-WT-V-306 as directed by the Test Director. 5.1.6.32 RECORD the final position for valve ANA-WT-V-306 below.

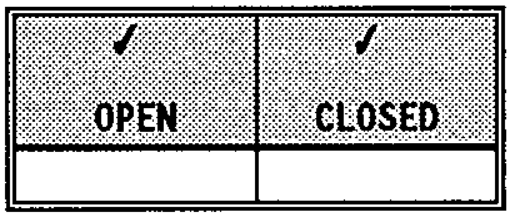

5.1.6.33 VERIFY by signing below that test 5.1 .6 is complete.

\begin{tabular}{ccc}
\hline Test Director Signature & & Date \\
\hline Operations Signature & & Date
\end{tabular}




\subsection{TEST 2-WAY VALVES (Cont.)}

5.1.7 TEST 2-inch valve ANA-WT-V-308:

5.1.7.1 RECORD calibrated electrical test equipment data below. ELECTRICAL TEST EQUIPMENT DATA TABLE

\begin{tabular}{|l|l|l|l|}
\hline TOOL NAME & ID. NUMBER & CAL DUE DATE & INITIAL/DATE \\
\hline & & & \\
\hline & & & \\
\hline & & & \\
\hline
\end{tabular}

5.1.7.2 ENSURE that ANA-WT-V-308 is CLOSED by rotating the valve handwheel CLOCKWISE until the handwheel turns no farther.

5.1.7.3 VERIFY the indicator line is oriented to BLOCK flow from Connector "L9" to ANA-WT-V-307.

Test Director Initial Date

5.1.7.4 VERIFY the indicator line is lined up with the correct reference pins for the CLOSED position, AND black stripe within the RED area on the decal is aligned as to be touching the applicable line on valve housing.

Test Director Initial

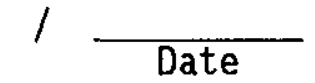

5.1.7.5 PLACE the long-shank padlock through the locking device in the ANA-WT-V-308 handwhee 1 .

5.1.7.6 VERIFY limited movement of the handwheel does NOT cause valve movement in either direction.

Test Director Initial

Date

5.1.7.7 REMOVE the long-shank padlock that was placed on the handwheel.

5.1.7.8 REMOVE the cover from ANA-WT-V-308 valve position sensor assembly.

5.1.7.9 ADJUST the top cam so pointer on the CAM is centered on the noncontact switch wired for valve position $A$.

5.1.7.10 POSITION ANA-WT-V-308 OPEN by rotating the valve handwheel

COUNTER CLOCKWISE unti1 the handwheel turns no farther. 


\subsection{TEST 2-WAY VALVES (Cont.)}

5.1.7.11 VERIFY the indicator line is oriented to show flow from Connector "L9" to ANA-WT-V-307.

\section{Test Director Initial Date}

5.1.7.12 VERIFY the indicator 1 ine is 1 ined up with the correct reference pins for the FLOW THROUGH position, AND within the RED area on the decal.

Test Director Initial

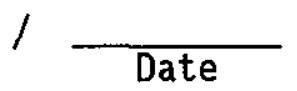

5.1.7.13 PLACE the long-shank padlock through the locking device in the ANA-WT-V-308 handwheel.

5.1.7.14 VERIFY limited movement of the handwheel does NOT cause valve movement in either direction.

Test Director Initial Date

5.1.7.15 REMOVE the long-shank padlock that was placed on the handwheel.

5.1.7.16 ADJUST the bottom CAM so pointer on the CAM is centered on the non-contact switch wired for valve position $B$.

5.1.7.17 ENSURE top CAM is NOT positioned at the non contact switch for valve position $A$ when in position $B$.

5.1.7.18 VERIFY installation of positive jumpers located within the valve position sensor terminal block. Refer to drawing H-14-100987, sheet 1 , for positive lead jumper locations.

Test Director Initia]

Date

5.1.7.19 APPLY 24 vdc to Terminal TB-DC4-29 in Field Terminal Box AN241WT-TBX-101, using the 24 vdc power supply. 


\subsection{TEST 2-WAY VALVES (Cont.)}

5.1.7.20 MEASURE AND RECORD the voltage BETWEEN Terminal TB-DC1-20 AND the NEGATIVE Terminal on the 24 volt dc power supply.

VOLTAGE

5.1.7.21 VERIFY the voltage recorded in Step 5.1.7.20 at a nominal voltage of 24 Volts dc.

Test Director Initial

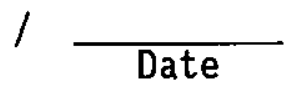

5.1.7.22 MEASURE AND RECORD the voltage BETWEEN Terminal TB-DC1-19 AND the NEGATIVE Terminal on the 24 volt dc power supply.

VOLTAGE

5.1.7.23 VERIFY the voltage recorded in Step 5.1.7.22 is at a nominal voltage of " 0 " Volts dc.

Test Director Initial

$$
\text { Date }
$$

5.1.7.24 POSITION ANA-WT-V-308 CLOSED by rotating the valve handwheel CLOCKWISE until the handwheel turns no farther.

5.1.7.25 VERIFY that ANA-WT-V-308 valve operator position indicator is oriented to BLOCK flow from Connector "L9" to ANA-WT-V-307.

Test Director Initial

Date

5.1.7.26 MEASURE AND RECORD the voltage BETWEEN Terminal TB-DC1-20 AND the NEGATIVE Terminal on the 24 volt dc power supply.

VOLTAGE

5.1.7.27 VERIFY the voltage recorded in Step 5.1.7.26 is at a nominal voltage of "O" Volts dc.
Test Director Initial
Date 


\begin{tabular}{|c|c|}
\hline әqеg & aunfeub! s suo!̣fedədo \\
\hline әте० & 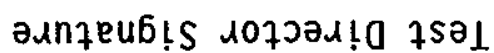 \\
\hline
\end{tabular}

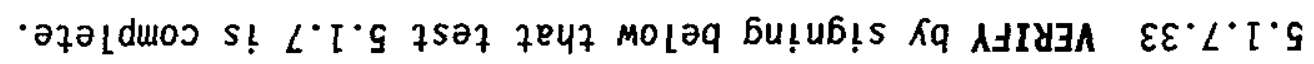

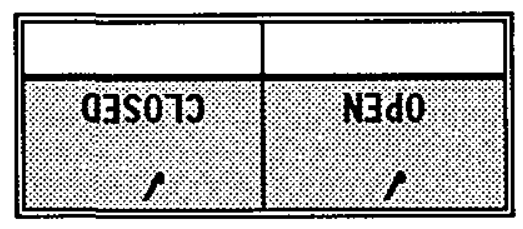

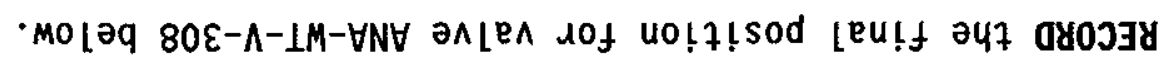

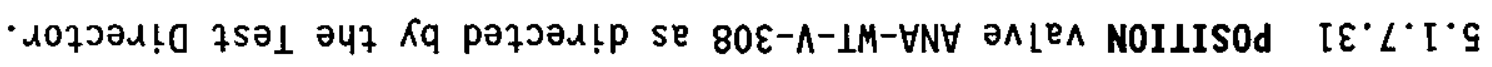

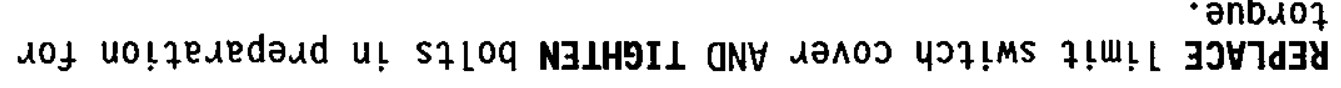
$0 \varepsilon^{*} L^{\prime} \cdot \cdot \cdot G$

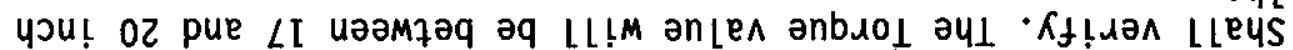

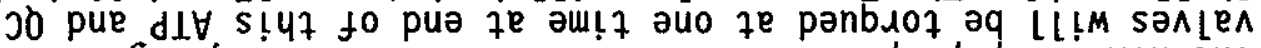

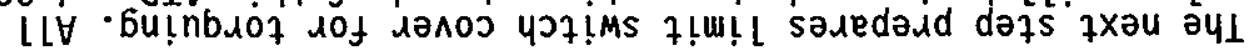

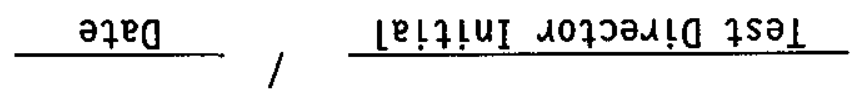

- sp sqlon tz to a6ezlon

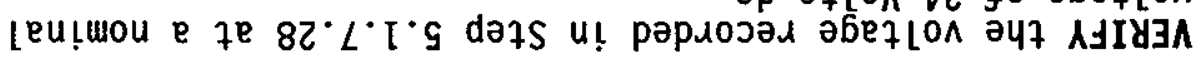

$62 \cdot L \cdot I \cdot 9$

$39 \forall 170 \wedge$

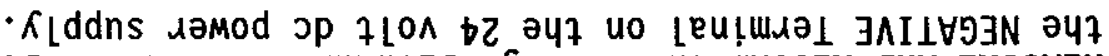

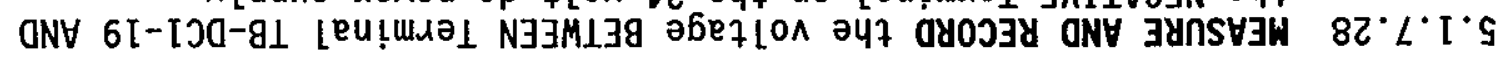

('quoJ) S $\exists \wedge 7 \forall \wedge \wedge \forall M-乙 \perp S \exists \perp$ L'G 


\subsection{TEST 2-WAY VALVES (Cont.)}

5.1.8 TEST 3 -inch valve ANA-WT-V-313:

5.1.8.1 RECORD calibrated electrical test equipment data below. ELECTRICAL TEST EQUIPMENT DATA TABLE

\begin{tabular}{|l|l|l|l|}
\hline TOOL NAME & ID. NUMBER & CAL DUE DATE & INITIAL/DATE \\
\hline & & & \\
\hline & & & \\
\hline & & & \\
\hline
\end{tabular}

5.1.8.2 ENSURE that ANA-WT-V-313 is CLOSED by rotating the valve handwheel CLOCKWISE until the handwheel turns no farther.

5.1.8.3 VERIFY the indicator line is oriented to BLOCK flow from Connector "L14" to ANA-WT-V-314.
Test Director Initial
Date

5.1.8.4 VERIFY the indicator line is 1 ined up with the correct reference pins for the CLOSED position, AND black stripe within the RED area on the decal is aligned as to be touching the applicable line on valve housing.

\section{Test Director Initial}

5.1.8.5 PLACE the long-shank padlock through the locking device in the ANA-WT-V-313 handwhee 1 .

5.1.8.6 VERIFY limited movement of the handwheel does NOT cause valve movement in either direction.
Test Director Initial
Date

5.1.8.7 REMOVE the long-shank padlock that was placed on the handwheel.

5.1.8.8 REMOVE the cover from ANA-WT-V-313 valve position sensor assembly.

5.1.8.9 ADJUST the top cam so pointer on the CAM is centered on the noncontact switch wired for valve position $A$.

5.1.8.10 POSITION ANA-WT-V-313 OPEN by rotating the valve handwheel COUNTER CLOCKWISE until the handwheel turns no farther. 


\subsection{TEST 2-WAY VALVES (Cont.)}

5.1.8.11 VERIFY the indicator line is oriented to show flow from Connector "L14" to ANA-WT-V-314.

Test Director Initial

/ Date

5.1.8.12 VERIFY the indicator line is lined up with the correct reference pins for the FLOW THROUGH position, AND within the RED area on the decal.
Test Director Initial

/ Date
5.1.8.13 PLACE the long-shank padlock through the locking device in the ANA-WT-V-313 handwhee 1 .

5.1.8.14 VERIFY 1 imited movement of the handwheel does NOT cause valve movement in either direction.

Test Director Initial

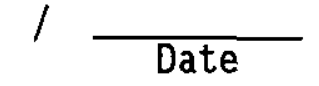

5.1.8.15 REMOVE the long-shank padlock that was placed on the handwheel.

5.1.8.16 ADJUST the bottom CAM so pointer on the CAM is centered on the non-contact switch wired for valve position $B$.

5.1.8.17 ENSURE top CAM is NOT positioned at the non contact switch for valve position $A$ when in position $B$.

5.1.8.18 VERIFY installation of positive jumpers located within the valve position sensor terminal block. Refer to drawing H-14-100987, sheet 1 , for positive lead jumper locations.

Test Director Initial

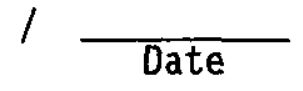

5.1.8.19 APPLY 24 vdc to Terminal TB-DC4-33 in Field Terminal Box AN241WT-TBX-101, using the 24 vdc power supply. 


\subsection{TEST 2-WAY VALVES (Cont.)}

5.1.8.20 MEASURE AND RECORD the voltage BETWEEN Terminal TB-DC1-29 AND the NEGATIVE Terminal on the 24 volt dc power supply.

VOLTAGE

5.1.8.21 VERIFY the voltage recorded in Step 5.1.8.20 at a nominal voltage of 24 Volts dc.

Test Director Initial

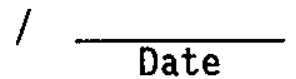

5.1.8.22 MEASURE AND RECORD the voltage BETWEEN Terminal TB-DC1-28 AND the NEGATIVE Terminal on the 24 volt dc power supply.

VOLTAGE

5.1.8.23 VERIFY the voltage recorded in Step 5.1.8.22 is at a nominal voltage of " 0 " Volts dc.

Test Director Initial

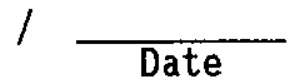

5.1.8.24 POSITION ANA-WT-V-313 CLOSED by rotating the valve handwhee] CLOCKWISE until the handwheel turns no farther.

5.1.8.25 VERIFY that ANA-WT-V-313 valve operator position indicator is oriented to BLOCK flow from Connector "L14" to ANA-WT-V-314.
Test Director Initial

/ Date

5.1.8.26 MEASURE AND RECORD the voltage BETWEEN Terminal TB-DC1-29 AND the NEGATIVE Terminal on the 24 volt dc power supply.

VOLTAGE

5.1.8.27 VERIFY the voltage recorded in Step 5.1.8.26 is at a nominal voltage of "O" Volts dc.
Test Director Initial
Date 


\subsection{TEST 2-WAY VALVES (Cont.)}

5.1.8.28 MEASURE AND RECORD the voltage BETWEEN Terminal TB-DC1-28 AND the NEGATIVE Terminal on the 24 volt dc power supply.

VOLTAGE

5.1.8.29 VERIFY the voltage recorded in Step 5.1.8.28 at a nomina] voltage of 24 Volts dc.

Test Director Initial $/$ Date

NOTE - The next step prepares limit switch cover for torquing. ATI valves will be torqued at one time at end of this ATP and QC Shall verify. The Torque value will be between 17 and 20 inch Tbs.

5.1.8.30 REPLACE limit switch cover AND TIGHTEN bolts in preparation for torque.

5.1.8.31 POSITION valve ANA-WT-V-313 as directed by the Test Director.

5.1.8.32 RECORD the final position for valve ANA-WT-V-313 below.

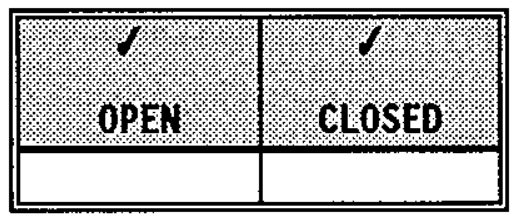

5.1.8.33 VERIFY by signing below that test 5.1 .8 is complete.

\begin{tabular}{cc} 
Test Director Signature & Date \\
\hline Operations Signature & Date
\end{tabular}




\subsection{TEST 2-WAY VALVES (Cont.)}

5.1.9 TEST 3 -inch vaTve ANA-WT-V-315:

5.1.9.1 RECORD calibrated electrical test equipment data below. ELECTRICAL TEST EQUIPMENT DATA TABLE

\begin{tabular}{|l|l|l|l|}
\hline TOOL NAME & ID. NUMBER & CAL DUE DATE & INITIAL/DATE \\
\hline & & & \\
\hline & & & \\
\hline & & & \\
\hline
\end{tabular}

5.1.9.2 ENSURE that ANA-WT-V-315 is CLOSED by rotating the valve handwheel CLOCKWISE unt 11 the handwheel turns no farther.

5.1.9.3 VERIFY the indicator line is oriented to BLOCK flow from Connector "L15" to ANA-WT-V-314.
Test Director Initial
Date

5.1.9.4 VERIFY the indicator line is lined up with the correct reference pins for the CLOSED position, AND black stripe within the RED area on the decal is aligned as to be touching the applicable line on valve housing.

\section{Test Director Initial}

Date

5.1.9.5 PLACE the long-shank padlock through the locking device in the ANA-WT-V-315 handwhee1.

5.1.9.6 VERIFY limited movement of the handwheel does NOT cause valve movement in either direction.

Test Director Initial

\section{Date}

5.1.9.7 REMOVE the long-shank padlock that was placed on the handwheel.

5.1.9.8 REMOVE the cover from ANA-WT-V-315 valve position sensor assembly.

5.1.9.9 ADJUST the top cam so pointer on the CAM is centered on the noncontact switch wired for valve position $A$.

5.1.9.10 POSITION ANA-WT-V-315 OPEN by rotating the valve handwhee] COUNTER CLOCKWISE until the handwheel turns no farther. 


\subsection{TEST 2-WAY VALVES (Cont.)}

5.1.9.11 VERIFY the indicator line is oriented to show flow from Connector "L15" to ANA-WT-V-314.

Test Director Initial

5.1.9.12 VERIFY the indicator line is lined up with the correct reference pins for the FLOW THROUGH position, AND within the RED area on the decal.

Test Director Initial

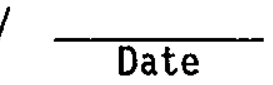

5.1.9.13 PLACE the long-shank padlock through the locking device in the ANA-WT-V-315 handwheet.

5.1.9.14 VERIFY limited movement of the handwheel does NOT cause valve movement in either direction.

\section{Test Director InitiaT Date}

5.1.9.15 REMOVE the long-shank padlock that was placed on the handwheel.

5.1.9.16 ADJUST the bottom CAM so pointer on the CAM is centered on the non-contact switch wired for valve position $B$.

5.1.9.17 ENSURE top CAM is NOT positioned at the non contact switch for valve position $A$ when in position $B$.

5.1.9.18 VERIFY installation of positive jumpers located within the valve position sensor terminal block. Refer to drawing H-14-100987, sheet 1 , for positive lead jumper locations.

Test Director Initial

5.1.9.19 APPLY $24 \mathrm{vdc}$ to Terminal TB-DC4-35 in Field Terminal Box AN241WT-TBX-101, using the 24 vdc power supply. 


\subsection{TEST 2-WAY VALVES (Cont.)}

5.1.9.20 MEASURE AND RECORD the voltage BETWEEN Terminal TB-DC1-34 AND the NEGATIVE Terminal on the 24 volt dc power supply.

VOLTAGE

5.1.9.21 VERIFY the voltage recorded in Step 5.1.9.20 at a nominal voltage of 24 Volts dc.

Test Director Initial

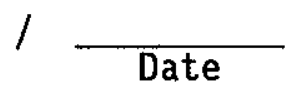

5.1.9.22 MEASURE AND RECORD the voltage BETWEEN Terminal TB-DC1-33 AND the NEGATIVE Terminal on the 24 volt dc power supply.

VOLTAGE

5.1.9.23 VERIFY the voltage recorded in Step 5.1.9.22 is at a nominal voltage of " 0 " Volts dc.

Test Director Initial

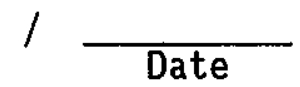

5.1.9.24 POSITION ANA-WT-V-315 CLOSED by rotating the valve handwheel CLOCKWISE unt il the handwheel turns no farther.

5.1.9.25 VERIFY that ANA-WT-V-315 valve operator position indicator is oriented to BLOCK flow from Connector "L15" to ANA-WT-V-314.

Test Director Initial

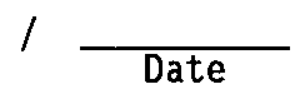

5.1.9.26 MEASURE AND RECORD the voltage BETWEEN Terminal TB-DC1-34 AND the NEGATIVE Terminal on the 24 volt dc power supply.

VOLTAGE

5.1.9.27 VERIFY the voltage recorded in Step 5.1.9.26 is at a nominal voltage of " 0 " Volts $d c$.

Test Director Initial

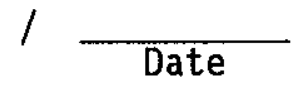




\subsection{TEST 2-WAY VALVES (Cont.)}

5.1.9.28 MEASURE AND RECORD the voltage BETWEEN Terminal TB-DC1-33 AND the NEGATIVE Terminal on the 24 volt dc power supply.

VOLTAGE

5.1.9.29 VERIFY the voltage recorded in Step 5.1.9.28 at a nominal voltage of 24 Volts dc.

\section{Test Director Initial}

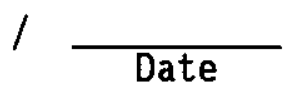

NOTE - The next step prepares limit switch cover for torquing. All valves will be torqued at one time at end of this ATP and QC Shall verify. The Torque value will be between 17 and 20 inch 1bs.

5.1.9.30 REPLACE limit switch cover AND TIGHTEN bolts in preparation for torque.

5.1.9.31 POSITION valve ANA-WT-V-315 as directed by the Test Director.

5.1.9.32 RECORD the final position for valve ANA-WT-V-315 below.

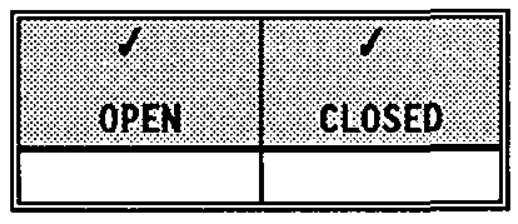

5.1.9.33 VERIFY by signing below that test 5.1 .9 is complete.

\begin{tabular}{ccc}
\hline Test Director Signature & Date \\
\hline Operations Signature & & Date
\end{tabular}




\subsection{TEST 2-WAY VALVES (Cont.)}

5.1.10 TEST 3-inch valve ANA-WT-V-317:

5.1.10.1 RECORD calibrated electrical test equipment data below. ELECTRICAL TEST EQUIPMENT DATA TABLE

\begin{tabular}{|l|c|l|l|}
\hline TOOL NAME & ID. NUMBER & CAL DUE DATE & INITIAL/DATE \\
\hline & & & \\
\hline & & & \\
\hline & & & \\
\hline
\end{tabular}

5.1.10.2 ENSURE that ANA-WT-V-317 is CLOSED by rotating the valve handwhee 1 CLOCKWISE until the handwheel turns no farther.

5.1.10.3 VERIFY the indicator line is oriented to BLOCK flow from Connector "L16" to ANA-WT-V-316.

Test Director Initial Date

5.1.10.4 VERIFY the indicator line is lined up with the correct reference pins for the CLOSED position, AND black stripe within the RED area on the decal is aligned as to be touching the applicable line on valve housing.
Test Director Initial
Date

5.1.10.5 PLACE the long-shank padlock through the locking device in the ANA-WT-V-317 handwheel.

5.1.10.6 VERIFY limited movement of the handwheel does NOT cause valve movement in either direction.

Test Director Initial

5.1.10.7 REMOVE the long-shank padlock that was placed on the handwheel.

5.1.10.8 REMOVE the cover from ANA-WT-V-317 valve position sensor assembly.

5.1.10.9 ADJUST the top cam so pointer on the CAM is centered on the noncontact switch wired for valve position $A$.

5.1.10.10 POSITION ANA-WT-V-317 OPEN by rotating the valve handwheel COUNTER CLOCKWISE until the handwheel turns no farther. 


\subsection{TEST 2-WAY VALVES (Cont.)}

5.1.10.11 VERIFY the indicator 1 ine is oriented to show flow from Connector "L16" to ANA-WT-V-316.

Test Director Initial $/$ Date

5.1.10.12 VERIFY the indicator line is lined up with the correct reference pins for the FLOW THROUGH position, AND within the RED area on the decal.

Test Director Initial $/ \frac{}{\text { Date }}$

5.1.10.13 PLACE the long-shank padlock through the locking device in the ANA-WT-V-317 handwheel.

5.1.10.14 VERIFY limited movement of the handwheel does NOT cause valve movement in either direction.

\section{Test Director Initial Date}

5.1.10.15 REMOVE the long-shank padlock that was placed on the handwheel.

5.1.10.16 ADJUST the bottom CAM so pointer on the CAM is centered on the non-contact switch wired for valve position $B$.

5.1.10.17 ENSURE top CAM is NOT positioned at the non contact switch for valve position $A$ when in position $B$.

5.1.10.18 VERIFY installation of positive jumpers located within the valve position sensor terminal block. Refer to drawing H-14-100987, sheet 1 , for positive lead jumper locations.

Test Director Initial

Date

5.1.10.19 APPLY 24 vdc to Terminat TB-DC4-37 in Field Terminal Box AN241WT-TBX-101, using the 24 vdc power supply. 


\subsection{TEST 2-WAY VALVES (Cont.)}

5.1.10.20 MEASURE AND RECORD the voltage BETWEEN Terminal TB-DC1-39 AND the NEGATIVE Terminal on the 24 volt dc power supply.

VOLTAGE

5.1.10.21 VERIFY the voltage recorded in Step 5.1.10.20 at a nominal voltage of 24 Volts dc.

\section{Test Director Initial}

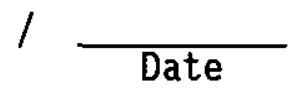

5.1.10.22 MEASURE AND RECORD the voltage BETWEEN Terminal TB-DC1-38 AND the NEGATIVE Terminal on the 24 volt dc power supply.

VOLTAGE

5.1.10.23 VERIFY the voltage recorded in Step 5.1.10.22 is at a nominal voltage of " 0 " Volts dc.

\section{Test Director Initial}

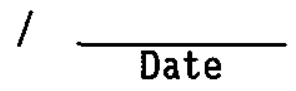

5.1.10.24 POSITION ANA-WT-V-317 CLOSED by rotating the valve handwhee CLOCKWISE unt il the handwheel turns no farther.

5.1.10.25 VERIFY that ANA-WT-V-317 valve operator position indicator is oriented to BLOCK flow from Connector "L16" to ANA-WT-V-316.
Test Director Initial
/
Date

5.1.10.26 MEASURE AND RECORD the voltage BETWEEN Terminal TB-DC1-39 AND the NEGATIVE Terminal on the 24 volt dc power supply.

VOLTAGE

5.1.10.27 VERIFY the voltage recorded in Step 5.1.10.26 is at a nominal voltage of " 0 " Volts dc.

Test Director Initial

Date

\begin{tabular}{|c|c|c|c|c|}
\hline 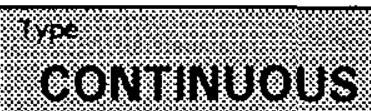 & : & (3) & ris & (4) \\
\hline
\end{tabular}




\subsection{TEST 2-WAY VALVES (Cont.)}

5.1.10.28 MEASURE AND RECORD the voltage BETWEEN Terminal TB-DC1-38 AND the NEGATIVE Terminal on the 24 volt dc power supply.

VOLTAGE

5.1.10.29 VERIFY the voltage recorded in Step 5.1.10.28 at a nominal voltage of 24 Volts dc.

Test Director Initial

NOTE - The next step prepares limit switch cover for torquing. All valves will be torqued at one time at end of this ATP and QC Shall verify. The Torque value will be between 17 and 20 inch 1bs.

5.1.10.30 REPLACE limit switch cover AND TIGHTEN bolts in preparation for torque.

5.1.10.31 POSITION valve ANA-WT-V-317 as directed by the Test Director. 5.1.10.32 RECORD the final position for valve ANA-WT-V-317 below.

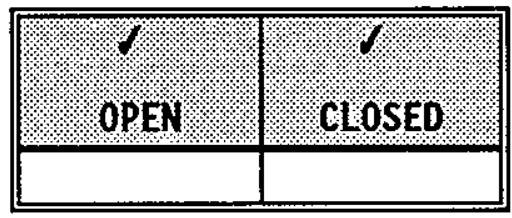

5.1.10.33 VERIFY by signing below that test 5.1 .10 is complete.

\begin{tabular}{ccc} 
Test Director Signature & Date \\
\hline Operations Signature & & Date
\end{tabular}




\subsection{TEST 2-WAY VALVES (Cont.)}

5.1.11 TEST 3-inch valve ANA-WT-V-320:

5.1.11.1 RECORD calibrated electrical test equipment data below. ELECTRICAL TEST EQUIPMENT DATA TABLE

\begin{tabular}{|l|l|l|l|}
\hline TOOL NAME & ID. NUMBER & CAL DUE DATE & INITIAL/DATE \\
\hline & & & \\
\hline & & & \\
\hline & & & \\
\hline
\end{tabular}

5.1.11.2 ENSURE that ANA-WT-V-320 is CLOSED by rotating the valve handwheel CLOCKWISE until the handwheel turns no farther.

5.1.11.3 VERIFY the indicator line is oriented to BLOCK flow from Connector "L19" to ANA-WT-V-319.

\section{Test Director Initia] Date}

5.1.11.4 VERIFY the indicator line is lined up with the correct reference pins for the CLOSED position, AND black stripe within the RED area on the decal is aligned as to be touching the applicable line on valve housing.
Test Director Initial
Date
5.1.11.5 PLACE the long-shank padlock through the locking device in the ANA-WT-V-320 handwhee1.

5.1.11.6 VERIFY limited movement of the handwheel does NOT cause valve movement in either direction.

\section{Test Director Initial Date}

5.1.11.7 REMOVE the long-shank padlock that was placed on the handwheel.

5.1.11.8 REMOVE the cover from ANA-WT-V-320 valve position sensor assembly.

5.1.11.9 ADJUST the top cam so pointer on the CAM is centered on the noncontact switch wired for valve position $A$.

5.1.11.10 POSITION ANA-WT-V-320 OPEN by rotating the valve handwheel COUNTER CLOCKWISE until the handwheel turns no farther. 


\subsection{TEST 2-WAY VALVES (Cont.)}

5.1.11.11 VERIFY the indicator line is oriented to show flow from Connector "L19" to ANA-WT-V-319.

\section{Test Director Initial Date}

5.1.11.12 VERIFY the indicator line is lined up with the correct reference pins for the FLOW THROUGH position, AND with in the RED area on the decal.

\section{Test Director Initial $/ \frac{}{\text { Date }}$}

5.1.11.13 PLACE the long-shank padlock through the locking device in the ANA-WT-V-320 handwhee1.

5.1.11.14 VERIFY limited movement of the handwheel does NOT cause valve movement in either direction.

Test Director Initial

5.1.11.15 REMOVE the long-shank padlock that was placed on the handwheel.

5.1.11.16 ADJUST the bottom CAM so pointer on the CAM is centered on the non-contact switch wired for valve position $B$.

5.1.11.17 ENSURE top CAM is NOT positioned at the non contact switch for valve position $A$ when in position $B$.

5.1.11.18 VERIFY installation of positive jumpers located within the valve position sensor terminal block. Refer to drawing $\mathrm{H}-14-100987$, sheet 1, for positive lead jumper locations.

Test Director Initial

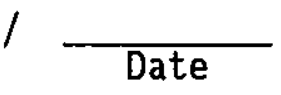

5.1.11.19 APPLY 24 vdc to Terminal TB-DC4-40 in Field Terminal Box AN241WT-TBX-101, using the 24 vdc power supply. 


\subsection{TEST 2-WAY VALVES (Cont.)}

5.1.11.20 MEASURE AND RECORD the voltage BETWEEN Terminal TB-DC1-47 AND the NEGATIVE Terminal on the 24 volt dc power supply.

VOLTAGE

5.1.11.21 VERIFY the voltage recorded in Step 5.1.11.20 at a nominal voltage of 24 Volts dc.

Test Director Initial Date

5.1.11.22 MEASURE AND RECORD the voltage BETWEEN Terminal TB-DC1-46 AND the NEGATIVE Terminal on the 24 volt dc power supply.

VOLTAGE

5.1.11.23 VERIFY the voltage recorded in Step 5.1.11.22 is at a nominal voltage of "O" Volts dc.

Test Director Initial Date

5.1.11.24 POSITION ANA-WT-V-320 CLOSED by rotating the valve handwheel CLOCKWISE until the handwheel turns no farther.

5.1.11.25 VERIFY that ANA-WT-V-320 valve operator position indicator is oriented to BLOCK flow from Connector "L19" to ANA-WT-V-319.

Test Director Initial

/

5.1.11.26 MEASURE AND RECORD the voltage BETWEEN Terminal TB-DC1-47 AND the NEGATIVE Terminal on the 24 volt dc power supply.

VOLTAGE

5.1.11.27 VERIFY the voltage recorded in Step 5.1.11.26 is at a nominal voltage of "O" Volts dc.

Test Director Initial

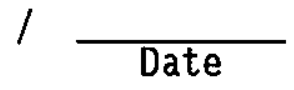




\subsection{TEST 2-WAY VALVES (Cont.)}

5.1.11.28 MEASURE AND RECORD the voltage BETWEEN Terminal TB-DC1-46 AND the NEGATIVE Terminal on the 24 volt dc power supply.

VOLTAGE

5.1.11.29 VERIFY the voltage recorded in Step 5.1.11.28 at a nomina1 voltage of 24 Volts dc.

\section{Test Director Initial}

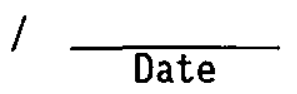

NOTE - The next step prepares limit switch cover for torquing. A11 valves will be torqued at one time at end of this ATP and QC Shall verify. The Torque value will be between 17 and 20 inch Tbs.

5.1.11.30 REPLACE 1imit switch cover AND TIGHTEN bolts in preparation for torque.

5.1.11.31 POSITION valve ANA-WT-V-320 as directed by the Test Director. 5.1.11.32 RECORD the final position for valve ANA-WT-V-320 below.

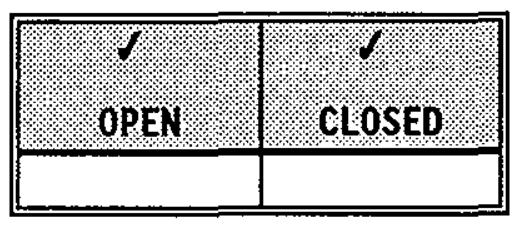

5.1.11.33 VERIFY by signing below that test 5.1 .11 is complete.

Test Director Signature

Date

Operations Signature

Date 


\subsection{TEST 3-WAY VALVES}

5.2.1 TEST 2-inch valve ANA-WT-V-302.

5.2.1.1 RECORD calibrated electrical test equipment data below. ELECTRICAL TEST EQUIPMENT DATA TABLE

\begin{tabular}{||l|l|l|l||}
\hline TOOL NAME & ID. NUMBER & CAL DUE DATE & INITIAL/DATE \\
\hline & & & \\
\hline & & & \\
\hline & & & \\
\hline
\end{tabular}

5.2.1.2 ENSURE that 2-inch valve ANA-WT-V-302 is in Position "A" by rotating the valve handwheel COUNTER-CLOCKWISE until the handwheel turns no farther.

5.2.1.3 VERIFY ANA-WT-V-302 is in Position " $A$ " by the line indicator tee connecting ANA-WT-V-301 and Blank Connection " $A$ ".

Test Director Initial

Date

5.2.1.4 VERIFY the indicator lines are lined up with the correct reference pins, AND within the RED area on the decal.
Test Director Initial
Date

5.2.1.5 VERIFY the indicator lines are oriented to BLOCK flow from ANAWT-V-303.

\section{Test Director Initial}

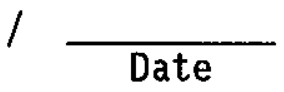

5.2.1.6 PLACE the long-shank padlock through the locking device in the ANA-WT-V-302 handwhee T.

5.2.1.7 VERIFY limited movement of the handwheel does NOT cause valve movement in either direction.
Test Director Initial
Date

5.2.1.8 REMOVE the long-shank padlock that was placed on the handwheel in Step 5.2.1.6. 


\subsection{TEST 3-WAY VALVES (Cont.)}

5.2.1.9 REMOVE the cover from ANA-WT-V-302 valve position sensor assembly.

5.2.1.10 ADJUST the top CAM so pointer on the CAM is centered on the noncontact switch wired for valve position $A$.

5.2.1.11 ENSURE the middle and the bottom CAMs are NOT positioned at their associated non-contact switches.

5.2.1.12 POSITION ANA-WT-V-302, to allow flow from ANA-WT-V-303 to ANAWT-V-301 by rotating the valve handwheel CLOCKWISE until the valve is at mid position.

5.2.1.13 VERIFY that ANA-WT-V-302 valve position indicator is aligned to ALLOW FLOW from ANA-WT-V-303 to ANA-WT-V-301.

Test Director Initial

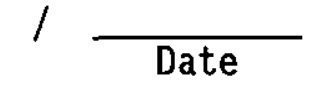

5.2.1.14 VERIFY the indicator line is lined up with the correct reference pins for the "B" or "MID" position, AND black stripe within the RED area on the decal is aligned as to be touching the applicable line on valve housing.

\section{Test Director Initial Date}

5.2.1.15 VERIFY the indicator lines are oriented to BLOCK flow from Blank Connection "A".

Test Director Initial

Date

5.2.1.16 ADJUST the middle CAM so pointer on the CAM is centered on the non-contact switch wired for valve position $B$.

5.2.1.17 ENSURE the top and bottom CAMs are NOT positioned at their associated non-contact switches.

5.2.1.18 PLACE the long-shank padlock through the locking device in the ANA-WT-V-302 handwheel.

5.2.1.19 VERIFY limited movement of the handwheel does NOT cause valve movement in either direction.

Test Director Initial

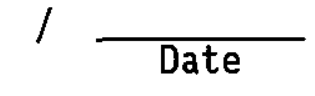




\subsection{TEST 3-WAY VALVES (Cont.)}

5.2.1.20 REMOVE the long-shank padlock that was placed on the handwheel in Step 5.2.1.18.

5.2.1.21 POSITION ANA-WT-V-302, to allow flow from ANA-WT-V-303 to Blank Connection "A" by rotating the valve handwheel CLOCKWISE as far as it will go.

5.2.1.22 VERIFY that ANA-WT-V-302 valve position indicator is aligned to allow flow from ANA-WT-V-303 to Blank Connection "A".

\section{Test Director Initial}

5.2.1.23 ADJUST the lower CAM so pointer on the CAM is centered on the non-contact switch wired for valve position $C$.

5.2.1.24 ENSURE the top and middle CAMs are NOT positioned at their associated non-contact switches.

5.2.1.25 VERIFY the indicator lines are lined up with the correct reference pins, AND within the RED area on the decal black stripe to black stripe alignment.

Test Director Initial

Date

5.2.1.26 PLACE the long-shank padlock through the locking device in the ANA-WT-V-302 handwhee?.

5.2.1.27 VERIFY limited movement of the handwheel does NOT cause valve movement in either direction.

\section{Test Director Initial Date}

5.2.1.28 REMOVE the long-shank padlock that was placed on the handwheel in step 5.2.1.26.

5.2.1.29 VERIFY installation of positive jumpers located on the valve position sensor terminal block. Refer to drawing H-14-100987, sh 1 , for positive lead jumper locations.

Test Director Initial

Date 


\subsection{TEST 3-WAY VALVES (Cont.)}

5.2.1.30 APPLY 24 volts de to Terminals TB-DC4-23 in Field Terminal Box AN241-WT-TBX-101, using the 24 volt dc power supply.

5.2.1.31 MEASURE AND RECORD the voltage BETWEEN Terminal TB-DC1-5 AND the NEGATIVE Terminal on the 24 volt power supply.

VOLTAGE

5.2.1.32 VERIFY the voltage recorded in Step 5.2.1.31 at a nominal voltage of 24 Volts dc.

Test Director Initial

Date

5.2.1.33 MEASURE AND RECORD the voltage BETWEEN Terminal TB-DC1-4 AND the NEGATIVE Terminal on the 24 volt power supply.

VOLTAGE

5.2.1.34 VERIFY the voltage recorded in Step 5.2.1.33 is at a nominal voltage of "0" Volts dc.

Test Director Initial

$$
\text { Date }
$$

5.2.1.35 MEASURE AND RECORD the voltage BETWEEN Terminal TB-DC1-3 AND the NEGATIVE Terminal on the 24 volt power supply.

VOLTAGE

5.2.1.36 VERIFY the voltage recorded in Step 5.2.1.35 is at a nominal voltage of "O" Volts dc.

Test Director Initial Date

NOTE- To ensure proper alignment for mid position of Three-Way Valve, When rotating in counter clockwise rotation, go past the "B" or mid position, then rotate to Mid position from a Clockwise direction.

5.2.1.37 POSITION ANA-WT-V-302, to allow flow from ANA-WT-V-301 to ANAWT-V -303 by rotating the valve handwhee 1 COUNTER-CLOCKWISE until the valve is at the mid position. 


\subsection{TEST 3-WAY VALVES (Cont.)}

5.2.1.38 MEASURE AND RECORD the vol tage BETWEEN Terminal TB-DC1-5 AND the NEGATIVE Terminal on the 24 volt dc power supply.

VOLTAGE

5.2.1.39 VERIFY the voltage recorded in Step 5.2.1.38 is at a nominal voltage of " 0 " Volts dc.

Test Director Initial

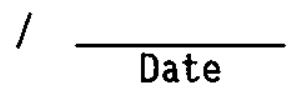

5.2.1.40 MEASURE AND RECORD the voltage BETWEEN Terminal TB-DC1-4 AND the NEGATIVE Terminal on the 24 volt dc power supply.

VOLTAGE

5.2.1.41 VERIFY the voltage recorded in Step 5.2.1.40 at a nominal voltage of 24 Volts dc.

Test Director Initial

Date

5.2.1.42 MEASURE AND RECORD the voltage BETWEEN Terminal TB-DC1-3 AND the NEGATIVE Terminal on the 24 volt dc power supply.

VOLTAGE

5.2.1.43 VERIFY the voltage recorded in Step 5.2.1.42 is at a nominal voltage of " 0 " Volts dc.

Test Director Initial

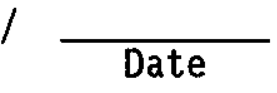

5.2.1.44 POSITION ANA-WT-V-302 to allow flow from ANA-WT-V-301 to Blank Connection " $A$ " by rotating the valve handwheel COUNTER-CLOCKWISE until the handwheel turns no farther.

5.2.1.45 MEASURE AND RECORD the voltage BETWEEN Terminal TB-DC1-5 AND the NEGATIVE Terminal on the 24 volt dc power supply.

VOLTAGE 


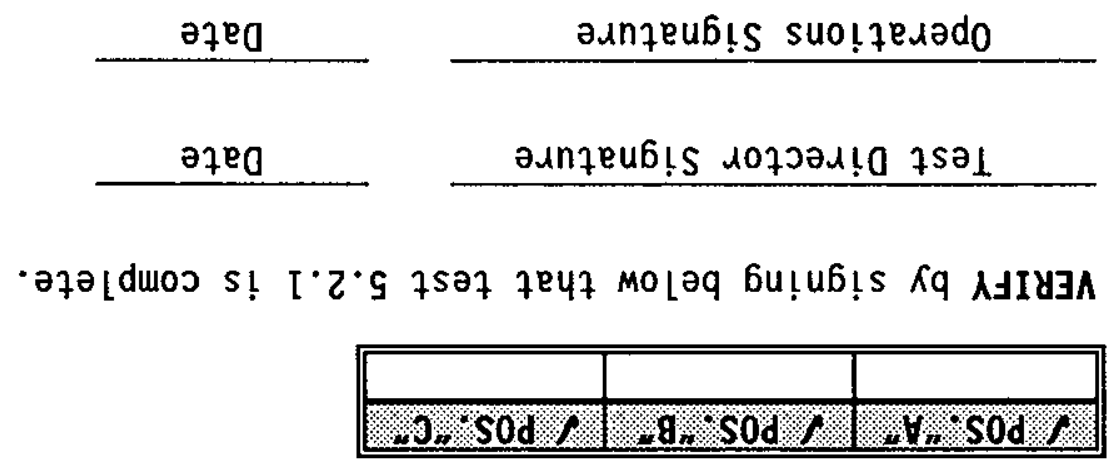

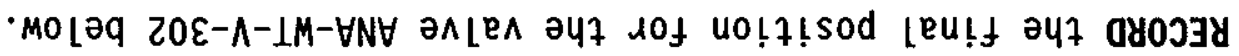

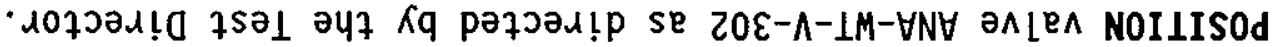
$Z g^{\cdot} \cdot I^{\cdot} \cdot \mathrm{g}$

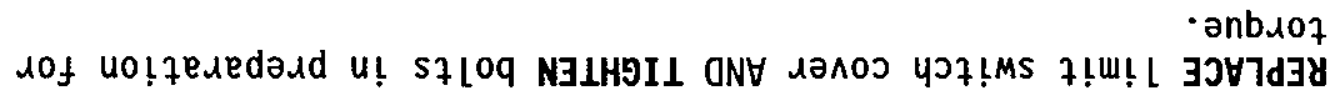
$I S \cdot I \cdot Z \cdot s$

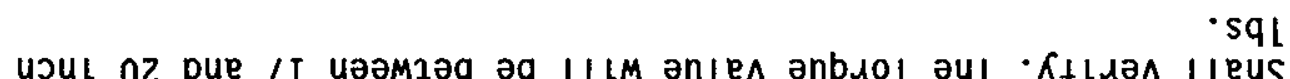

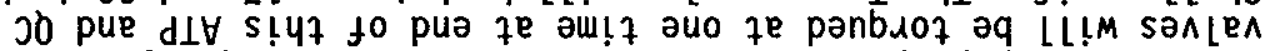

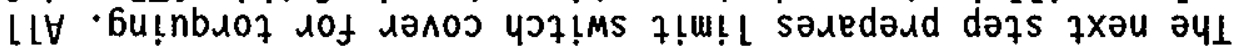

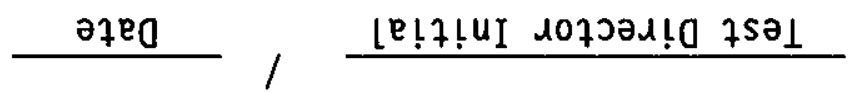

- op sqLon tz to ә6eqLon

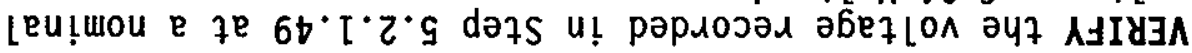

$O G \cdot I \cdot \tau \cdot g$

$39 \forall 170 \wedge$

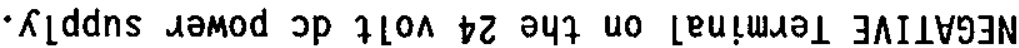

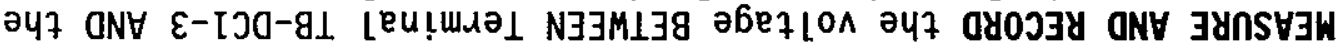

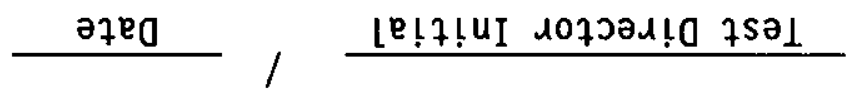

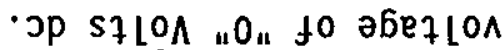

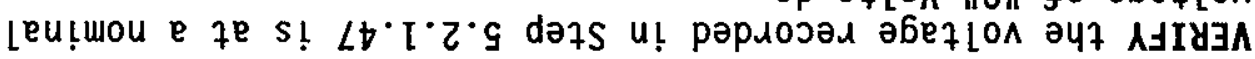

$\exists 9 \forall \perp 70 \wedge$

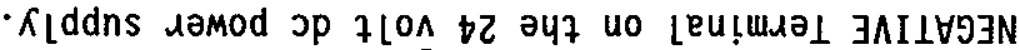

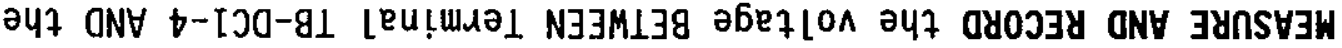

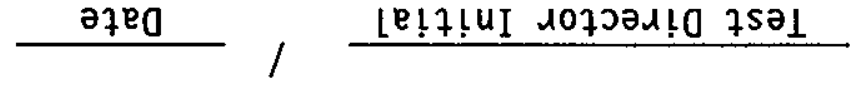

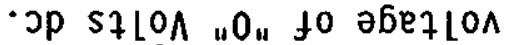

$\angle t^{\cdot} \mathrm{I} \cdot \mathrm{Z} \cdot \mathrm{G}$

$8 t \cdot i \cdot z \cdot s$

$9 t \cdot I \cdot Z \cdot G$

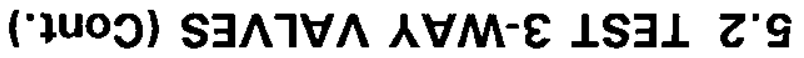




\subsection{TEST 3-WAY VALVES (Cont.)}

5.2.2 TEST 2-inch valve ANA-WT-V-303.

5.2.2.1 RECORD calibrated electrical test equipment data below. ELECTRICAL TEST EQUIPMENT DATA TABLE

\begin{tabular}{|l|l|l|l|}
\hline TOOL NAME & ID. NUMBER & CAL DUE DATE & INITIAL/DATE \\
\hline & & & \\
\hline & & & \\
\hline & & & \\
\hline
\end{tabular}

5.2.2.2 ENSURE that 2-inch valve ANA-WT-V-303 is in Position "A" by rotating the valve handwheel COUNTER-CLOCKWISE until the handwheel turns no farther.

5.2.2.3 VERIFY ANA-WT-V-303 is in Position "A" by the line indicator tee connecting ANA-WT-V-302 and ANA-WT-V-304.

Test Director Initial

Date

5.2.2.4 VERIFY the indicator lines are 1 ined up with the correct reference pins, AND within the RED area on the decal.
Test Director Initial
Date

5.2.2.5 VERIFY the indicator lines are oriented to BLOCK flow from ANAWT-V-305.

\section{Test Director Initial}

Date

5.2.2.6 PLACE the long-shank padlock through the locking device in the ANA-WT-V-303 handwhee1.

5.2.2.7 VERIFY 1imited movement of the handwheel does NOT cause valve movement in either direction.

Test Director Initial

Date

5.2.2.8 REMOVE the long-shank padlock that was placed on the handwheel in Step 5.2.2.6. 


\subsection{TEST 3-WAY VALVES (Cont.)}

5.2.2.9 REMOVE the cover from ANA-WT-V-303 valve position sensor assembly.

5.2.2.10 ADJUST the top CAM so pointer on the CAM is centered on the noncontact switch wired for valve position $A$.

5.2.2.11 ENSURE the middle and the bottom CAMs are NOT positioned at their associated non-contact switches.

5.2.2.12 POSITION ANA-WT-V-303, to allow flow from ANA-WT-V-302 to ANAWT $-V-305$ by rotating the valve handwheel CLOCKWISE until the valve is at mid position.

5.2.2.13 VERIFY that ANA-WT-V-303 valve position indicator is aligned to ALLOW FLOW from ANA-WT-V-302 to ANA-WT-V-305.

Test Director Initial

Date

5.2.2.14 VERIFY the indicator line is lined up with the correct reference pins for the "B" or "MID" position, AND black stripe within the RED area on the decal is aligned as to be touching the applicable line on valve housing.

Test Director Initial Date

5.2.2.15 VERIFY the indicator lines are oriented to BLOCK flow from ANAWT-V-304.

Test Director Initial

Date

5.2.2.16 ADJUST the middle CAM so pointer on the CAM is centered on the non-contact switch wired for valve position $B$.

5.2.2.17 ENSURE the top and bottom CAMs are NOT positioned at their associated non-contact switches.

5.2.2.18 PLACE the long-shank padlock through the locking device in the ANA-WT-V-303 handwhee1.

5.2.2.19 VERIFY limited movement of the handwheel does NOT cause valve movement in either direction.

Test Director Initial

Date 


\subsection{TEST 3-WAY VALVES (Cont.)}

5.2.2.20 REMOVE the long-shank padlock that was $p$ laced on the handwheel in Step 5.2.2.18.

5.2.2.21 POSITION ANA-WT-V-303, to al low flow from ANA-WT-V-305 to ANAWT-V-304 by rotating the valve handwheel CLOCKWISE as far as it will go.

5.2.2.22 VERIFY that ANA-WT-V-303 valve position indicator is aligned to allow flow from ANA-WT-V-305 to ANA-WT-V-304.

Test Director Initial $/$ Date

5.2.2.23 ADJUST the lower CAM so pointer on the CAM is centered on the non-contact switch wired for valve position $C$.

5.2.2.24 ENSURE the top and middle CAMs are NOT positioned at their associated non-contact switches.

5.2.2.25 VERIFY the indicator lines are 7 ined up with the correct reference pins, AND within the RED area on the decal black stripe to black stripe alignment.

Test Director Initial

Date

5.2.2.26 PLACE the long-shank padlock through the locking device in the ANA-WT-V-303 handwhee1.

5.2.2.27 VERIFY limited movement of the handwheel does NOT cause valve movement in either direction.

Test Director Initial $/ \frac{\text { Date }}{}$

5.2.2.28 REMOVE the long-shank padlock that was placed on the handwheel in step 5.2.2.26.

5.2.2.29 VERIFY installation of positive jumpers located on the valve position sensor terminal block. Refer to drawing H-14-100987, sh 1 , for positive lead jumper locations.

Test Director Initial 


\subsection{TEST 3-WAY VALVES (Cont.)}

5.2.2.30 APPLY 24 volts de to Terminal TB-DC4-24 in Field Terminal Box AN241-WT-TBX-101, using the 24 volt dc power supply.

5.2.2.31 MEASURE AND RECORD the voltage BETWEEN Terminal TB-DC1-8 AND the NEGATIVE Terminal on the 24 volt power supply.

VOLTAGE

5.2.2.32 VERIFY the voltage recorded in Step 5.2.2.31 at a nominal voltage of 24 Volts dc.

Test Director Initial
Date

5.2.2.33 MEASURE AND RECORD the voltage BETWEEN Terminal TB-DC1-7 AND the NEGATIVE Terminal on the 24 volt power supply.

VOLTAGE

5.2.2.34 VERIFY the voltage recorded in Step 5.2.2.33 is at a nominal voltage of "O" Volts dc.

Test Director Initial $/$ Date

5.2.2.35 MEASURE AND RECORD the voltage BETWEEN Terminal TB-DC1-6 AND the NEGATIVE Terminal on the 24 volt power supply.

VOLTAGE

5.2.2.36 VERIFY the voltage recorded in Step 5.2.2.35 is at a nominal voltage of " 0 " Volts dc.

\section{Test Director Initial Date}

NOTE- $\quad$ To ensure proper alignment for mid position of Three-Way Valve, When rotating in counter clockwise rotation, go past the "B" or mid position, then rotate to Mid position from a Clockwise direction.

5.2.2.37 POSITION ANA-WT-V-303, to allow flow from ANA-WT-V-302 to ANAWT-V -305 by rotating the valve handwhee the valve is at the mid position. 


\subsection{TEST 3-WAY VALVES (Cont.)}

5.2.2.38 MEASURE AND RECORD the voltage BETWEEN Terminal TB-DCl-8 AND the NEGATIVE Terminal on the 24 volt dc power supply.

VOLTAGE

5.2.2.39 VERIFY the voltage recorded in Step 5.2.2.38 is at a nominal voltage of " 0 " Volts dc.

\section{Test Director Initial}

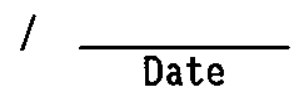

5.2.2.40 MEASURE AND RECORD the voltage BETWEEN Terminal TB-DC1-7 AND the NEGATIVE Terminal on the 24 volt dc power supply.

VOLTAGE

5.2.2.41 VERIFY the voltage recorded in Step 5.2.2.40 at a nominal voltage of 24 Volts dc.
Test Director Initial

$/-\frac{}{\text { Date }}$

5.2.2.42 MEASURE AND RECORD the voltage BETWEEN Terminal TB-DCI-6 AND the NEGATIVE Terminal on the 24 volt dc power supply.

VOLTAGE

5.2.2.43 VERIFY the voltage recorded in Step 5.2.2.42 is at a nominal voltage of " 0 " Volts dc.
Test Director Initial

/

5.2.2.44 POSITION ANA-WT-V-303 to allow flow from ANA-WT-V-302 to ANA-WT$V-304$ by rotating the valve handwheel COUNTER-CLOCKWISE until the handwheel turns no farther.

5.2.2.45 MEASURE AND RECORD the voltage BETWEEN Terminat TB-DC1-8 AND the NEGATIVE Terminal on the 24 volt dc power supply.

VOLTAGE

\begin{tabular}{|c|c|c|c|c|}
\hline "yor & 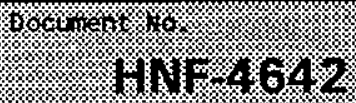 & \% & k & (2) \\
\hline
\end{tabular}




\subsection{TEST 3-WAY VALVES (Cont.)}

5.2.2.46 VERIFY the voltage recorded in Step 5.2.2.45 is at a nominal voltage of "O" Volts dc.

Test Director Initial $\quad$ Date

5.2.2.47 MEASURE AND RECORD the voltage BETWEEN Terminal TB-DC1-7 AND the NEGATIVE Terminal on the 24 volt dc power supply.

VOLTAGE

5.2.2.48 VERIFY the voltage recorded in Step 5.2.2.47 is at a nominal voltage of "O" Volts dc.

Test Director Initial

5.2.2.49 MEASURE AND RECORD the voltage BETWEEN Terminal TB-DC1-6 AND the NEGATIVE Terminal on the 24 volt dc power supply.

VOLTAGE

5.2.2.50 VERIFY the voltage recorded in Step 5.2.2.49 at a nominal voltage of 24 Volts dc.

Test Director Initia] $/ \frac{}{\text { Date }}$

NOTE - The next step prepares limit switch cover for torquing. All valves will be torqued at one time at end of this ATP and QC Shall verify. The Torque value will be between 17 and 20 inch Ibs.

5.2.2.51 REPLACE Timit switch cover AND TIGHTEN bolts in preparation for torque.

5.2.2.52. POSITION valve ANA-WT-V-303 as directed by the Test Director.

5.2.2.53 RECORD the final position for the valve ANA-WT-V-303 below.

\begin{tabular}{|c|c|c|}
\hline FPOS & $1 \%$ POS & $1 \mathrm{POS} \times \mathrm{O}$ \\
\hline
\end{tabular}

5.2.2.54 VERIFY by signing below that test 5.2.2 is complete.

\begin{tabular}{ccc} 
& & Date \\
\hline Operations Signature & & Date
\end{tabular}




\subsection{TEST 3-WAY VALVES (Cont.)}

5.2.3 TEST 2-inch valve ANA-WT-V-305.

5.2.3.1 RECORD calibrated electrical test equipment data below.

ELECTRICAL TEST EQUIPMENT DATA TABLE

\begin{tabular}{|l|l|l|l|}
\hline TOOL NAME & ID. NUMBER & CAL DUE DATE & INITIAL/DATE \\
\hline & & & \\
\hline & & & \\
\hline & & & \\
\hline
\end{tabular}

5.2.3.2 ENSURE that 2 -inch valve ANA-WT-V-305 is in Position " $A$ " by rotating the valve handwhee 1 COUNTER-CLOCKWISE until the handwheel turns no farther.

5.2.3.3 VERIFY ANA-WT-V-305 is in Position " $A$ " by the Tine indicator tee connecting ANA-WT-V-303 and ANA-WT-V-306.

Test Director Initial

5.2.3.4 VERIFY the indicator lines are lined up with the correct reference pins, AND within the RED area on the decal.

Test Director Initial $/$ Date

5.2.3.5 VERIFY the indicator Tines are oriented to BLOCK flow from ANAWT-V -307 .

Test Director Initial $/-\frac{}{\text { Date }}$

5.2.3.6 PLACE the long-shank padlock through the locking device in the ANA-WT-V-305 handwhee1.

5.2.3.7 VERIFY limited movement of the handwheel does NOT cause valve movement in either direction.

\section{Test Director Initial Date}

5.2.3.8 REMOVE the long-shank padlock that was placed on the handwheel in Step 5.2.3.6. 


\subsection{TEST 3-WAY VALVES (Cont.)}

5.2.3.9 REMOVE the cover from ANA-WT-V-305 valve position sensor assembly.

5.2.3.10 ADJUST the top CAM so pointer on the CAM is centered on the noncontact switch wired for valve position $A$.

5.2.3.11 ENSURE the middle and the bottom CAMs are NOT positioned at their associated non-contact switches.

5.2.3.12 POSITION ANA-WT-V-305, to allow flow from ANA-WT-V-303 to ANAWT-V -307 by rotating the valve handwheel CLOCKWISE until the valve is at mid position.

5.2.3.13 VERIFY that ANA-WT-V-305 valve position indicator is aligned to ALLOW FLOW from ANA-WT-V-303 to ANA-WT-V-307.
Test Director Initial
Date

5.2.3.14 VERIFY the indicator line is lined up with the correct reference pins for the "B" or "MID" position, AND black stripe within the RED area on the decal is aligned as to be touching the applicable line on valve housing.
Test Director Initial
Date

5.2.3.15 VERIFY the indicator lines are oriented to BLOCK fTow from ANAWT-V -306 .
Test Director Initial
Date

5.2.3.16 ADJUST the middle CAM so pointer on the CAM is centered on the non-contact switch wired for valve position $B$.

5.2.3.17 ENSURE the top and bottom CAMs are NOT positioned at their associated non-contact switches.

5.2.3.18 PLACE the long-shank padlock through the locking device in the ANA-WT-V-305 handwhee 1 .

5.2.3.19 VERIFY limited movement of the handwheel does NOT cause valve movement in either direction.

Test Director Initial 


\subsection{TEST 3-WAY VALVES (Cont.)}

5.2.3.20 REMOVE the long-shank padlock that was placed on the handwheel in Step 5.2.3.18.

5.2.3.21 POSITION ANA-WT-V-305, to allow flow from ANA-WT-V-307 to ANAWT-V-306 by rotating the valve handwheel CLOCKWISE as far as it wi11 go.

5.2.3.22 VERIFY that ANA-WT-V-305 valve position indicator is aligned to allow flow from ANA-WT-V-307 to ANA-WT-V-306.

Test Director Initial

5.2.3.23 ADJUST the lower CAM so pointer on the CAM is centered on the non-contact switch wired for valve position $C$.

5.2.3.24 ENSURE the top and middle CAMs are NOT positioned at their associated non-contact switches.

5.2.3.25 VERIFY the indicator lines are lined up with the correct reference pins, AND within the RED area on the decal black stripe to black stripe alignment.

Test Director Initial

Date

5.2.3.26 PLACE the long-shank padlock through the locking device in the ANA-WT-V-305 handwhee1.

5.2.3.27 VERIFY limited movement of the handwheel does NOT cause valve movement in either direction.

Test Director Initial
Date

5.2.3.28 REMOVE the long-shank padlock that was placed on the handwheel in step 5.2.3.26.

5.2.3.29 VERIFY installation of positive jumpers located on the valve position sensor terminal block. Refer to drawing H-14-100987, sh 1 , for positive lead jumper locations.

Test Director Initial Date

9om




\subsection{TEST 3-WAY VALVES (Cont.)}

5.2.3.30 APPLY 24 volts dc to Terminal TB-DC4-26 in Field Terminal Box AN241-WT-TBX-101, using the 24 volt dc power supply.

5.2.3.31 MEASURE AND RECORD the voltage BETWEEN Terminat TB-DC1-13 AND the NEGATIVE Terminal on the 24 volt power supply.

VOLTAGE

5.2.3.32 VERIFY the voltage recorded in Step 5.2.3.31 at a nominal voltage of 24 Volts dc.

Test Director Initial

/

5.2.3.33 MEASURE AND RECORD the voltage BETWEEN Terminal TB-DC1-12 AND the NEGATIVE Terminal on the 24 volt power supply.

VOLTAGE

5.2.3.34 VERIFY the voltage recorded in Step 5.2.3.33 is at a nominal voltage of " 0 " Volts dc.

Test Director Initial

/

5.2.3.35 MEASURE AND RECORD the voltage BETWEEN Terminal TB-DC1-11 AND the NEGATIVE Terminal on the 24 volt power supply.

VOLTAGE

5.2.3.36 VERIFY the voltage recorded in Step 5.2.3.35 is at a nominal voltage of "O" Volts dc.

\section{Test Director Initial}

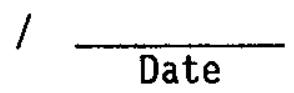

NOTE- $\quad$ To ensure proper alignment for mid position of Three-Way Valve, When rotating in counter clockwise rotation, go past the "B" or mid position, then rotate to Mid position from a Clockwise direction.

5.2.3.37 POSITION ANA-WT-V-305, to allow flow from ANA-WT-V-303 to ANAWT-V -307 by rotating the valve handwhee 7 COUNTER-CLOCKWISE until the valve is at the mid position. 


\subsection{TEST 3-WAY VALVES (Cont.)}

5.2.3.38 MEASURE AND RECORD the voltage BETWEEN Termina] TB-DC1-13 AND the NEGATIVE Terminal on the 24 volt dc power supply.

VOLTAGE

5.2.3.39 VERIFY the voltage recorded in Step 5.2.3.38 is at a nominal voltage of " 0 " Volts $d c$.

Test Director Initial Date

5.2.3.40 MEASURE AND RECORD the voltage BETWEEN Terminal TB-DC1-12 AND the NEGATIVE Terminal on the 24 volt dc power supply.

VOLTAGE

5.2.3.41 VERIFY the voltage recorded in Step 5.2.3.40 at a nominal voltage of 24 Volts dc.

Test Director Initial

/ Date

5.2.3.42 MEASURE AND RECORD the voltage BETWEEN Terminal TB-DC1-11 AND the NEGATIVE Terminal on the 24 volt dc power supply.

VOLTAGE

5.2.3.43 VERIFY the voltage recorded in Step 5.2.3.42 is at a nominal voltage of " 0 " Volts $\mathrm{dc}$.

Test Director Initial

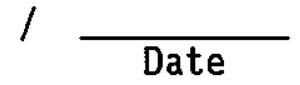

5.2.3.44 POSITION ANA-WT-V-305 to allow flow from ANA-WT-V-303 to ANA-WT$V-306$ by rotating the valve handwheel COUNTER-CLOCKWISE until the handwhee] turns no farther.

5.2.3.45 MEASURE AND RECORD the voltage BETWEEN Terminal TB-DC1-13 AND the NEGATIVE Terminal on the 24 volt dc power supply.

VOLTAGE 


\subsection{TEST 3-WAY VALVES (Cont.)}

5.2.3.46 VERIFY the voltage recorded in Step 5.2.3.45 is at a nominal voltage of " 0 " Volts dc.

Test Director Initial $\quad$ Date

5.2.3.47 MEASURE AND RECORD the voltage BETWEEN Terminal TB-DC1-12 AND the NEGATIVE Terminal on the 24 volt dc power supply.

VOLTAGE

5.2.3.48 VERIFY the voltage recorded in Step 5.2.3.47 is at a nominal voltage of " 0 " Volts dc.

Test Director Initial

Date

5.2.3.49 MEASURE AND RECORD the voltage BETWEEN Terminal TB-DC1-11 AND the NEGATIVE Terminal on the 24 volt dc power supply.

VOLTAGE

5.2.3.50 VERIFY the voltage recorded in Step 5.2.3.49 at a nominal voltage of 24 Volts dc.

Test Director Initial $\quad$ Date

NOTE - The next step prepares limit switch cover for torquing. A1T valves will be torqued at one time at end of this ATP and QC Shall verify. The Torque value will be between 17 and 20 inch Tbs.

5.2.3.51 REPLACE limit switch cover AND TIGHTEN bolts in preparation for torque.

5.2.3.52 POSITION valve ANA-WT-V-305 as directed by the Test Director.

5.2.3.53 RECORD the final position for the valve ANA-WT-V-305 below.

\begin{tabular}{|c|c|c|}
\hline POOS & POS. B" & 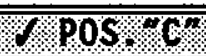 \\
\hline
\end{tabular}

5.2.3.54 VERIFY by signing below that test 5.2 .3 is complete.

Test Director Signature

Operations Signature
Date

Date




\subsection{TEST 3-WAY VALVES (Cont.)}

5.2.4 TEST 2-inch valve ANA-WT-V-307.

5.2.4.1 RECORD calibrated electrical test equipment data below. ELECTRICAL TEST EQUIPMENT DATA TABLE

\begin{tabular}{||l|l|l|l||}
\hline \hline TOOL NAME & ID. NUMBER & CAL DUE DATE & INITIAL/DATE \\
\hline & & & \\
\hline & & & \\
\hline & & & \\
\hline
\end{tabular}

5.2.4.2 ENSURE that 2-inch valve ANA-WT-V-307 is in Position "A" by rotating the valve handwheel COUNTER-CLOCKWISE until the handwheel turns no farther.

5.2.4.3 VERIFY ANA-WT-V-307 is in Position " $A$ " by the 1 ine indicator tee connecting ANA-WT-V-309 and ANA-WT-V-305.

Test Director Initial $/$ Date

5.2.4.4 VERIFY the indicator lines are lined up with the correct reference pins, AND within the RED area on the decal.

Test Director Initial $/$ Date

5.2.4.5 VERIFY the indicator lines are oriented to BLOCK flow from ANAWT-V-308.

Test Director Initial

5.2.4.6 PLACE the long-shank padlock through the locking device in the ANA-WT-V-307 handwhee?.

5.2.4.7 VERIFY limited movement of the handwheel does NOT cause valve movement in either direction.

Test Director Initial

Date

5.2.4.8 REMOVE the long-shank padlock that was placed on the handwheel in Step 5.2.4.6. 


\subsection{TEST 3-WAY VALVES (Cont.)}

5.2.4.9 REMOVE the cover from ANA-WT-V-307 valve position sensor assembly.

5.2.4.10 ADJUST the top CAM so pointer on the CAM is centered on the noncontact switch wired for valve position $A$.

5.2.4.11 ENSURE the middle and the bottom CAMs are NOT positioned at their associated non-contact switches.

5.2.4.12 POSITION ANA-WT-V-307, to allow flow from ANA-WT-V-308 to ANAWT-V-309 by rotating the valve handwheel CLOCKWISE until the valve is at mid position.

5.2.4.13 VERIFY that ANA-WT-V-307 valve position indicator is aligned to ALLOW FLOW from ANA-WT-V-308 to ANA-WT-V-309.

Test Director Initial

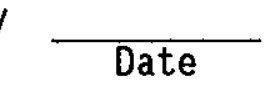

5.2.4.14 VERIFY the indicator line is lined up with the correct reference pins for the "B" or "MID" position, AND black stripe within the RED area on the decal is aligned as to be touching the applicable line on valve housing.

Test Director Initial Date

5.2.4.15 VERIFY the indicator lines are oriented to BLOCK flow from ANAWT $-V-305$.

Test Director Initial Date

5.2.4.16 ADJUST the middle CAM so pointer on the CAM is centered on the non-contact switch wired for valve position $B$.

5.2.4.17 ENSURE the top and bottom CAMs are NOT positioned at their associated non-contact switches.

5.2.4.18 PLACE the long-shank padlock through the locking device in the ANA-WT-V-307 handwhee1.

5.2.4.19 VERIFY limited movement of the handwheel does NOT cause valve movement in either direction.

Test Director Initial

Date 


\subsection{TEST 3-WAY VALVES (Cont.)}

5.2.4.20 REMOVE the long-shank padlock that was placed on the handwheel in Step 5.2.4.18.

5.2.4.21 POSITION ANA-WT-V-307, to allow flow from ANA-WT-V-308 to ANAWT-V -305 by rotating the valve handwheel CLOCKWISE as far as it will go.

5.2.4.22 VERIFY that ANA-WT-V-307 valve position indicator is aligned to allow flow from ANA-WT-V-308 to ANA-WT-V-305.

Test Director Initial $/ \frac{}{\text { Date }}$

5.2.4.23 ADJUST the lower CAM so pointer on the CAM is centered on the non-contact switch wired for valve position $C$.

5.2.4.24 ENSURE the top and middle CAMs are NOT positioned at their associated non-contact switches.

5.2.4.25 VERIFY the indicator lines are lined up with the correct reference pins, AND within the RED area on the decal black stripe to black stripe alignment.

Test Director Initial

5.2.4.26 PLACE the long-shank padlock through the locking device in the ANA-WT-V-307 handwhee1.

5.2.4.27 VERIFY limited movement of the handwheel does NOT cause valve movement in either direction.

Test Director Initial $/$ Date

5.2.4.28 REMOVE the Tong-shank padlock that was placed on the handwheel in step 5.2.4.26.

5.2.4.29 VERIFY installation of positive jumpers located on the valve position sensor terminal block. Refer to drawing H-14-100987, sh 1 , for positive lead jumper locations.

Test Director Initial Date 


\subsection{TEST 3-WAY VALVES (Cont.)}

5.2.4.30 APPLY 24 volts dc to Terminal TB-DC4-28 in Field Terminal Box AN241-WT-TBX-101, using the 24 volt dc power supply.

5.2.4.31 MEASURE AND RECORD the voltage BETWEEN Terminal TB-DC1-18 AND the NEGATIVE Terminal on the 24 volt power supply.

VOLTAGE

5.2.4.32 VERIFY the voltage recorded in Step 5.2.4.31 at a nominal voltage of 24 Volts dc.

Test Director Initial

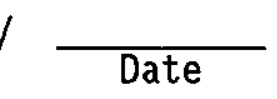

5.2.4.33 MEASURE AND RECORD the voltage BETWEEN Terminal TB-DC1-17 AND the NEGATIVE Terminal on the 24 volt power supply.

VOLTAGE

5.2.4.34 VERIFY the voltage recorded in Step 5.2.4.33 is at a nominal voltage of "O" Volts dc.

Test Director Initial Date

5.2.4.35 MEASURE AND RECORD the voltage BETWEEN Terminal TB-DC1-16 AND the NEGATIVE Terminal on the 24 volt power supply.

VOLTAGE

5.2.4.36 VERIFY the voltage recorded in Step 5.2.4.35 is at a nominal voltage of "O" Volts dc.

\section{Test Director Initial}

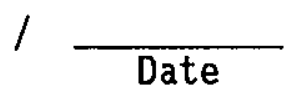

NOTE- To ensure proper alignment for mid position of Three-Way Valve, When rotating in counter clockwise rotation, go past the "B" or mid position, then rotate to Mid position from a Clockwise direction.

5.2.4.37 POSITION ANA-WT-V-307, to allow flow from ANA-WT-V-309 to ANAWT-V-308 by rotating the valve handwhee 1 COUNTER-CLOCKWISE unt il the valve is at the mid position. 


\subsection{TEST 3-WAY VALVES (Cont.)}

5.2.4.38 MEASURE AND RECORD the voltage BETWEEN Terminal TB-DC1-18 AND the NEGATIVE Terminal on the 24 volt dc power supply.

VOLTAGE

5.2.4.39 VERIFY the voltage recorded in Step 5.2.4.38 is at a nominal voltage of " 0 " Volts dc.

Test Director Initial

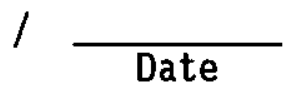

5.2.4.40 MEASURE AND RECORD the voltage BETWEEN Terminat TB-DC1-17 AND the NEGATIVE Terminal on the 24 volt dc power supply.

VOLTAGE

5.2.4.41 VERIFY the voltage recorded in Step 5.2.4.40 at a nominal voltage of 24 Volts dc.

Test Director Initial

Date

5.2.4.42 MEASURE AND RECORD the voltage BETWEEN Terminal TB-DC1-16 AND the NEGATIVE Terminal on the 24 volt dc power supply.

VOLTAGE

5.2.4.43 VERIFY the voltage recorded in Step 5.2.4.42 is at a nominal voltage of " 0 " Volts dc.

Test Director Initial

Date

5.2.4.44 POSITION ANA-WT-V-307 to allow flow from ANA-WT-V-309 to ANA-WT$V-305$ by rotating the valve handwheel COUNTER-CLOCKWISE until the handwheel turns no farther.

5.2.4.45 MEASURE AND RECORD the voltage BETWEEN Terminat TB-DC1-18 AND the NEGATIVE Terminal on the 24 volt dc power supply.

VOLTAGE 


\subsection{TEST 3-WAY VALVES (Cont.)}

5.2.4.46 VERIFY the voltage recorded in Step 5.2.4.45 is at a nominal voltage of " 0 " Volts dc.

Test Director Initial

5.2.4.47 MEASURE AND RECORD the voltage BETWEEN Terminal TB-DC1-17 AND the NEGATIVE Terminal on the 24 volt dc power supply.

VOLTAGE

5.2.4.48 VERIFY the voltage recorded in Step 5.2.4.47 is at a nominal voltage of " 0 " Volts dc.

Test Director Initial $\quad /$ Date

5.2.4.49 MEASURE AND RECORD the voltage BETWEEN Terminal TB-DC1-16 AND the NEGATIVE Terminal on the 24 volt dc power supply.

VOLTAGE

5.2.4.50 VERIFY the voltage recorded in Step 5.2.4.49 at a nominal voltage of 24 Volts dc.

\section{Test Director Initial}

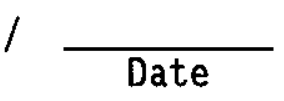

NOTE - The next step prepares limit switch cover for torquing. All valves will be torqued at one time at end of this ATP and QC Shall verify. The Torque value will be between 17 and 20 inch 1bs.

5.2.4.51 REPLACE limit switch cover AND TIGHTEN bolts in preparation for torque.

5.2.4.52 POSITION valve ANA-WT-V-307 as directed by the Test Director.

5.2.4.53 RECORD the final position for the valve ANA-WT-V-307 below.

\begin{tabular}{|c|c|c|}
\hline$\checkmark P O S$ A & $\%$ POS & POS $/ \mathrm{CH}$ \\
\hline
\end{tabular}

5.2.4.54 VERIFY by signing below that test 5.2 .4 is complete.

\begin{tabular}{l}
\hline Test Director Signature \\
\hline Operations Signature
\end{tabular}

$\frac{\text { Date }}{\text { Date }}$




\subsection{TEST 3-WAY VALVES (Cont.)}

5.2.5 TEST 3-inch valve ANA-WT-V-314.

5.2.5.1 RECORD calibrated electrical test equipment data below.

ELECTRICAL TEST EQUIPMENT DATA TABLE

\begin{tabular}{||c|c|c|c||}
\hline \hline TOOL NAME & ID. NUMBER & CAL DUE DATE & INITIAL/DATE \\
\hline & & & \\
\hline & & & \\
\hline & & & \\
\hline
\end{tabular}

5.2.5.2 ENSURE that 2-inch valve ANA-WT-V-314 is in Position " $A$ " by rotating the valve handwheel COUNTER-CLOCKWISE until the handwheel turns no farther.

5.2.5.3 VERIFY ANA-WT-V-314 is in Position " $A$ " by the line indicator tee connecting ANA-WT-V-313 and ANA-WT-V-315.

Test Director Initial $/$ Date

5.2.5.4 VERIFY the indicator lines are lined up with the correct

reference pins, AND within the RED area on the decal.

Test Director Initial

5.2.5.5 VERIFY the indicator lines are oriented to BLOCK flow from ANAWT-V-316.

Test Director Initial Date

5.2.5.6 PLACE the long-shank padlock through the locking device in the ANA-WT-V-314 handwheel.

5.2.5.7 VERIFY limited movement of the handwheel does NOT cause valve movement in either direction.

Test Director Initial

Date

5.2.5.8 REMOVE the long-shank padlock that was placed on the handwhee 1 in Step 5.2.5.6. 


\section{әqе $/ \frac{\text { Le!q!UI } 1070 \partial \lambda ! 075 \partial \perp}{}$}

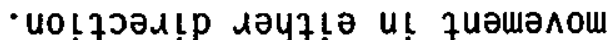

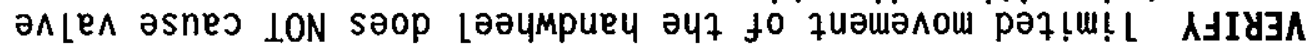

- Lәумрuеy $\multimap[\varepsilon-\Lambda-1 M-\forall N \forall$

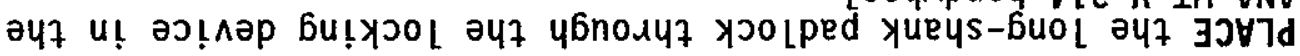

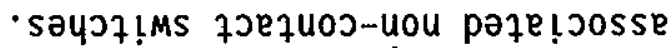

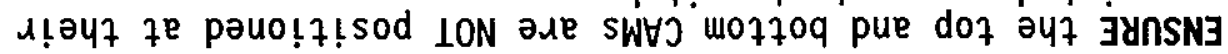

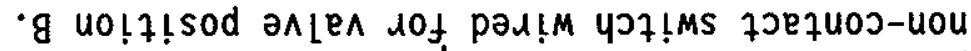

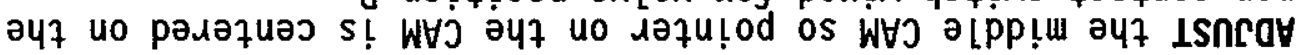

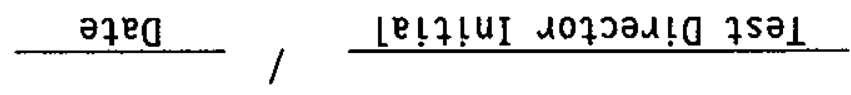

- $q I \varepsilon-\Lambda-1 M$

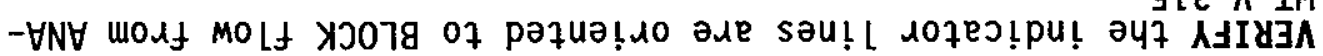

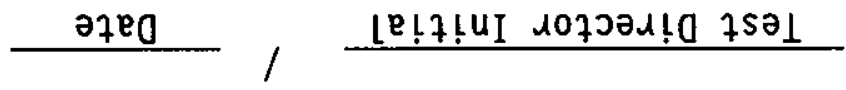

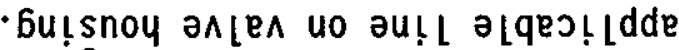

әч7 6u!yonoz әq of se paú! Le s! leכap ә47 uo ease ojy

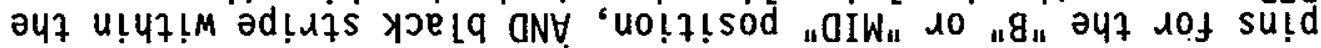

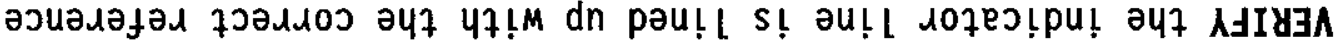

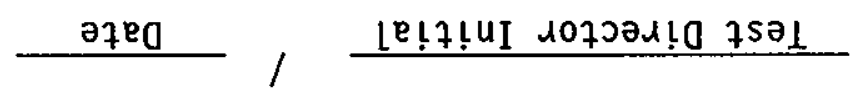

- $9[\varepsilon-\Lambda-\perp M-\forall N \forall$ of $\varepsilon[\varepsilon-\Lambda-1 M-\forall N \forall$ modf M07J MOT7甘

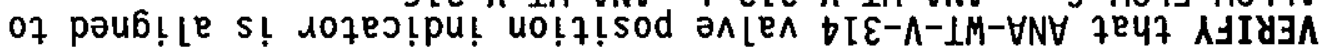

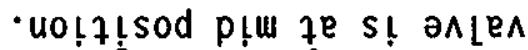

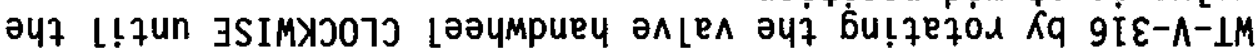
$-\forall N \forall$ of $\varepsilon I \varepsilon-\Lambda-I M-\forall N \forall$ WOAf MOLf MOLLE of ' $\Rightarrow[\varepsilon-\Lambda-I M-\forall N \forall$ NOILISOd

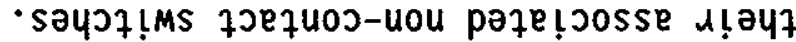

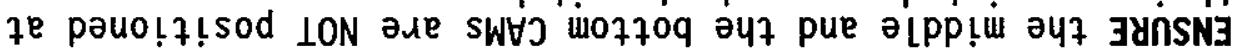

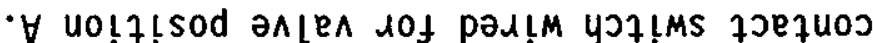

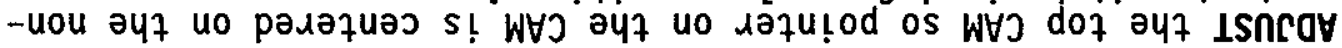
- Klquasse

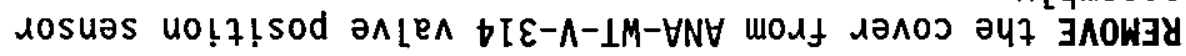

$6 I \cdot g \cdot z \cdot g$

$8[\cdot q \cdot i$

$L I \cdot g \cdot z \cdot g$

$9 I \cdot g \cdot z \cdot g$

$g[\cdot g \cdot q \cdot G$

$\rightarrow I \cdot G \cdot 2 \cdot G$

$\varepsilon[\cdot \mathcal{G} \cdot \tau \cdot \mathfrak{g}$

$2 I \cdot g \cdot 2 \cdot s$

$I[\cdot G \cdot z \cdot G$

$O I \cdot g \cdot Z \cdot g$

$6^{\prime} \cdot c^{\prime} \cdot \mathrm{s}$

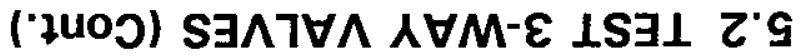




\subsection{TEST 3-WAY VALVES (Cont.)}

5.2.5.20 REMOVE the long-shank padlock that was placed on the handwheel in Step 5.2.5.18.

5.2.5.21 POSITION ANA-WT-V-314, to allow flow from ANA-WT-V-316 to ANAWT-V -315 by rotating the valve handwheel CLOCKWISE as far as it will go.

5.2.5.22 VERIFY that ANA-WT-V-314 valve position indicator is aligned to allow flow from ANA-WT-V-316 to ANA-WT-V-315.

Test Director Initial $/$ Date

5.2.5.23 ADJUST the lower CAM so pointer on the CAM is centered on the non-contact switch wired for valve position $C$.

5.2.5.24 ENSURE the top and middle CAMs are NOT positioned at their associated non-contact switches.

5.2.5.25 VERIFY the indicator lines are lined up with the correct reference pins, AND within the RED area on the decal black stripe to black stripe alignment.

Test Director Initial

5.2.5.26 PLACE the long-shank padlock through the locking device in the ANA-WT-V-314 handwheel.

5.2.5.27 VERIFY limited movement of the handwheel does NOT cause valve movement in either direction.

Test Director Initial Date

5.2.5.28 REMOVE the long-shank padlock that was placed on the handwheel in step 5.2.5.26.

5.2.5.29 VERIFY installation of positive jumpers located on the valve position sensor terminal block. Refer to drawing H-14-100987, sh 1 , for positive lead jumper locations.

Test Director Initial

Date

Tom




\subsection{TEST 3-WAY VALVES (Cont.)}

5.2.5.30 APPLY 24 volts dc to Terminal TB-DC4-34 in Field Terminal Box AN241-WT-TBX-101, using the 24 volt dc power supply.

5.2.5.31 MEASURE AND RECORD the voltage BETWEEN Terminal TB-DC1-32 AND the NEGATIVE Terminal on the 24 volt power supply.

VOLTAGE

5.2.5.32 VERIFY the voltage recorded in Step 5.2.5.31 at a nominal voltage of 24 Volts dc.

Test Director Initial

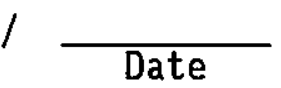

5.2.5.33 MEASURE AND RECORD the voltage BETWEEN Terminal TB-DC1-31 AND the NEGATIVE Terminal on the 24 volt power supply.

VOLTAGE

5.2.5.34 VERIFY the voltage recorded in Step 5.2.5.33 is at a nominal voltage of "O" Volts dc.

Test Director Initial Date

5.2.5.35 MEASURE AND RECORD the voltage BETWEEN Terminal TB-DC1-30 AND the NEGATIVE Terminal on the 24 volt power supply.

VOLTAGE

5.2.5.36 VERIFY the voltage recorded in Step 5.2.5.35 is at a nominal voltage of "O" Volts dc.

\section{Test Director Initial Date}

NOTE- To ensure proper alignment for mid position of Three-Way Valve, When rotating in counter clockwise rotation, go past the "B" or mid position, then rotate to Mid position from a Clockwise direction.

5.2.5.37 POSITION ANA-WT-V-314, to allow flow from ANA-WT-V-313 to ANAWT-V -316 by rotating the valve handwheel COUNTER-CLOCKWISE unt il the valve is at the mid position. 


\subsection{TEST 3-WAY VALVES (Cont.)}

5.2.5.38 MEASURE AND RECORD the voltage BETWEEN Terminal TB-DC1-32 AND the NEGATIVE Terminal on the 24 volt dc power supply.

VOLTAGE

5.2.5.39 VERIFY the voltage recorded in Step 5.2.5.38 is at a nominal voltage of " 0 " Volts dc.

Test Director Initial

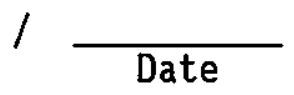

5.2.5.40 MEASURE AND RECORD the voltage BETWEEN Terminal TB-DC1-31 AND the NEGATIVE Terminal on the 24 volt dc power supply.

VOLTAGE

5.2.5.41 VERIFY the voltage recorded in Step 5.2.5.40 at a nominal voltage of 24 Volts dc.

Test Director Initial

5.2.5.42 MEASURE AND RECORD the voltage BETWEEN Terminal TB-DC1-30 AND the NEGATIVE Terminal on the 24 volt dc power supply.

VOLTAGE

5.2.5.43 VERIFY the voltage recorded in Step 5.2.5.42 is at a nominal voltage of "O" Volts dc.

Test Director Initial

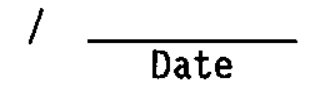

5.2.5.44 POSITION ANA-WT-V-314 to allow flow from ANA-WT-V-313 to ANA-WT$V-315$ by rotating the valve handwheel COUNTER-CLOCKWISE unt il the handwheel turns no farther.

5.2.5.45 MEASURE AND RECORD the voltage BETWEEN Terminal TB-DC1-32 AND the NEGATIVE Terminal on the 24 volt dc power supply.

VOLTAGE 


\subsection{TEST 3-WAY VALVES (Cont.)}

5.2.5.46 VERIFY the voltage recorded in Step 5.2.5.45 is at a nominal voltage of " 0 " Volts dc.

Test Director Initial

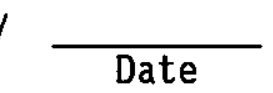

5.2.5.47 MEASURE AND RECORD the voltage BETWEEN Terminal TB-DC1-31 AND the NEGATIVE Terminal on the 24 volt dc power supply.

VOLTAGE

5.2.5.48 VERIFY the voltage recorded in Step 5.2.5.47 is at a nominal voltage of " 0 " Volts dc.

Test Director Initial

5.2.5.49 MEASURE AND RECORD the voltage BETWEEN Terminal TB-DCl-30 AND the NEGATIVE Terminal on the 24 volt dc power supply.

VOLTAGE

5.2.5.50 VERIFY the voltage recorded in Step 5.2.5.49 at a nominal voltage of 24 Volts dc.

\section{Test Director Initial}

/ 


\subsection{TEST 3-WAY VALVES (Cont.)}

5.2.6 TEST 3 -inch valve ANA-WT-V-316.

5.2.6.1 RECORD calibrated electrical test equipment data below.

ELECTRICAL TEST EQUIPMENT DATA TABLE

\begin{tabular}{||l|l|l|l||}
\hline \hline TOOL NAME & ID. NUMBER & CAL DUE DATE & INITIAL/DATE \\
\hline & & & \\
\hline & & & \\
\hline & & & \\
\hline
\end{tabular}

5.2.6.2 ENSURE that 2-inch valve ANA-WT-V-316 is in Position " $A$ " by rotating the valve handwheel COUNTER-CLOCKWISE until the handwheel turns no farther.

5.2.6.3 VERIFY ANA-WT-V-316 is in Position " $A$ " by the line indicator tee connecting ANA-WT-V-318 and ANA-WT-V-314.

Test Director Initial $/$ Date

5.2.6.4 VERIFY the indicator lines are lined up with the correct

reference pins, AND within the RED area on the decal.

Test Director Initial $/$ Date

5.2.6.5 VERIFY the indicator lines are oriented to BLOCK flow from ANAWT-V -317 .

Test Director Initial $/$ Date

5.2.6.6 PLACE the long-shank padlock through the locking device in the ANA-WT-V-316 handwheel.

5.2.6.7 VERIFY limited movement of the handwhee] does NOT cause valve movement in either direction.
Test Director Initial
Date

5.2.6.8 REMOVE the long-shank padlock that was placed on the handwheel in Step 5.2.6.6. 


\subsection{TEST 3-WAY VALVES (Cont.)}

5.2.6.9 REMOVE the cover from ANA-WT-V-316 valve position sensor as sembly.

5.2.6.10 ADJUST the top CAM so pointer on the CAM is centered on the noncontact switch wired for valve position $A$.

5.2.6.11 ENSURE the middle and the bottom CAMs are NOT positioned at their associated non-contact switches.

5.2.6.12 POSITION ANA-WT-V-316, to allow flow from ANA-WT-V-318 to ANAWT-V -317 by rotating the valve handwheel CLOCKWISE until the valve is at mid position.

5.2.6.13 VERIFY that ANA-WT-V-3I6 valve position indicator is aligned to ALLOW FLOW from ANA-WT-V-318 to ANA-WT-V-317.

Test Director Initial

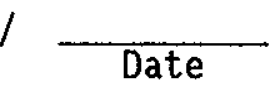

5.2.6.14 VERIFY the indicator line is lined up with the correct reference pins for the "B" or "MID" position, AND black stripe within the RED area on the decal is aligned as to be touching the applicable line on valve housing.

Test Director Initial Date

5.2.6.15 VERIFY the indicator lines are oriented to BLOCK flow from ANAWT-V-314.

Test Director Initial Date

5.2.6.16 ADJUST the middle CAM so pointer on the CAM is centered on the non-contact switch wired for valve position $B$.

5.2.6.17 ENSURE the top and bottom CAMs are NOT positioned at their associated non-contact switches.

5.2.6.18 PLACE the long-shank padlock through the locking device in the ANA-WT-V-316 handwheel.

5.2.6.19 VERIFY limited movement of the handwheel does NOT cause valve movement in either direction.

Test Director Initial

Date 


\subsection{TEST 3-WAY VALVES (Cont.)}

5.2.6.20 REMOVE the long-shank padlock that was placed on the handwheel in Step 5.2.6.18.

5.2.6.21 POSITION ANA-WT-V-316, to allow flow from ANA-WT-V-317 to ANAWT-V-314 by rotating the valve handwheel CLOCKWISE as far as it will go.

5.2.6.22 VERIFY that ANA-WT-V-316 valve position indicator is aligned to allow flow from ANA-WT-V-317 to ANA-WT-V-314.

Test Director Initial

Date

5.2.6.23 ADJUST the lower CAM so pointer on the CAM is centered on the non-contact switch wired for valve position $C$.

5.2.6.24 ENSURE the top and middle CAMs are NOT positioned at their associated non-contact switches.

5.2.6.25 VERIFY the indicator Tines are lined up with the correct reference pins, AND within the RED area on the decal black stripe to black stripe alignment.

Test Director Initial $/$ Date

5.2.6.26 PLACE the long-shank padlock through the locking device in the ANA-WT-V-316 handwhee 1.

5.2.6.27 VERIFY limited movement of the handwheel does NOT cause valve movement in either direction.

Test Director Initial

Date

5.2.6.28 REMOVE the long-shank padlock that was placed on the handwheel in step 5.2.6.26.

5.2.6.29 VERIFY installation of positive jumpers located on the valve position sensor terminal block. Refer to drawing H-14-100987, sh 1 , for positive lead jumper locations.

\footnotetext{
Test Director Initial Date
} 


\subsection{TEST 3-WAY VALVES (Cont.)}

5.2.6.30 APPLY 24 volts de to Terminal TB-DC4-36 in Field Terminal Box AN241-WT-TBX-101, using the 24 volt dc power supply.

5.2.6.31 MEASURE AND RECORD the voltage BETWEEN Terminal TB-DC1-37 AND the NEGATIVE Terminal on the 24 volt power supply.

VOLTAGE

5.2.6.32 VERIFY the voltage recorded in Step 5.2.6.31 at a nominal voltage of 24 Volts dc.

Test Director Initial

Date

5.2.6.33 MEASURE AND RECORD the voltage BETWEEN Terminal TB-DC1-36 AND the NEGATIVE Terminal on the 24 volt power supply.

VOLTAGE

5.2.6.34 VERIFY the voltage recorded in Step 5.2.6.33 is at a nominal voltage of " 0 " Volts dc.
Test Director Initial
Date

5.2.6.35 MEASURE AND RECORD the voltage BETWEEN Terminal TB-DC1-35 AND the NEGATIVE Terminal on the 24 volt power supply.

VOLTAGE

5.2.6.36 VERIFY the voltage recorded in Step 5.2.6.35 is at a nominal voltage of " 0 " Volts dc.

\section{Test. Director Initial}

NOTE- $\quad$ To ensure proper alignment for mid position of Three-Way Valve, When rotating in counter clockwise rotation, go past the " $B$ " or mid position, then rotate to Mid position from a Clockwise direction.

5.2.6.37 POSITION ANA-WT-V-316, to allow flow from ANA-WT-V-318 to ANAWT-V-317 by rotating the valve handwhee the valve is at the mid position. 


\subsection{TEST 3-WAY VALVES (Cont.)}

5.2.6.38 MEASURE AND RECORD the voltage BETWEEN Terminat TB-DC1-37 AND the NEGATIVE Terminal on the 24 volt dc power supply.

VOLTAGE

5.2.6.39 VERIFY the voltage recorded in Step 5.2.6.38 is at a nominal voltage of " 0 " Volts dc.

Test Director Initial

5.2.6.40 MEASURE AND RECORD the voltage BETWEEN Terminat TB-DC1-36 AND the NEGATIVE Terminal on the 24 volt dc power supply.

VOLTAGE

5.2.6.41 VERIFY the voltage recorded in Step 5.2.6.40 at a nominal voltage of 24 Volts dc.
Test Director Initial

/

5.2.6.42 MEASURE AND RECORD the voltage BETWEEN Terminal TB-DC1-35 AND the NEGATIVE Terminal on the 24 volt dc power supply.

VOLTAGE

5.2.6.43 VERIFY the voltage recorded in Step 5.2.6.42 is at a nominal voltage of " 0 " Volts $d c$.

\section{Test Director Initial Date}

5.2.6.44 POSITION ANA-WT-V-316 to allow flow from ANA-WT-V-318 to ANA-WT$V-314$ by rotating the valve handwheel COUNTER-CLOCKWISE until the handwheel turns no farther.

5.2.6.45 MEASURE AND RECORD the voltage BETWEEN Terminal TB-DC1-37 AND the NEGATIVE Terminal on the 24 volt dc power supply.

VOLTAGE

\begin{tabular}{|c|c|c|c|c|}
\hline 4\% & 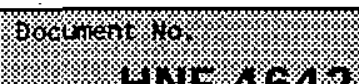 & (3) & S & 4. \\
\hline
\end{tabular}




\subsection{TEST 3-WAY VALVES (Cont.)}

5.2.6.46 VERIFY the voltage recorded in Step 5.2.6.45 is at a nominal voltage of " 0 " Volts dc.

Test Director Initial $/$ Date

5.2.6.47 MEASURE AND RECORD the voltage BETWEEN Terminal TB-DC1-36 AND the NEGATIVE Terminal on the 24 volt dc power supply.

VOLTAGE

5.2.6.48 VERIFY the voltage recorded in Step 5.2.6.47 is at a nominal voltage of " 0 " volts dc.
Test Director Initial
Date

5.2.6.49 MEASURE AND RECORD the voltage BETWEEN Terminal TB-DC1-35 AND the NEGATIVE Terminal on the 24 volt dc power supply.

VOLTAGE

5.2.6.50 VERIFY the voltage recorded in Step 5.2.6.49 at a nominal voltage of 24 Volts dc.
Test Director Initial
Date

NOTE - The next step prepares limit switch cover for torquing. All valves will be torqued at one time at end of this ATP and QC Shall verify. The Torque value will be between 17 and 20 inch Tbs.

5.2.6.51 REPLACE limit switch cover AND TIGHTEN bolts in preparation for torque.

5.2.6.52 POSITION valve ANA-WT-V-316 as directed by the Test Director.

5.2.6.53 RECORD the final position for the valve ANA-WT-V-316 below.

\begin{tabular}{|c|c|c|}
\hline $1 \mathrm{POS}-\mathrm{A}$ & PPOS."B" & POS. C \\
\hline
\end{tabular}

5.2.6.54 VERIFY by signing below that test 5.2.6 is complete.

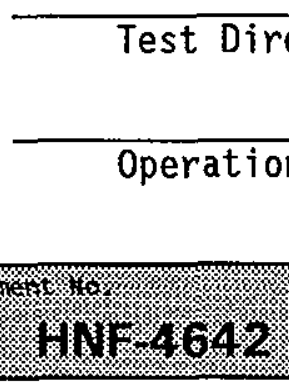

$\frac{\text { Date }}{\text { Date }}$

\begin{tabular}{|c|c|c|c|c|}
\hline 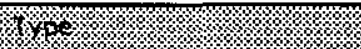 & 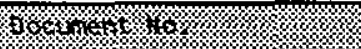 & $48 \% 1 \%$ & 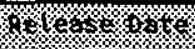 & (2) \\
\hline OSOI IIISULO & 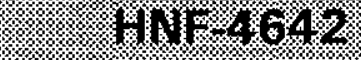 & 6 & & 8 (b) 8$\}$ \\
\hline
\end{tabular}




\subsection{TEST 3-WAY VALVES (Cont.)}

5.2.7 TEST 3 -inch valve ANA-WT-V-318.

5.2.7.1 RECORD calibrated electrical test equipment data below.

ELECTRICAL TEST EQUIPMENT DATA TABLE

\begin{tabular}{||l|l|l|l||}
\hline TOOL NAME & ID. NUMBER & CAL DUE DATE & INITIAL/DATE \\
\hline & & & \\
\hline & & & \\
\hline & & & \\
\hline
\end{tabular}

5.2.7.2 ENSURE that 2-inch valve ANA-WT-V-318 is in Position "A" by rotating the valve handwheel COUNTER-CLOCKWISE until the handwhee 1 turns no farther.

5.2.7.3 VERIFY ANA-WT-V-318 is in Position " $A$ " by the line indicator tee connecting ANA-WT-V-319 and BT ank Connection "F".

Test Director Initial

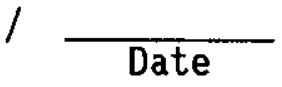

5.2.7.4 VERIFY the indicator lines are lined up with the correct reference pins, AND within the RED area on the decal.

Test Director Initial

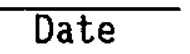

5.2.7.5 VERIFY the indicator lines are oriented to BLOCK flow from ANAWT-V-316.

Test Director Initial

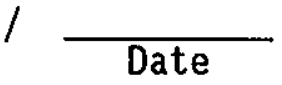

5.2.7.6 PLACE the long-shank padlock through the locking device in the ANA-WT-V-318 handwhee1.

5.2.7.7 VERIFY limited movement of the handwheel does NOT cause valve movement in either direction.

Test Director Initial

5.2.7.8 REMOVE the long-shank padlock that was placed on the handwhee] in Step 5.2.7.6. 


\subsection{TEST 3-WAY VALVES (Cont.)}

5.2.7.9 REMOVE the cover from ANA-WT-V-318 valve position sensor assembly.

5.2.7.10 ADJUST the top CAM so pointer on the CAM is centered on the noncontact switch wired for valve position $A$.

5.2.7.11 ENSURE the middle and the bottom CAMs are NOT positioned at their associated non-contact switches.

5.2.7.12 POSITION ANA-WT-V-318, to allow flow from ANA-WT-V-319 to ANAWT-V-316 by rotating the valve handwhee CLOCKWISE until the valve is at mid position.

5.2.7.13 VERIFY that ANA-WT-V-318 valve position indicator is aligned to ALLOW FLOW from ANA-WT-V-319 to ANA-WT-V-316.

Test Director Initial

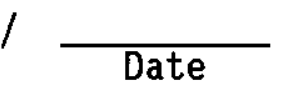

5.2.7.14 VERIFY the indicator line is lined up with the correct reference pins for the "B" or "MID" position, AND black stripe within the RED area on the decal is aligned as to be touching the applicable line on valve housing.
Test Director InitiaT

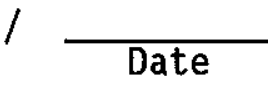

5.2.7.15 VERIFY the indicator lines are oriented to BLOCK flow from Blank Connection "F".

\section{Test Director Initial}

5.2.7.16 ADJUST the middle CAM so pointer on the CAM is centered on the non-contact switch wired for valve position $B$.

5.2.7.17 ENSURE the top and bottom CAMs are NOT positioned at their associated non-contact switches.

5.2.7.18 PLACE the long-shank padlock through the locking device in the ANA-WT-V-318 handwhee1.

5.2.7.19 VERIFY limited movement of the handwheel does NOT cause valve movement in either direction.

Test Director Initial

Date 


\subsection{TEST 3-WAY VALVES (Cont.)}

5.2.7.20 REMOVE the long-shank padlock that was placed on the handwheel in Step 5.2.7.18.

5.2.7.21 POSITION ANA-WT-V-318, to allow flow from ANA-WT-V-316 to Blank Connection " $F$ " by rotating the valve handwheel CLOCKWISE as far as it will go.

5.2.7.22 VERIFY that ANA-WT-V-318 valve position indicator is aligned to allow flow from ANA-WT-V-316 to Blank Connection " $F$ ".

Test Director Initial

5.2.7.23 ADJUST the lower CAM so pointer on the CAM is centered on the non-contact switch wired for valve position $C$.

5.2.7.24 ENSURE the top and middle CAMs are NOT positioned at their associated non-contact switches.

5.2.7.25 VERIFY the indicator lines are lined up with the correct reference pins, AND within the RED area on the decal black stripe to black stripe alignment.

Test Director Initial

5.2.7.26 PLACE the long-shank padlock through the locking device in the ANA-WT-V-318 handwhee 1 .

5.2.7.27 VERIFY limited movement of the handwheel does NOT cause valve movement in either direction.
Test Director Initial
Date

5.2.7.28 REMOVE the long-shank padlock that was placed on the handwheel in step 5.2.3.26.

5.2.7.29 VERIFY installation of positive jumpers located on the valve position sensor terminal block. Refer to drawing H-14-100987, sh 1 , for positive lead jumper locations.

Test Director Initial

Date 


\subsection{TEST 3-WAY VALVES (Cont.)}

5.2.7.30 APPLY 24 volts dc to Terminal TB-DC4-38 in Field Terminal Box AN241-WT-TBX-101, using the 24 volt dc power supply.

5.2.7.31 MEASURE AND RECORD the voltage BETWEEN Terminal TB-DC1-42 AND the NEGATIVE Terminal on the 24 volt power supply.

VOLTAGE

5.2.7.32 VERIFY the voltage recorded in Step 5.2.7.31 at a nominal voltage of 24 Volts dc.

Test Director Initial

5.2.7.33 MEASURE AND RECORD the voltage BETWEEN Terminal TB-DC1-41 AND the NEGATIVE Terminal on the 24 volt power supply.

VOLTAGE

5.2.7.34 VERIFY the voltage recorded in Step 5.2.7.33 is at a nominal voltage of " 0 " Volts dc.
Test Director Initial
Date

5.2.7.35 MEASURE AND RECORD the voltage BETWEEN Terminal TB-DC1-40 AND the NEGATIVE Terminal on the 24 volt power supply.

VOLTAGE

5.2.7.36 VERIFY the voltage recorded in Step 5.2.7.35 is at a nominal voltage of " 0 " Volts dc.

$$
\text { Test Director Initial }
$$

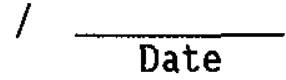

NOTE- To ensure proper alignment for mid position of Three-Way Valve, When rotating in counter clockwise rotation, go past the "B" or mid position, then rotate to Mid position from a Clockwise direction.

5.2.7.37 POSITION ANA-WT-V-318, to allow flow from ANA-WT-V-319 to ANAWT- $V-316$ by rotating the valve handwhee 1 COUNTER-CLOCKWISE unti] the valve is at the mid position. 


\subsection{TEST 3-WAY VALVES (Cont.)}

5.2.7.38 MEASURE AND RECORD the voltage BETWEEN Terminal TB-DC1-42 AND the NEGATIVE Terminal on the 24 volt dc power supply.

VOLTAGE

5.2.7.39 VERIFY the voltage recorded in Step 5.2.7.38 is at a nominal voltage of " 0 " Volts dc.

\section{Test Director Initial}

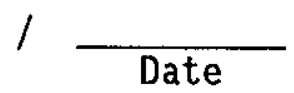

5.2.7.40 MEASURE AND RECORD the voltage BETWEEN Terminal TB-DC1-41 AND the NEGATIVE Terminal on the 24 volt dc power supply.

VOLTAGE

5.2.7.41 VERIFY the voltage recorded in Step 5.2.7.40 at a nominal voltage of 24 Volts dc.

Test Director Initial

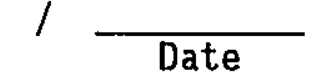

5.2.7.42 MEASURE AND RECORD the voltage BETWEEN Terminat TB-DC1-40 AND the NEGATIVE Terminal on the 24 volt dc power supply.

VOLTAGE

5.2.7.43 VERIFY the voltage recorded in Step 5.2.7.42 is at a nominal voltage of " 0 " Volts dc.

Test Director Initial

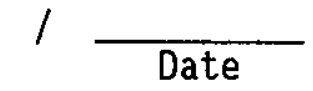

5.2.7.44 POSITION ANA-WT-V-318 to allow flow from ANA-WT-V-319 to Blank Connection " $\mathrm{F}$ " by rotating the valve handwheel COUNTER-CLOCKWISE until the handwheel turns no farther.

5.2.7.45 MEASURE AND RECORD the voltage BETWEEN Terminal TB-DC1-42 AND the NEGATIVE Terminal on the 24 volt dc power supply.

VOLTAGE 


\subsection{TEST 3-WAY VALVES (Cont.)}

5.2.7.46 VERIFY the voltage recorded in Step 5.2.7.45 is at a nominal voltage of " 0 " Volts dc.

Test Director Initial

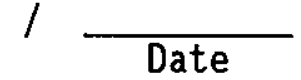

5.2.7.47 MEASURE AND RECORD the voltage BETWEEN Terminal TB-DCl-41 AND the NEGATIVE Terminal on the 24 volt dc power supply.

VOLTAGE

5.2.7.48 VERIFY the voltage recorded in Step 5.2.7.47 is at a nominal voltage of " 0 " Volts dc.

Test Director Initia]

$/ \frac{}{\text { Date }}$

5.2.7.49 MEASURE AND RECORD the voltage BETWEEN Terminal TB-DC1-40 AND the NEGATIVE Terminal on the 24 volt dc power supply.

VOLTAGE

5.2.7.50 VERIFY the voltage recorded in Step 5.2.7.49 at a nominal voltage of 24 Volts dc.
Test Director Initial
Date

NOTE - The next step prepares limit switch cover for torquing. ATl valves will be torqued at one time at end of this ATP and QC Shall verify. The Torque value will be between 17 and 20 inch 1bs.

5.2.7.51 REPLACE 1imit switch cover AND TIGHTEN bolts in preparation for torque.

5.2.7.52 POSITION valve ANA-WT-V-318 as directed by the Test Director.

5.2.7.53 RECORD the final position for the valve ANA-WT-V-318 below.

\begin{tabular}{|c|c|c|}
\hline HPOS & POS & POS CO \\
\hline & & \\
\hline
\end{tabular}

5.2.7.54 VERIFY by signing below that test 5.2 .7 is complete.

\begin{tabular}{ccc}
\hline Test Director Signature & Date \\
${ } }$ & Date
\end{tabular}

\begin{tabular}{|c|c|c|c|c|}
\hline 7\%? & 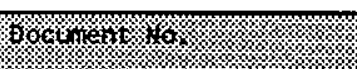 & 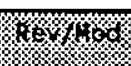 & 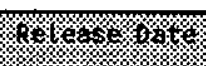 & 4 \\
\hline 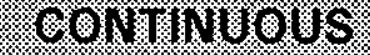 & ন ন ন & 8 & & 10\% \\
\hline
\end{tabular}




\subsection{TEST 3-WAY VALVES (Cont.)}

5.2.8 TEST 3 -inch valve ANA-WT-V-319.

5.2.8.1 RECORD calibrated electrical test equipment data below. ELECTRICAL TEST EQUIPMENT DATA TABLE

\begin{tabular}{|l|c|c|c|}
\hline TOOL NAME & ID. NUMBER & CAL DUE DATE & INITIAL/DATE \\
\hline & & & \\
\hline & & & \\
\hline & & & \\
\hline
\end{tabular}

5.2.8.2 ENSURE that 2-inch valve ANA-WT-V-319 is in Position "A" by rotating the vaTve handwheel COUNTER-CLOCKWISE until the handwheel turns no farther.

5.2.8.3 VERIFY ANA-WT-V-319 is in Position "A" by the line indicator tee connecting ANA-WT-V-321 and ANA-WT-V-318.

Test Director Initial

Date

5.2.8.4 VERIFY the indicator lines are lined up with the correct reference pins, AND within the RED area on the decal.

Test Director Initial Date

5.2.8.5 VERIFY the indicator Tines are oriented to BLOCK flow from ANAWT-V-320.

Test Director Initial

Date

5.2.8.6 PLACE the long-shank padlock through the locking device in the ANA-WT-V-319 handwhee?.

5.2.8.7 VERIFY limited movement of the handwheel does NOT cause valve movement in either direction.

Test Director Initial Date

5.2.8.8 REMOVE the long-shank padlock that was placed on the handwheel in Step 5.2.8.6. 


\subsection{TEST 3-WAY VALVES (Cont.)}

5.2.8.9 REMOVE the cover from ANA-WT-V-319 valve position sensor assembly.

5.2.8.10 ADJUST the top CAM so pointer on the CAM is centered on the noncontact switch wired for valve position $A$.

5.2.8.11 ENSURE the middle and the bottom CAMs are NOT positioned at their associated non-contact switches.

5.2.8.12 POSITION ANA-WT-V-319, to allow flow from ANA-WT-V-321 to ANAWT- $V-320$ by rotating the valve handwheel CLOCKWISE until the valve is at mid position.

5.2.8.13 VERIFY that ANA-WT-V-319 valve position indicator is aligned to ALLOW FLOW from ANA-WT-V-321 to ANA-WT-V-320.
Test Director Initial
Date

5.2.8.14 VERIFY the indicator 1 ine is lined up with the correct reference pins for the "B" or "MID" position, AND black stripe within the RED area on the decal is aligned as to be touching the applicable line on valve housing.

Test Director Initial Date

5.2.8.15 VERIFY the indicator lines are oriented to BLOCK flow from ANAWT-V -318.
Test Director Initial
Date

5.2.8.16 ADJUST the middle CAM so pointer on the CAM is centered on the non-contact switch wired for valve position $B$.

5.2.8.17 ENSURE the top and bottom CAMs are NOT positioned at their associated non-contact switches.

5.2.8.18 PLACE the long-shank padlock through the locking device in the ANA-WT-V-319 handwhee 1 .

5.2.8.19 VERIFY limited movement of the handwheel does NOT cause valve movement in either direction.
Test Director Initial
Date 


\subsection{TEST 3-WAY VALVES (Cont.)}

5.2.8.20 REMOVE the long-shank padlock that was placed on the handwhee? in Step 5.2.8.18.

5.2.8.21 POSITION ANA-WT-V-319, to allow flow from ANA-WT-V-320 to ANAWT-V -318 by rotating the valve handwheel CLOCKWISE as far as it will go.

5.2.8.22 VERIFY that ANA-WT-V-319 valve position indicator is aligned to a) $10 \mathrm{~W}$ flow from ANA-WT-V-320 to ANA-WT-V-318.

Test Director Initial Date

5.2.8.23 ADJUST the lower CAM so pointer on the CAM is centered on the non-contact switch wired for valve position $C$.

5.2.8.24 ENSURE the top and middle CAMs are NOT positioned at their associated non-contact switches.

5.2.8.25 VERIFY the indicator lines are lined up with the correct reference pins, AND within the RED area on the decal b]ack stripe to black stripe alignment.
Test Director Initial
/

Date

5.2.8.26 PLACE the long-shank padlock through the locking device in the ANA-WT-V-319 handwhee?.

5.2.8.27 VERIFY limited movement of the handwheel does NOT cause valve movement in either direction.

\section{Test Director Initial Date}

5.2.8.28 REMOVE the long-shank padlock that was placed on the handwheel in step 5.2.8.26.

5.2.8.29 VERIFY installation of positive jumpers located on the valve position sensor terminal block. Refer to drawing H-14-100987, sh 1 , for positive lead jumper locations.

\footnotetext{
Test Director Initial Date
}

\begin{tabular}{|c|c|c|c|c|}
\hline 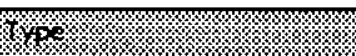 & 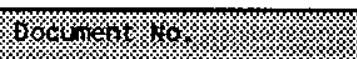 & 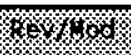 & 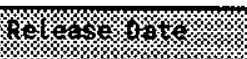 & (2) \\
\hline 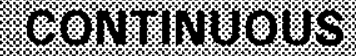 & 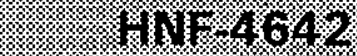 & 济 & & 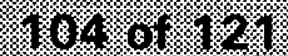 \\
\hline
\end{tabular}




\subsection{TEST 3-WAY VALVES (Cont.)}

5.2.8.30 APPLY 24 volts dc to Terminal TB-DC4-39 in Field Terminal Box AN241-WT-TBX-101, using the 24 volt dc power supply.

5.2.8.31 MEASURE AND RECORD the voltage BETWEEN Terminal TB-DC1-45 AND the NEGATIVE Terminal on the 24 volt power supply.

VOLTAGE

5.2.8.32 VERIFY the voltage recorded in Step 5.2.8.31 at a nominal voltage of 24 Volts dc.

Test Director Initial

5.2.8.33 MEASURE AND RECORD the voltage BETWEEN Terminal TB-DC1-44 AND the NEGATIVE Terminal on the 24 volt power supply.

VOLTAGE

5.2.8.34 VERIFY the voltage recorded in Step 5.2.8.33 is at a nominal voltage of "O" Volts dc.

Test Director Initial

5.2.8.35 MEASURE AND RECORD the voltage BETWEEN Terminal TB-DC1-43 AND the NEGATIVE Terminal on the 24 volt power supply.

VOLTAGE

5.2.8.36 VERIFY the voltage recorded in Step 5.2.8.35 is at a nominal voltage of " 0 " Volts dc.

Test Director Initial

NOTE- To ensure proper alignment for mid position of Three-Way Valve, When rotating in counter clockwise rotation, go past the "B" or mid position, then rotate to Mid position from a Clockwise direction.

5.2.8.37 POSITION ANA-WT-V-319, to allow flow from ANA-WT-V-321 to ANAWT- $V-320$ by rotating the valve handwhee 1 COUNTER-CLOCKWISE unt 11 the valve is at the mid position.

\begin{tabular}{|c|c|c|c|c|}
\hline אל & (3) & & 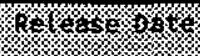 & 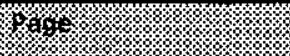 \\
\hline 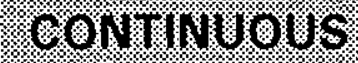 & (s) & (3) & & $\log 5010 \%$ \\
\hline
\end{tabular}




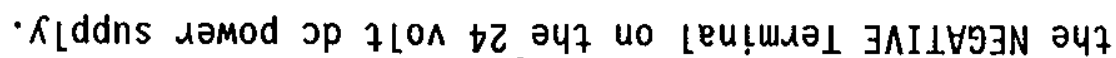

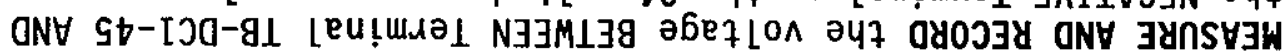

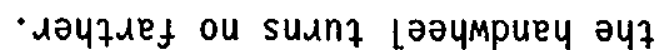

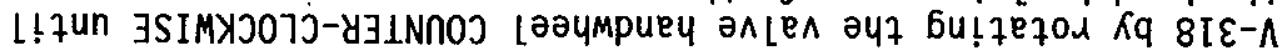

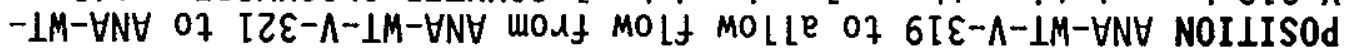

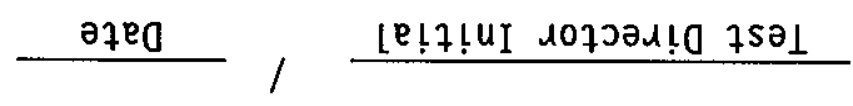
- op sflon "O" jo әEеzlon

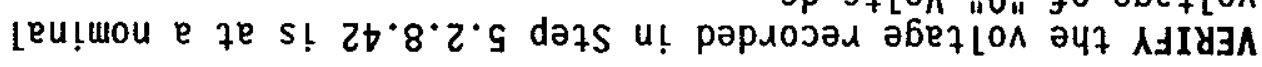
$96 \cdot 8 \cdot 2 \cdot 9$

$\exists 9 \forall 170 \AA$

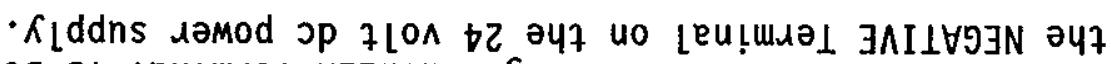

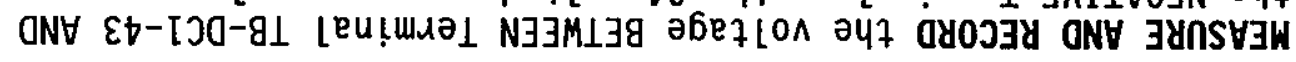

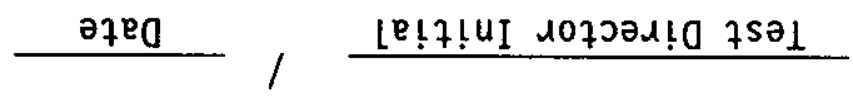

-op $2710 \Lambda$ tZ fo ә6еzlon

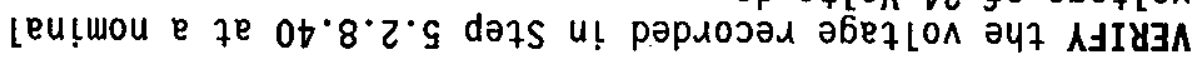
$16 \cdot 8 \cdot 2 \cdot 9$ $39 \forall 170 \mathrm{~N}$

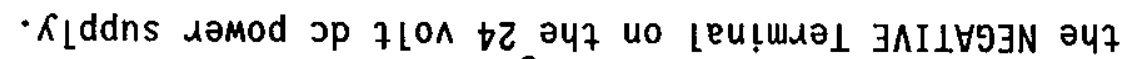

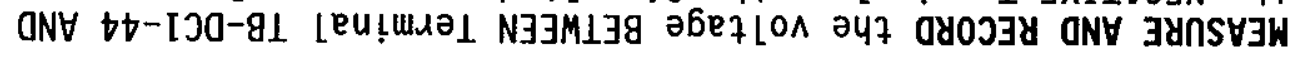
$0 t \cdot 8 \cdot 2 \cdot 9$

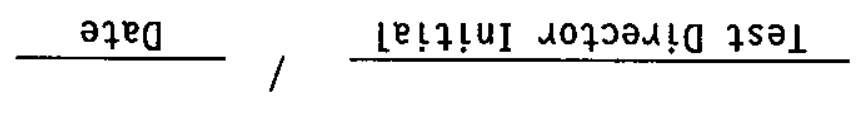

- op sqLON "On to ә6ezlon

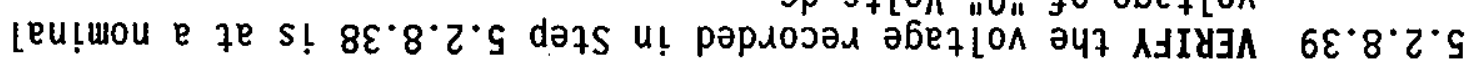
$\exists 9 \forall 170 \wedge$

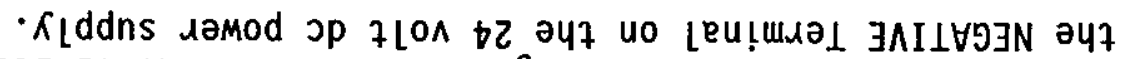

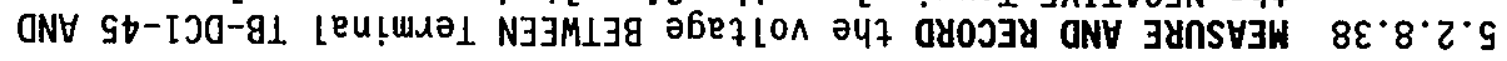




\subsection{TEST 3-WAY VALVES (Cont.)}

5.2.8.46 VERIFY the voltage recorded in Step 5.2.8.45 is at a nominat voltage of " 0 " Volts dc.

Test Director Initial

5.2.8.47 MEASURE AND RECORD the voltage BETWEEN Terminal TB-DC1-44 AND the NEGATIVE Terminal on the 24 volt dc power supply.

VOLTAGE

5.2.8.48 VERIFY the voltage recorded in Step 5.2.8.47 is at a nominal voltage of " 0 " Volts dc.

5.2.8.49 MEASURE AND RECORD the voltage BETWEEN Terminal TB-DC1-43 AND the NEGATIVE Terminal on the 24 volt dc power supply.

VOLTAGE

5.2.8.50 VERIFY the voltage recorded in Step 5.2.8.49 at a nominal voltage of 24 Volts dc.

Test Director Initial

NOTE - The next step prepares limit switch cover for torquing. All valves will be torqued at one time at end of this ATP and QC Shall verify. The Torque value will be between 17 and 20 inch 1bs.

5.2.8.51 REPLACE 1 imit switch cover AND TIGHTEN bolts in preparation for torque.

5.2.8.52 POSITION valve ANA-WT-V-319 as directed by the Test Director.

5.2.8.53 RECORD the final position for the valve ANA-WT-V-319 below.

\begin{tabular}{|c|c|c|}
\hline F POS. AP & .POS $/ \mathrm{B}^{\circ}$ & PPOS. Cl: \\
\hline
\end{tabular}

5.2.8.54 VERIFY by signing below that test 5.2 .8 is complete.

\begin{tabular}{l} 
Test Director Signature \\
\hline Operations Signature
\end{tabular}

$\overline{\text { Date }}$




\subsection{TEST 3-WAY VALVES (Cont.)}

5.2.9 TEST 3 -inch valve ANA-WT-V-321.

5.2.9.1 RECORD calibrated electrical test equipment data below.

ELECTRICAL TEST EQUIPMENT DATA TABLE

\begin{tabular}{|l|l|l|l|}
\hline TOOL NAME & ID. NUMBER & CAL DUE DATE & INITIAL/DATE \\
\hline & & & \\
\hline & & & \\
\hline & & & \\
\hline
\end{tabular}

5.2.9.2 ENSURE that 2-inch valve ANA-WT-V-321 is in Position "A" by rotating the valve handwheel COUNTER-CLOCKWISE until the handwheel turns no farther.

5.2.9.3 VERIFY ANA-WT- $V-321$ is in Position "A" by the 1ine indicator tee connecting ANA-WT-V-323 and ANA-WT-V-322.

Test Director Initial $/$ Date

5.2.9.4 VERIFY the indicator lines are lined up with the correct

reference pins, AND within the RED area on the decal.

Test Director Initial

5.2.9.5 VERIFY the indicator lines are oriented to BLOCK flow from ANAWT-V-319.

Test Director Initial

5.2.9.6 PLACE the long-shank padlock through the locking device in the ANA-WT-V-321 handwhee1.

5.2.9.7 VERIFY limited movement of the handwheel does NOT cause valve movement in either direction.

Test Director Initial Date

5.2.9.8 REMOVE the long-shank padlock that was placed on the handwheel in Step 5.2.9.6. 


\subsection{TEST 3-WAY VALVES (Cont.)}

5.2.9.9 REMOVE the cover from ANA-WT-V-321 valve position sensor assembly.

5.2.9.10 ADJUST the top CAM so pointer on the CAM is centered on the noncontact switch wired for valve position $A$.

5.2.9.11 ENSURE the middle and the bottom CAMs are NOT positioned at their associated non-contact switches.

5.2.9.12 POSITION ANA-WT-V-321, to allow flow from ANA-WT-V-323 to ANAWT-V -319 by rotating the valve handwheel CLOCKWISE unt il the valve is at mid position.

5.2.9.13 VERIFY that ANA-WT-V-321 valve position indicator is aligned to ALLOW FLOW from ANA-WT-V-323 to ANA-WT-V-319.

Test Director Initial
/

Date

5.2.9.14 VERIFY the indicator line is lined up with the correct reference pins for the "B" or "MID" position, AND black stripe within the RED area on the decal is aligned as to be touching the applicable line on valve housing.

Test Director Initial

5.2.9.15 VERIFY the indicator lines are oriented to BLOCK flow from ANAWT-V -322 .

Test Director Initial

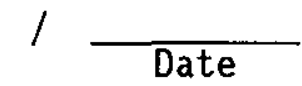

5.2.9.16 ADJUST the middle CAM so pointer on the CAM is centered on the non-contact switch wired for valve position $B$.

5.2.9.17 ENSURE the top and bottom CAMs are NOT positioned at their associated non-contact switches.

5.2.9.18 PLACE the long-shank padlock through the locking device in the ANA-WT-V-321 handwhee?.

5.2.9.19 VERIFY limited movement of the handwheel does NOT cause valve movement in either direction.

Test Director Initial

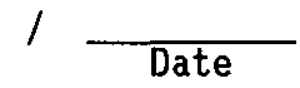




\subsection{TEST 3-WAY VALVES (Cont.)}

5.2.9.20 REMOVE the long-shank padlock that was placed on the handwhee 1 in Step 5.2.9.18.

5.2.9.21 POSITION ANA-WT-V-321, to allow flow from ANA-WT-V-319 to ANAWT-V-322 by rotating the valve handwheel CLOCKWISE as far as it will go.

5.2.9.22 VERIFY that ANA-WT-V-321 valve position indicator is aligned to a) low flow from ANA-WT-V-319 to ANA-WT-V-322.

Test Director Initial $/$ Date

5.2.9.23 ADJUST the Tower CAM so pointer on the CAM is centered on the non-contact switch wired for valve position $C$.

5.2.9.24 ENSURE the top and middle CAMs are NOT positioned at their associated non-contact switches.

5.2.9.25 VERIFY the indicator lines are lined up with the correct reference pins, AND within the RED area on the decal black stripe to black stripe alignment.

Test Director Initial

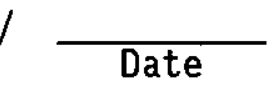

5.2.9.26 PLACE the long-shank padlock through the locking device in the ANA-WT-V-321 handwheel.

5.2.9.27 VERIFY limited movement of the handwheel does NOT cause valve movement in either direction.

\section{Test Director Initial Date}

5.2.9.28 REMOVE the long-shank padlock that was placed on the handwheel in step 5.2.9.26.

5.2.9.29 VERIFY installation of positive jumpers located on the valve position sensor terminal block. Refer to drawing H-14-100987, sh 1, for positive lead jumper locations.

Test Director Initial

Date 


\subsection{TEST 3-WAY VALVES (Cont.)}

5.2.9.30 APPLY 24 volts dc to Terminal TB-DC4-41 in Field Terminal Box AN241-WT-TBX-101, using the 24 volt dc power supply.

5.2.9.31 MEASURE AND RECORD the voltage BETWEEN Terminal TB-DC1-50 AND the NEGATIVE Terminal on the 24 volt power supply.

VOLTAGE

5.2.9.32 VERIFY the voltage recorded in Step 5.2.9.31 at a nominal voltage of 24 Volts dc.

Test Director Initial

5.2.9.33 MEASURE AND RECORD the voltage BETWEEN Terminal TB-DC1-49 AND the NEGATIVE Terminal on the 24 volt power supply.

VOLTAGE

5.2.9.34 VERIFY the voltage recorded in Step 5.2.9.33 is at a nominal voltage of " 0 " Volts dc.
Test Director Initial
Date

5.2.9.35 MEASURE AND RECORD the voltage BETWEEN Terminal TB-DC1-48 AND the NEGATIVE Terminal on the 24 volt power supply.

VOLTAGE

5.2.9.36 VERIFY the voltage recorded in Step 5.2.9.35 is at a nominal voltage of " 0 " Volts dc.
Test Director Initial
Date

NOTE- To ensure proper alignment for mid position of Three-Way Valve, When rotating in counter clockwise rotation, go past the " $B$ " or mid position, then rotate to Mid position from a Clockwise direction.

5.2.9.37 POSITION ANA-WT-V-321, to allow flow from ANA-WT-V-323 to ANAWT-V-319 by rotating the valve handwheel COUNTER-CLOCKWISE unti] the valve is at the mid position. 


\subsection{TEST 3-WAY VALVES (Cont.)}

5.2.9.38 MEASURE AND RECORD the voltage BETWEEN Terminal TB-DC1-50 AND the NEGATIVE Terminal on the 24 volt dc power supply.

VOLTAGE

5.2.9.39 VERIFY the voltage recorded in Step 5.2.9.38 is at a nominal voltage of " 0 " Volts dc.

Test Director Initial

5.2.9.40 MEASURE AND RECORD the voltage BETWEEN Terminal TB-DC1-49 AND the NEGATIVE Terminal on the 24 volt dc power supply.

VOLTAGE

5.2.9.41 VERIFY the voltage recorded in Step 5.2.9.40 at a nominal voltage of 24 Volts dc.

Test Director Initial

$$
\text { Date }
$$

5.2.9.42 MEASURE AND RECORD the voltage BETWEEN Terminal TB-DC1-48 AND the NEGATIVE Terminal on the 24 volt dc power supply.

VOLTAGE

5.2.9.43 VERIFY the voltage recorded in Step 5.2.9.42 is at a nominal voltage of "O" Volts dc.

Test Director Initial

Date

5.2.9.44 POSITION ANA-WT-V-321 to allow flow from ANA-WT-V-323 to ANA-WT$V-322$ by rotating the valve handwheel COUNTER-CLOCKWISE until the handwheel turns no farther.

5.2.9.45 MEASURE AND RECORD the voltage BETWEEN Terminat TB-DCI-50 AND the NEGATIVE Terminal on the 24 volt dc power supply.

VOLTAGE 


\subsection{TEST 3-WAY VALVES (Cont.)}

5.2.9.46 VERIFY the voltage recorded in Step 5.2.9.45 is at a nominal voltage of " 0 " Volts dc.
Test Director Initial
Date

5.2.9.47 MEASURE AND RECORD the voltage BETWEEN Terminal TB-DC1-49 AND the NEGATIVE Terminal on the 24 volt dc power supply.

VOLTAGE

5.2.9.48 VERIFY the voltage recorded in Step 5.2.9.47 is at a nominal voltage of " 0 " Volts dc.
Test Director Initial
Date

5.2.9.49 MEASURE AND RECORD the voltage BETWEEN Terminat TB-DC1-48 AND the NEGATIVE Terminal on the 24 volt dc power supply.

VOLTAGE

5.2.9.50 VERIFY the voltage recorded in Step 5.2.9.49 at a nominal voltage of 24 Volts dc.

Test Director Initial

NOTE - The next step prepares limit switch cover for torquing. All valves will be torqued at one time at end of this ATP and QC Shall verify. The Torque value will be between 17 and 20 inch lbs.

5.2.9.51 REPLACE limit switch cover AND TIGHTEN bolts in preparation for torque.

5.2.9.52 POSITION valve ANA-WT-V-321 as directed by the Test Director.

5.2.9.53 RECORD the final position for the valve ANA-WT-V-321 below.

\begin{tabular}{|c|c|c|}
\hline$\checkmark$ POS $\%$ A & $180 S$ B & I POS. \\
\hline & & \\
\hline
\end{tabular}

5.2.9.54 VERIFY by signing below that test 5.2 .9 is complete.

\begin{tabular}{l} 
Test Director Signature \\
\hline Operations Signature
\end{tabular}

\begin{tabular}{c}
\hline Date \\
\hline Date
\end{tabular}




\subsection{TEST 3-WAY VALVES (Cont.)}

5.2.10 VERIFY by signing below that Section 5.2 is complete.

\begin{tabular}{lll}
\hline Test Director Signature & & Date \\
\hline Operations Signature & & Date
\end{tabular}

\subsection{VALVE TOROUING}

5.3.1 QC VERIFY all valve limit switch covers for valves are installed and bolts torqued between 17 and 22 inch 1bs. AND RECORD below.

\begin{tabular}{|c|c|c|c|c|c|}
\hline Valve Number & $\begin{array}{c}\text { Limit } \\
\text { Switch } \\
\text { Cover } \\
(\boldsymbol{})\end{array}$ & $\begin{array}{l}\text { Limit Switch } \\
\text { Cover Boits } \\
\text { Torqued } \\
(\boldsymbol{})\end{array}$ & Valve Number & $\begin{array}{l}\text { Limit } \\
\text { Switch } \\
\text { Cover } \\
(\boldsymbol{})\end{array}$ & $\begin{array}{l}\text { Limit Switch } \\
\text { Cover Bo7ts } \\
\text { Torqued } \\
(\boldsymbol{})\end{array}$ \\
\hline \hline ANA-WT-V-301 & & & ANA-WT-V-320 & & \\
\hline ANA-WT-V-309 & & & ANA-WT-V-302 & & \\
\hline ANA-WT-V-322 & & & ANA-WT-V-303 & & \\
\hline ANA-WT-V-323 & & & ANA-WT-V-305 & & \\
\hline ANA-WT-V-304 & & & ANA-WT-V-307 & & \\
\hline ANA-WT-V-306 & & & ANA-WT-V-314 & & \\
\hline ANA-WT-V-308 & & & ANA-WT-V-316 & & \\
\hline ANA-WT-V-313 & & & ANA-WT-V-318 & & \\
\hline ANA-WT-V-315 & & & ANA-WT-V-319 & & \\
\hline ANA-WT-V-317 & & & ANA-WT-V-321 & & \\
\hline
\end{tabular}

TOOL NAME

ID. NUMBER

CAL DUE DATE

INITIAL/DATE

5.3.2 VERIFY by signing below that Section 5.3 is complete.

\begin{tabular}{lll}
\hline Test Director Signature & & Date \\
\hline Operations Signature & & Date
\end{tabular}




\subsection{ENCASEMENT VALVE TESTING}

5.4.1 Test Encasement Drain Valve ANA-WT-403.

5.4.1.1 ENSURE valve labeling on "TEE" handle is correct.

5.4.1.2 ENSURE "TEE" handle fits through coverblock, into funnel and sets into valve.

5.4.1.3 ROTATE "TEE" handle to "DRAIN" position AND VERIFY vaTve aligns properly with applicable line on coverblock.
Test Director Initial
Date

5.4.1.4 ROTATE "TEE" handle to "HYDRO" position AND VERIFY valve aligns properly with applicable line on coverblock.
Test Director Initial
Date

5.4.1.5 ROTATE "TEE" handle to "OPERATE" position AND VERIFY valve aligns properly with applicable line on coverblock.

Test Director Initial

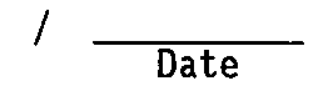

5.4.1.6 POSITION valve as directed by the Test Director.

5.4.1.7 RECORD the final position for valve ANA-WT-V-403 below.

\begin{tabular}{|l|l|l|l|l|}
\hline OPERATE & OPYRO & DRAIN & DR \\
\hline & & \\
\hline
\end{tabular}

\begin{tabular}{|c|c|c|c|c|}
\hline \% & 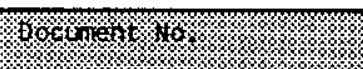 & ror & $x^{2}$ & 8 \\
\hline (6) & (: & 0 & & 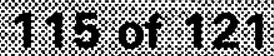 \\
\hline
\end{tabular}




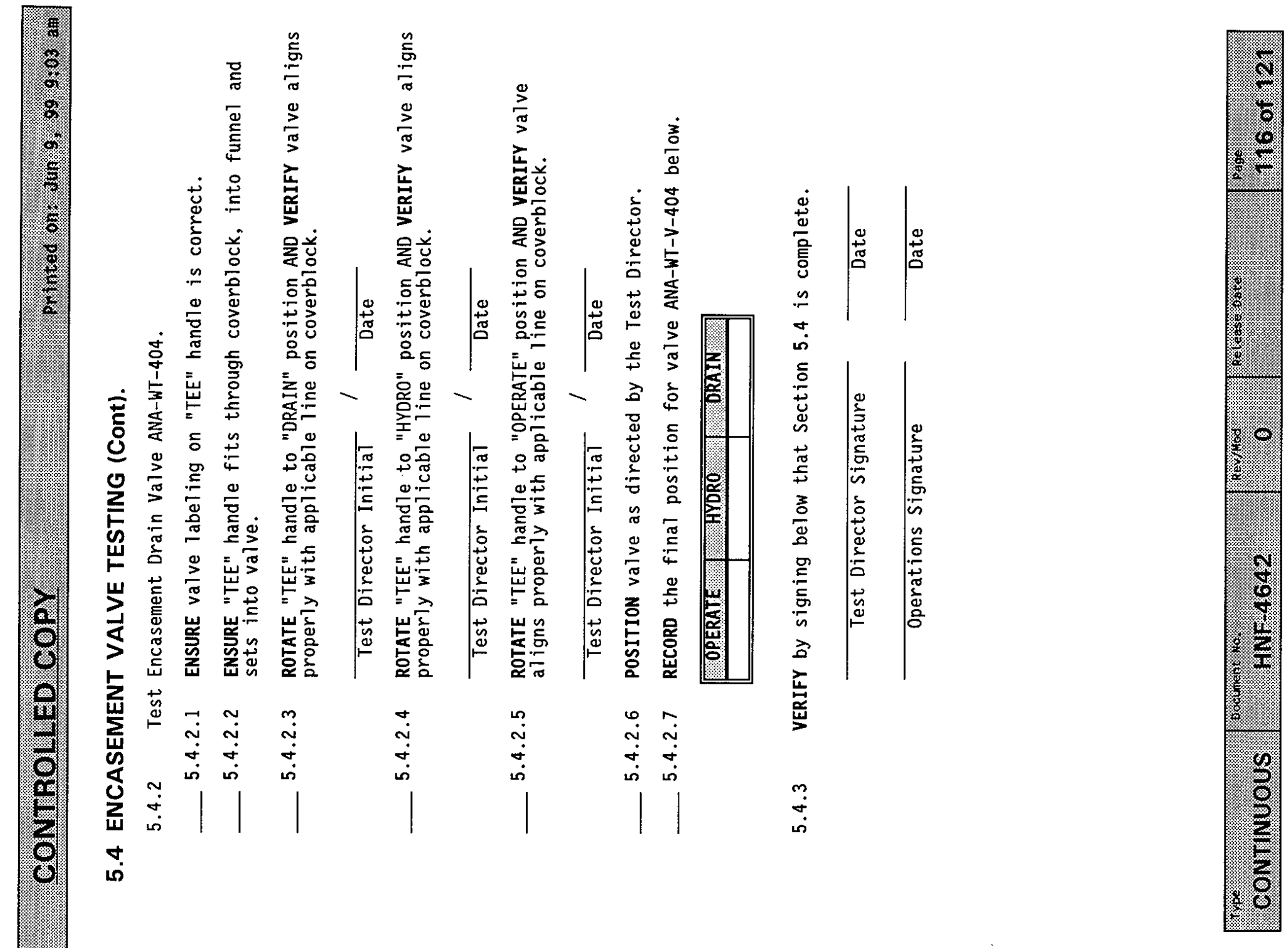




\section{ATP PERFORMANCE LOG}

This page may be reproduced as necessary.

ATP PERFORWANCE EVENT
Page of

\begin{tabular}{|c|c|c|}
\hline : & DATE & INHT MLS \\
\hline & & \\
\hline & & \\
\hline & & \\
\hline & & \\
\hline & & \\
\hline & & \\
\hline & & \\
\hline & & \\
\hline & & \\
\hline & & \\
\hline & & \\
\hline & & \\
\hline & & \\
\hline & & \\
\hline & & \\
\hline & & \\
\hline & & \\
\hline & & \\
\hline & & \\
\hline & & \\
\hline
\end{tabular}




\section{ATP EXCEPTION LOG}

This page may be reproduced as necessary.

Page of

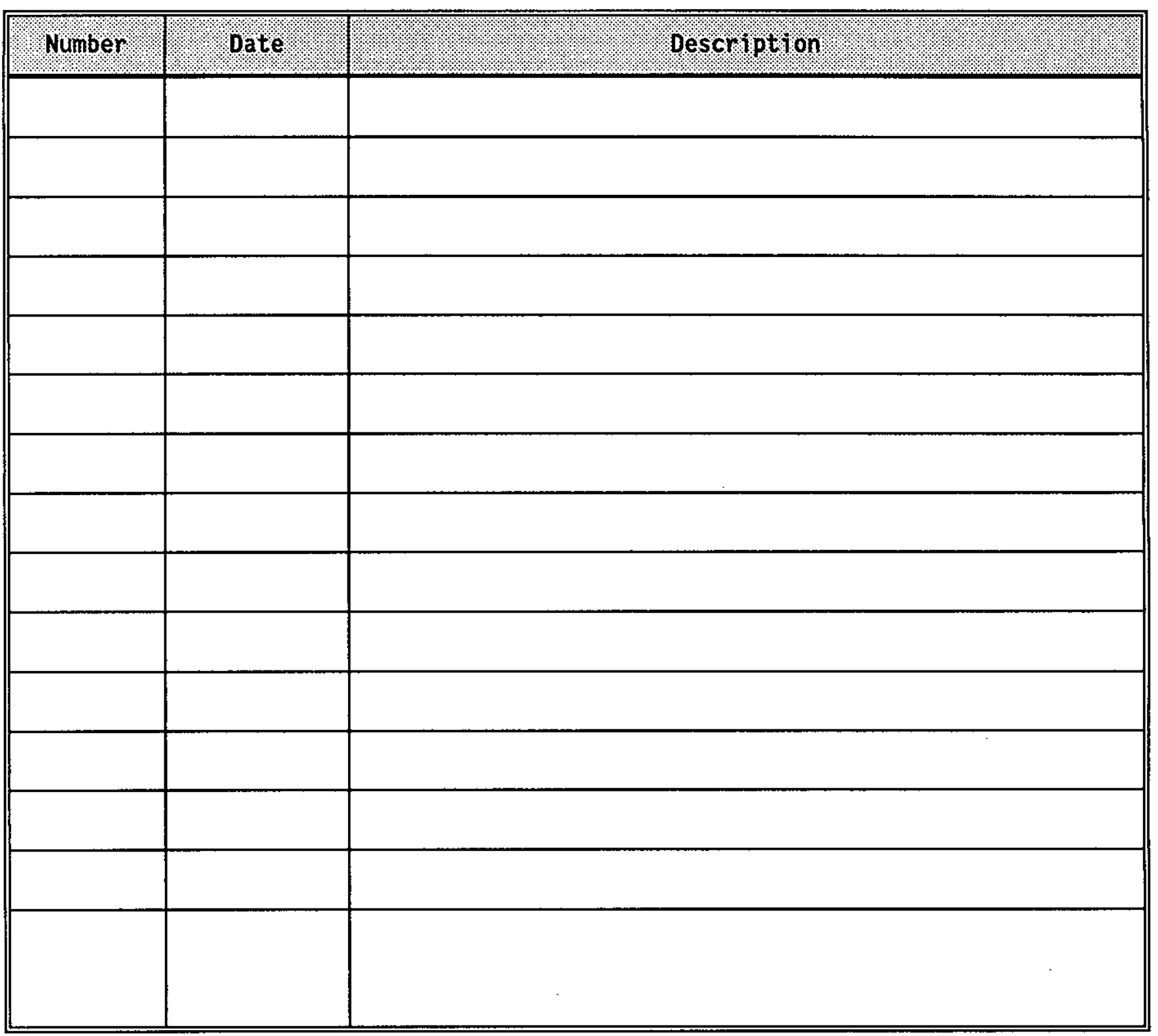




\section{ATP EXCEPTION RECORD}

This page may be reproduced as necessary.

Page of

\begin{tabular}{||l}
\hline ATP Step Number: \\
\hline Description OF Exception: \\
\hline \\
\hline \\
\hline \\
\hline Initiator NaMe/Organization:
\end{tabular}

Date of EXception:

RESOLUTION OF EXCEPTION:

\section{Correction Approval:}

Test Director Initial:

DATE:

DAte of Resolution:

\begin{tabular}{||l|l||}
\hline Test Director Signature: & Date: \\
\hline Project Engineer Signature: & Date: \\
\hline Quality Assurance Signature: & Date: \\
\hline
\end{tabular}




\section{PROCEDURE SIGNATURE SHEET}

PRINT NAME
INITIALS

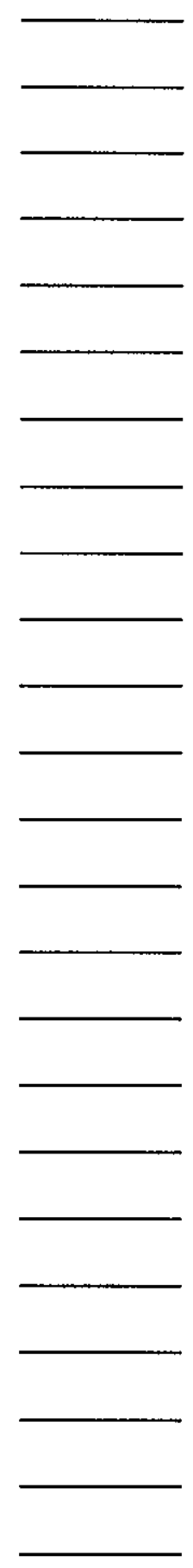




\section{PROCEDURE HISTORY SIGNATURE SHEET}

Gom

